\title{
Performance Based Analysis of Steel Buildings
}

\author{
A Thesis \\ Presented to \\ The Faculty of California Polytechnic State University \\ San Luis Obispo, California
}

\begin{abstract}
In partial fulfillment
of the Requirements for the Degree

Master of Science in Architecture with a Specialization in Architectural Engineering
\end{abstract}

by

Matthew Joseph Williams

November 2009 
(C) 2009

Matthew Joseph Williams

ALL RIGHTS RESERVED

Performance Based Analysis of Steel Buildings 
TITLE: $\quad$ Performance Based Analysis of Steel Buildings

AUTHOR: $\quad$ Matthew Joseph Williams

DATE SUBMITTED: $\quad$ November 2009

COMMITTEE CHAIR: $\quad$ Cole McDaniel, Ph.D, P.E.

COMMITTEE MEMBER: Kevin Dong, S.E.

COMMITTEE MEMBER: Chris Poland, S.E.

COMMITTEE MEMBER: Robert Pekelnicky, S.E. 


\author{
ABSTRACT \\ Performance Based Analysis of Steel Buildings \\ Matthew Joseph Williams
}

This project investigated the performance of two separate building types, designed using ASCE 7-05, using the analysis procedures from ASCE 41-06. The results from the ASCE 41-06 analyses were compared to the expected performance level of Life Safety to determine the adequacy of the ASCE 7-05 design. ASCE 7-05 is intended to result in designs that perform to a Life Safety performance level regardless of the building type. A design using the AISC specifications for a steel Special Moment Frame and the lateral loads from ASCE 7-05 resulted in a building that slightly exceeded an Immediate Occupancy performance level for the BSE-1 Hazard Level. In comparison, a design using the AISC specifications for steel Special Concentric Braced Frame resulted in a building that performed to a Collapse Prevention performance level for the BSE-1 Hazard Level. 


\section{ACKNOWLEDGEMENTS}

I would like to thank Degenkolb Engineers for their support of this project.

Specifically, I would like to thank committee members Chris Poland and Robert

Pekelnicky for suggesting the topic for this research and for their invaluable support and advice on this project. 


\section{TABLE OF CONTENTS}

List of Tables ..................................................................................................... viii

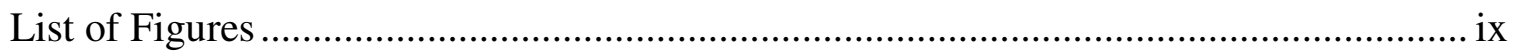

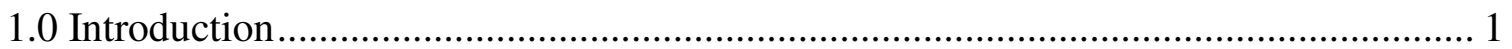

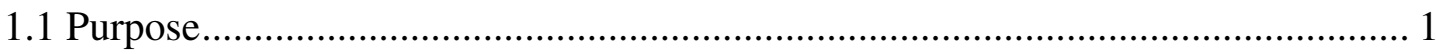

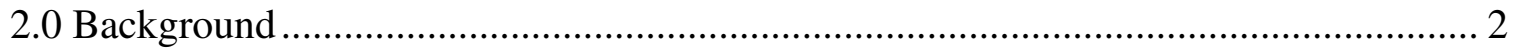

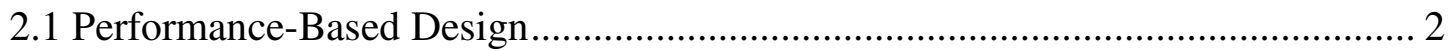

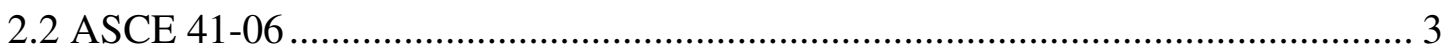

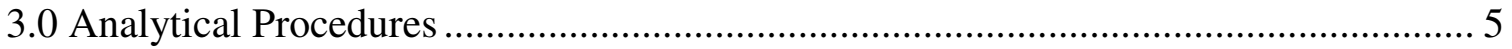

3.1 Applicability of Linear Procedures ................................................................... 6

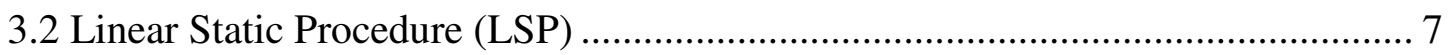

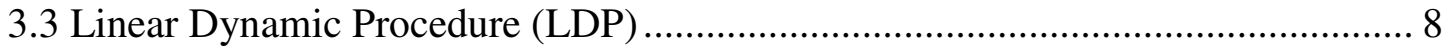

3.4 Nonlinear Static Procedure (NSP) .............................................................. 9

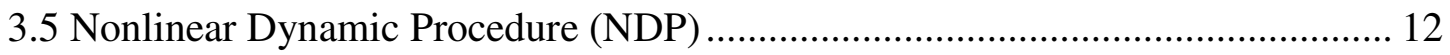

3.6 Vertical Seismic Effects and Multidirectional Effects...................................... 15

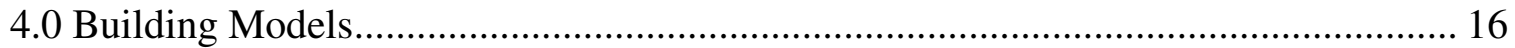

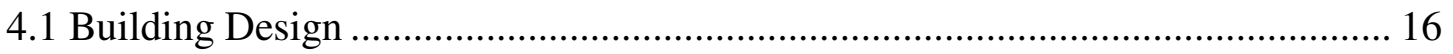

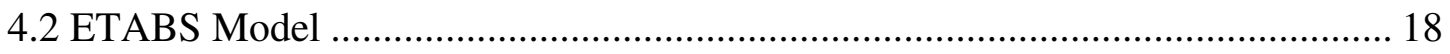

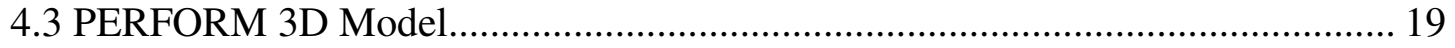

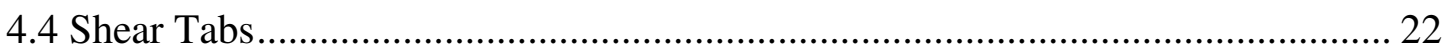

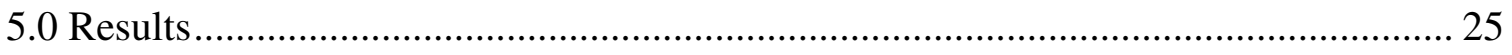

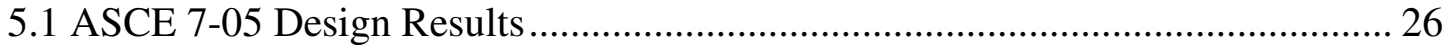

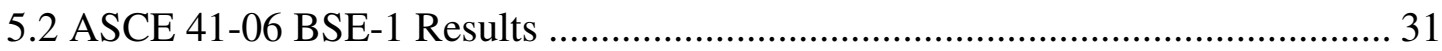

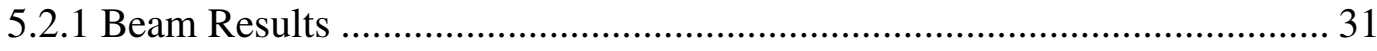

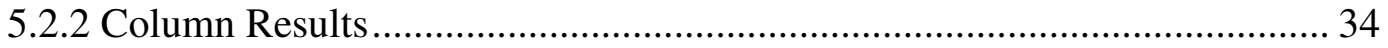

5.2.3 Story Drift and Roof Displacement ....................................................... 36

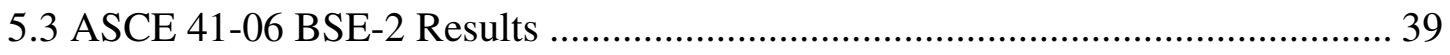

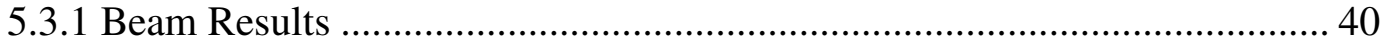

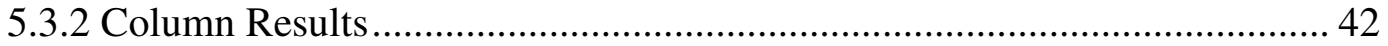




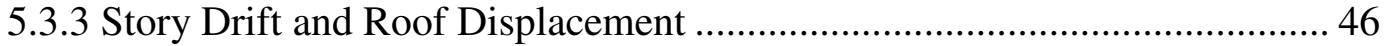

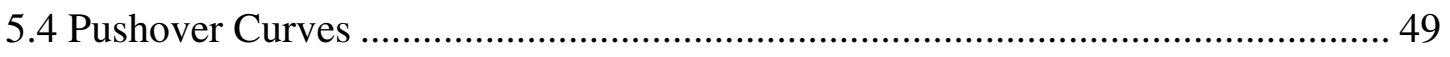

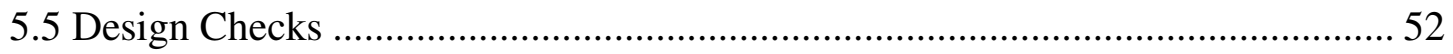

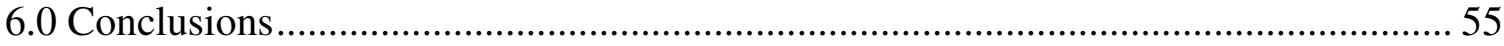

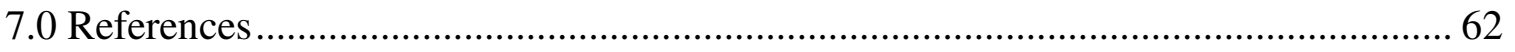

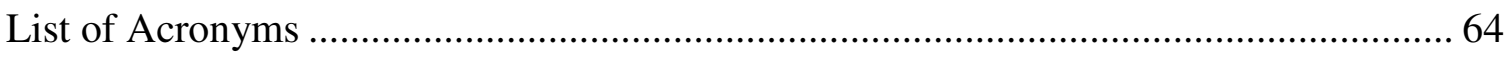

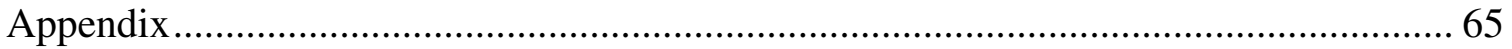




\section{LIST OF TABLES}

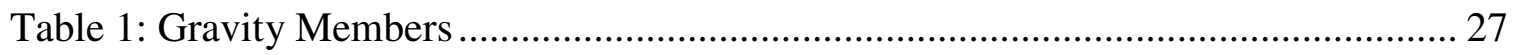

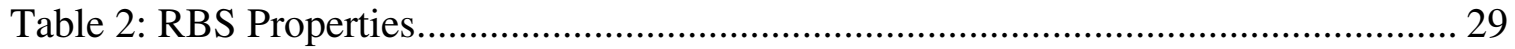

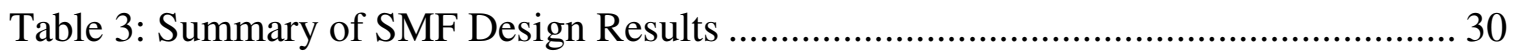

Table 4: Summary of Building Performance Level Results ....................................... 55 


\section{LIST OF FIGURES}

Figure A: BSE-1 Hazard Level Response Spectrum .................................................. 8

Figure B: Sample Inertia Force Distributions .............................................................. 9

Figure C: Scaled Ground Motions ......................................................................... 14

Figure D: Scaled BSE-1 Response Spectrums for 7 Ground Motions .............................. 15

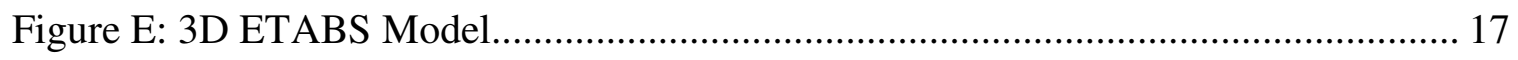

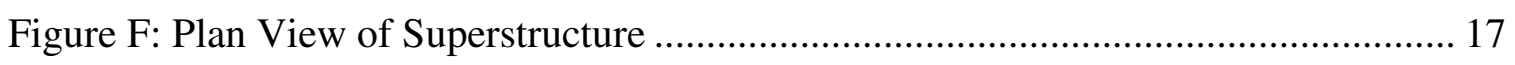

Figure G: Generalized Force-Deformation Relation for Steel Components .................... 19

Figure H: PERFORM 3D Rayleigh Damping ......................................................... 22

Figure I: Model of Moment-Rotation Behavior of Shear Tabs ……………………...... 23

Figure J: Moment Rotation Relationship for W18x35 Beam ........................................... 24

Figure K: Plan View of Superstructure................................................................... 27

Figure L: Moment Frame Elevation on Gridlines $1 \& 6$............................................... 27

Figure M: Moment Frame Elevation on Gridlines A \& G.............................................. 28

Figure N: Moment Frame Elevation on Gridlines B \& F ................................................ 28

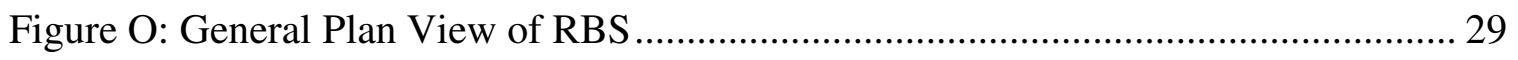

Figure P: SMF Beams in East-West Direction ........................................................ 32

Figure Q: SMF Exterior Beams in North-South Direction ................................................ 33

Figure R: SMF Interior Beams in North-South Direction .............................................. 33

Figure S: SMF Columns in East-West Direction...................................................... 35

Figure T: SMF Exterior Columns in North-South Direction........................................... 35

Figure U: SMF Interior Columns in North-South Direction ............................................ 36

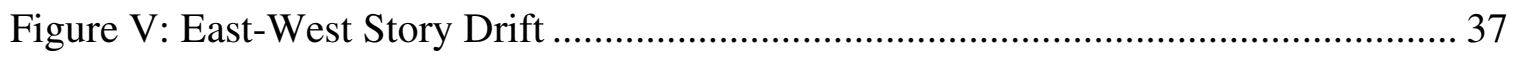

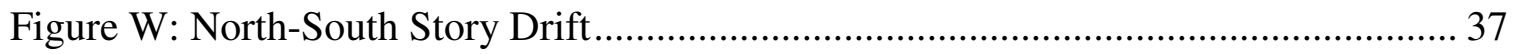

Figure X: Maximum Roof Displacements in East-West Direction .................................... 38

Figure Y: Maximum Roof Displacements in North-South Direction................................ 38

Figure Z: SMF Beams in the East-West Direction ......................................................... 41

Figure AA: SMF Exterior Beams in the North-South Direction ......................................... 41

Figure BB: SMF Interior Beams in the North-South Direction........................................ 42 
Figure CC: SMF Columns in the East-West Direction............................................. 43

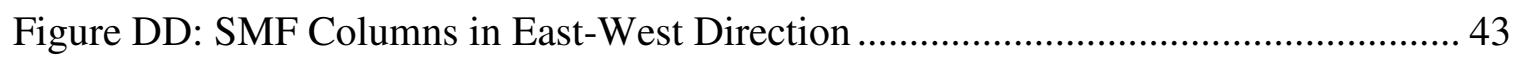

Figure EE: SMF Exterior Columns in North-South Direction .................................... 44

Figure FF: SMF Exterior Columns in North-South Direction ...................................... 44

Figure GG: SMF Interior Columns in the North-South Direction................................ 45

Figure HH: SMF Interior Columns in North-South Direction..................................... 45

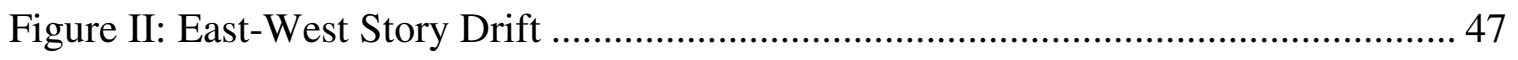

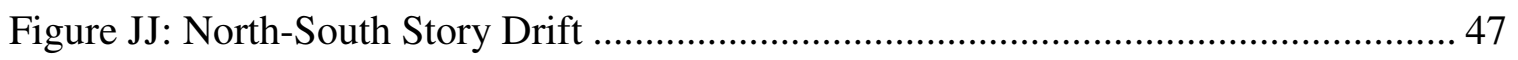

Figure KK: Maximum Roof Displacements in East-West Direction ............................. 48

Figure LL: Maximum Roof Displacements in North-South Direction........................... 48

Figure MM: Krawinkler Model for Panel Zones ...................................................... 50

Figure NN: Pushover Curve in East-West Direction ................................................... 51

Figure OO: Pushover Curve in North-South Direction ............................................ 51

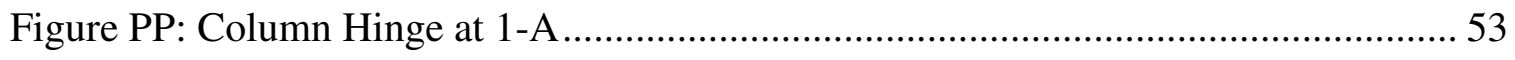

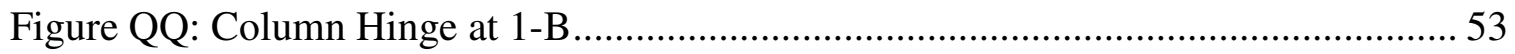

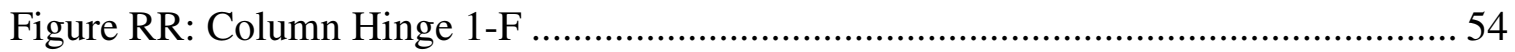




\subsection{INTRODUCTION}

The seismic design of buildings is continuing to evolve. Traditional design methods have the objective of achieving life safety in a building by providing sufficient strength and ductility to resist total and/or partial collapse. Using the California Building Code (CBC), buildings in California have met the goal of life safety reasonably well, although many have not experienced a design level seismic event. In today's society, however, the goal of limiting excessive damage and maintaining function of the building after an earthquake is becoming more desirable. In order to more accurately predict damage to a structure in an earthquake, performance-based design methodologies are being developed.

\subsection{Purpose}

The purpose of the project was to investigate the performance of a steel Special Moment Frame building designed according to current codes and standards when analyzed using the four prescribed performance-based analysis procedures in American Society of Civil Engineers (ASCE) Standard 41-06, Seismic Rehabilitation of Existing Structures. The project also investigated the differing results from the pushover analyses completed using ETABS and PERFORM 3D, two commonly used structural analysis programs. Lastly, the results were compared to a similar project using a braced frame structure to compare performances of different building types. The results of the comparison will provide data for the engineering profession to assess performance-based engineering as it continues to evolve and help engineers choose a building type to use based on the desired performance. 


\subsection{BACKGROUND}

The purpose of the current building code in California is "to establish the minimum requirements to safeguard the public health, safety and general welfare through structural strength" (IBC 2006 1). Because of the continuing desire to limit excessive damage and maintain function of the structure after a moderate earthquake, performancebased seismic design and analysis is gaining in popularity. Performance-based design is a methodology in which structural design criteria are expressed in terms of performance objectives. These objectives will vary based on the design goals and may be a level of stress not to be exceeded, a maximum load, a maximum displacement, a limit state, or a damage state.

\subsection{Performance-Based Design}

Three documents are credited with laying the foundation for performance-based design: Structural Engineers Association of California's (SEAOC) Vision 2000, Advanced Technology Council (ATC) 40, and FEMA 273/274 (Ghobarah 879). The SEAOC publication Vision 2000 was published in 1995 with the intent of defining a series of performance levels for seismic resistance, a series of reference earthquake hazard and design levels, a series of uniform performance objectives, and recommendations for uniform engineering procedures for performance-based engineering (Vision 2000, 1-2). SEAOC had previously recognized that the current building codes were adequate for life-safety design of structures; however, these codes poorly predicted the amount of damage that a structure would undergo during a seismic event. The Loma Prieta and Northridge earthquakes occurred six years and one year prior to the 
publication of Vision 2000, respectively. Combined, these earthquakes caused approximately $\$ 27$ billion in damage and 124 lives lost (Vision 2000, 1-2). Although most structures performed up to code standards, the engineering community and the public at large judged the economic loss of the earthquakes too great. Vision 2000 provided the practicing engineer guidelines to more accurately predict the damage to a structure under a given seismic loading.

Although Vision 2000 provided guidelines for performance-based engineering, it did not provide analytical approaches or methods to assess the likely performance of the building. FEMA 273/274, NEHRP Guidelines for the Seismic Rehabilitation of Buildings, built on SEAOC's Vision 2000 by incorporating the introduction of analysis procedures for performance-based design and the introduction of subjective factors to address the issue of structural uncertainty.

\subsection{ASCE 41-06}

The next major development in performance-based methodologies was FEMA 356, Prestandard and Commentary for the Seismic Rehabilitation of Structures.

Although based on the guidelines from FEMA 273/274, significant improvements were made. After completion of FEMA 273/274, a comprehensive program of case studies was undertaken in 1998 to test more thoroughly the analysis techniques and acceptability criteria provided by the document.

The Northridge earthquake in 1994 also provided data that led to significant improvements in the design of steel moment frame connections, as documented in FEMA 350 and FEMA 351. The improvements discussed in FEMA 350 and FEMA 351, along 
with the most advanced analytical techniques considered practical at the time, were included in FEMA 356.

Following FEMA 356, the American Society of Civil Engineers (ASCE) produced ASCE Standard 41-06, Seismic Rehabilitation of Structures. ASCE 41-06 is based on FEMA 356; however ASCE 41-06 included many significant improvements over FEMA 356, which included:

- Revised coefficients for calculating the pseudo-lateral force and target displacement

- Comprehensive soil-structure interaction provisions

- Revised acceptance criteria for steel moment frames

- Expanded acceptance criteria for concentrically braced frames

- Updated nonstructural provisions

- Revisions to modeling parameters and acceptance criteria for reinforced concrete structures (ASCE 41-06).

ASCE 41-06 represents the current accepted performance-based design procedures to be used in the seismic assessment of buildings. 


\subsection{ANALYTICAL PROCEDURES}

American Society of Civil Engineers (ASCE) Standard 41-06, Seismic

Rehabilitation of Existing Structures, contains four procedures for use in seismic evaluation of structures. Although the standard does not specify when to use a specific procedure, it does present limits of applicability for all procedures. Before performing any of the four analysis procedures, however, a rehabilitation objective, building performance levels, and seismic hazard level must be selected.

The rehabilitation objective is chosen by the building owner and can vary from a limited rehabilitation objective to an enhanced rehabilitation. In ASCE 41-06, the Basic Safety Objective (BSO) is used to approximate the earthquake risk to life safety traditionally considered acceptable in the United States (ASCE 41-06, 8). Any rehabilitation that provides building performance exceeding the BSO is considered an enhanced rehabilitation objective and any that provides building performance that is less than the BSO is termed limited rehabilitation objective. The BSO was chosen for this project because it is the intended performance objective for new buildings.

For all rehabilitation objectives, there are corresponding building performance levels that must be maintained. Building structural and nonstructural performance levels are used to express discrete damage states that buildings could experience during an earthquake. The building performance level is chosen by the owner of the structure and can range from Operational to Collapse Prevention. ASCE 41-06 Tables C1-2 through C1-7 define building performance levels and the readily anticipated consequences associated with the post-earthquake condition of the building. 
After the safety objective and building performance level have been selected, the seismic hazard level is determined. ASCE 41-06 defines two Earthquake Hazard Levels for use in conjunction within the standard: Basic Safety Earthquake 1 (BSE-1) and Basic Safety Earthquake 2 (BSE-2). The BSE-2 Hazard Level is the lesser of the ground motion with $2 \%$ probability of exceedance in fifty years, or a 2500 year return period, and $150 \%$ of the mean deterministic estimate ground motion. The BSE-1 Hazard Level is the smaller of the $10 \%$ probability of exceedance in fifty years, or 500 year return period, and two-thirds of the BSE-2 Hazard Level values (ASCE 41-06 § 1.6.1, 22-24). The Earthquake Hazard Level is used to define the demands for each analytical procedure.

In order to achieve the Basic Safety Objective, the building under analysis should achieve a Life Safety (LS) performance level with the BSE-1 Hazard Level and a Collapse Prevention (CP) performance level with the BSE-2 Hazard Level.

\subsection{Applicability of Linear Procedures}

Because "the actual response of buildings to earthquakes is not typically linear", the use of linear procedures prescribed by ASCE 41-06 is limited (ASCE 41-06 2). ASCE 41-06 lists four irregularities that, if occurring in the building, prohibit linear procedures. These irregularities are the following:

- In-plane discontinuities

- Out-of-plane discontinuities

- Weak stories irregularities

- Torsional strength irregularities. 
These irregularities are similar to those listed in ASCE 7-05; however, they are not analogous. The definitions for these irregularities can be found in ASCE 41-06 §2.4.1.1.

\subsection{Linear Static Procedure (LSP)}

The LSP is the most basic of the four procedures. A static seismic load is determined using the seismic weight of the structure, an appropriate response spectrum acceleration based on the structure's period and damping, and modifications factors listed in ASCE 41-06 § 3.3.1.3. In order to more accurately approximate the maximum displacement achieved during a seismic event, the LSP utilizes a lateral load that is generally much greater than the capacity of the structure. The load is then distributed vertically based on the seismic weight, height of each story, and building period. The LSP model represents the building with a linear-elastic stiffness that corresponds to the building's stiffness before yield occurs. Although the procedure is described as linear, geometric nonlinearity such as P-delta effects are considered.

Because the lateral load used is generally greater than the capacity of the structure, ASCE 41-06 provides factors, called $m$-factors, to reduce demands on the individual components of the structure. $M$-factors are used as a measure of the nonlinear deformation capacity of the components in the structure and indirectly incorporate the nonlinear response of a building to the linear analysis procedures.

If the building contains one of the following characteristics, the LSP is not an acceptable analysis procedure:

- The fundamental period of the building is greater than or equal to 3.5 times $\mathrm{T}_{\mathrm{s}}$, where $\mathrm{T}_{\mathrm{s}}$ is defined by ASCE 41-06 Eq. 1-11 
- The ratio of the horizontal dimension at any story to the corresponding dimension at an adjacent story is greater than 1.4

- The building has a torsional stiffness irregularity in any story

- The building has a vertical stiffness irregularity

- The building has a non-orthogonal lateral-force-resisting system

The building used for the project does not contain any of the previous characteristics; therefore, the LSP was an acceptable procedure to be used for the project.

\subsection{Linear Dynamic Procedure (LDP)}

The LDP is based on loading generated using modal response spectrum analysis or linear time history analysis. The damped general response spectrum provided by ASCE 41-06 § 1.6.1.5 for use in the LDP is the same as the one used in the LSP and can be seen in Figure A. Because this project utilizes the general response spectrum, a 5\% damped response spectrum is assumed (ASCE 41-06 § 1.6.1.5.3).

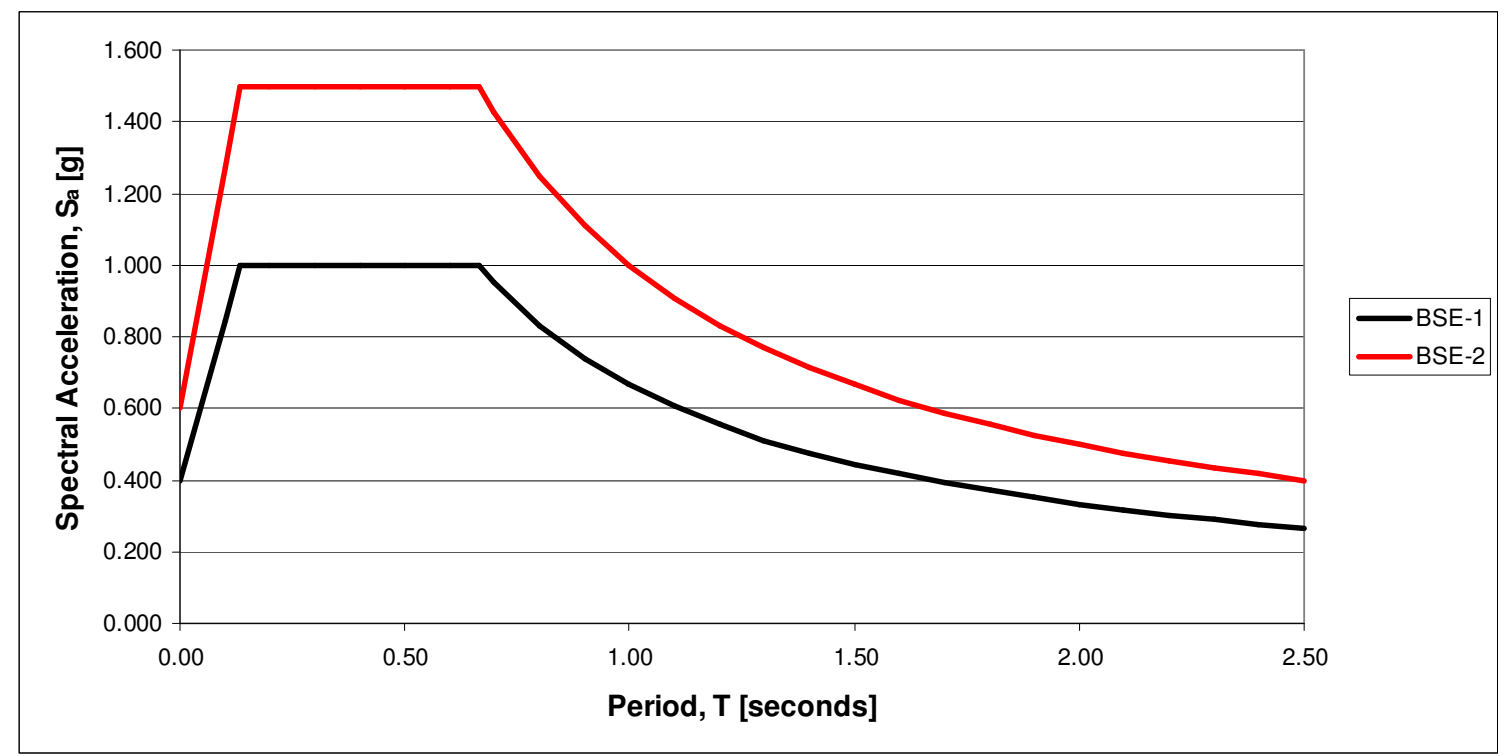

Figure A: ASCE 41-06 Response Spectra 
Because the effect of higher modes is considered in the LDP procedure, the base shear produced is generally smaller than the base shear from the LSP, as illustrated in Figure B (FEMA 274 C3.3.2.2, 3-17).

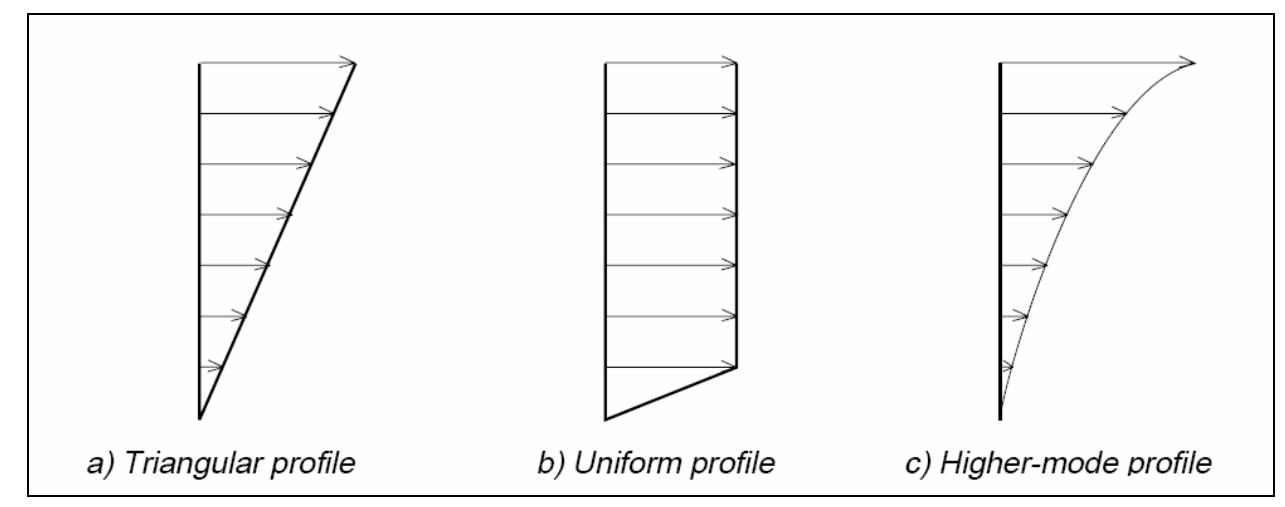

Figure B: Sample Inertia Force Distributions

Source: FEMA 274, 1997

ASCE 41-06 requires that sufficient modes be considered to capture ninety percent of the building mass in the building's two principal orthogonal directions. As in the LSP, the building is modeled with a linearly-elastic stiffness and analyzed with a base shear that is generally greater than the capacity of the structure. $M$-factors and acceptance criteria for the components are the same as in the LSP.

\subsection{Nonlinear Static Procedure (NSP)}

The NSP, commonly referred to as a pushover analysis, directly incorporates the nonlinear response of members in the structure. A model of the structure that incorporates the "nonlinear load-deformation characteristics of individual components of a building" is loaded with "monotonically increasing lateral loads representing inertia forces in an earthquake until a target displacement is exceeded" (ASCE 41-06 § 3.3.3.1, 67). The target displacement is developed using procedures provided by ASCE $41-06 \S$ 
3.3.3.3.2 and is intended to represent the maximum displacement likely to be experienced during the design level earthquake. The target displacement represents the mean displacement for the design level earthquake for the building at a given location; because considerable scatter can exist about the mean, ASCE 41-06 requires the building be pushed to $150 \%$ of the target displacement. Although the strength and deformation levels are checked at the target displacement, the requirement to push the building to $150 \%$ of the target displacement encourages the design engineer to investigate likely building performance of the model under extreme load and deformation conditions that exceed the design values (ASCE 41-06 68). The 150\% requirement also allows the engineer to ensure there is not a sudden loss of strength if the target displacement is exceeded. Acceptance criteria for plastic rotations, deflections, and force levels for each component are provided by ASCE 41-06 Chapter 5 for steel buildings.

The target displacements for the building were calculated in accordance with ASCE 41-06 $§ 3.3 .3 .3 .2$. The target displacements are calculated using modification factors to relate spectral displacement of an equivalent single-degree of freedom system to the roof displacement of building, relate expected maximum inelastic displacement to linear elastic displacement, and represent the effect of pinched hysteric behavior. The equation for target displacements also includes the ASCE 41-06 response spectrum acceleration and the effective fundamental period, calculated in accordance with ASCE 41-06 $§ 3.3 .3 .2 .6$ (ASCE 41-06 69-71). The target displacements for the building for the two hazard levels are shown in

\begin{tabular}{|l|l|}
\hline BSE-1 Hazard Level & BSE-2 Hazard Level \\
\hline
\end{tabular}


\begin{tabular}{|l|l|}
15.3 in & $23.0 \mathrm{in}$ \\
\hline
\end{tabular}

Table 1 on the following page.

\begin{tabular}{|c|c|}
\hline BSE-1 Hazard Level & BSE-2 Hazard Level \\
\hline 15.3 in & 23.0 in \\
\hline
\end{tabular}

Table 1: Target Displacements

The lateral load pattern used for the NSP is an important facet of the analysis.

During a seismic event, however, the actual distribution of the lateral inertial forces

continuously vary due to portions of the structure yielding and stiffness characteristics

changing. FEMA 356, Prestandard and Commentary for the Seismic Rehabilitation of

Buildings, requires that two load patterns be used for the NSP (FEMA $356 \S$ 3.3.3.2.3).

The use of two load patterns is intended to bound the range of design actions that could occur during a seismic event. In comparison, ASCE 41-06 recommends the use of a single load pattern based on the shape of the first mode (ASCE 41-06 § 3.3.3.2.4). The difference between the two documents resulted from Applied Technology Council's (ATC) Project 55, which was published as FEMA 440, Improvement of Nonlinear Static Seismic Analysis Procedures. In this study, the ATC concluded that "the use of multiple load vectors in FEMA 356 implies unwarranted accuracy and does not provide reliable results... a single first-mode vector is sufficient" as long as higher mode effects are not significant (FEMA 440 9-10). For this project it was decided to use both a load pattern based on the shape of the first mode and a uniform load pattern, although the final results shown are based on the first mode shaped loading pattern. 
ASCE 41-06 permits the use of nonlinear procedures for all structures; however it restricts the use of pushover analysis for some structures. The two requirements that must be met are (1) the strength ratio, $\mathrm{R}$, a measure of the extent of nonlinearity in the analysis, cannot be greater than a limiting value, $R_{\max }$, defined in ASCE 41-06 $§$

3.3.3.3.2, and (2) higher mode effects in the structure cannot be significant. The NSP is not permitted for structures where $\mathrm{R}$ exceeds $\mathrm{R}_{\max }$ because these structures experience significant degradation and the nonlinear dynamic procedure is required to confirm the dynamic stability of the building (ASCE 41-06 37). Structures that have significant higher mode effects are not permitted to be analyzed using only the NSP because a pushover analysis is generally performed with a single loading pattern and higher modes lead to different yielding patterns; therefore, structures that do not have a dominant mode cannot accurately be analyzed using only the NSP. The determination of whether higher modes are significant is defined in ASCE 41-06 $§ 2.4 .2 .1$. Because the first mode mass participation factor for the building was $86 \%$, it was determined higher modes were not significant and the NSP was an acceptable analysis procedure.

\subsection{Nonlinear Dynamic Procedure (NDP)}

The nonlinear dynamic procedure generally uses a similar computer model as the nonlinear static procedure; however, the loading and computational methods differ. The response of the structure is generated using nonlinear time-history analysis. This method of analysis is highly sensitive to characteristics of individual ground motions and to assumptions made in computer modeling. Because of the NDP's high sensitivity, to ground motions and modeling assumptions, ASCE 41-06 requires the NDP be performed 
with a minimum of three earthquake ground motions (ASCE 41-06 § 3.3.4.1, 72). Per ASCE 41-06, if fewer than seven ground motions are performed, the maximum demand in any component must be used for design. If seven or more ground motions are performed, an average value from the analyses may be used. Because the average value will generally result in lower demands, this project utilized seven ground motions for use in the NDP. Plots of the acceleration time-histories for the seven ground motions are shown in Figure $\mathrm{C}$ on the following page. All of the plots were truncated at 45 seconds, although some of the ground motions were longer. Larger versions of the complete plots can be found in the Appendix. The ground motions were chosen to be representative of the expected ground motions for the San Francisco Financial District. All seven ground motions were scaled to the ASCE 41-06 response spectrum to match the spectral acceleration at a period of 1.9 seconds for both the BSE-1 and BSE-2 levels according to ASCE 41-06 $§ ~ 1.6 .2 .2$. The ground motions were all recorded with 0.01 second time intervals and are shown in Figure $\mathrm{C}$ on page 14. The ground motion response spectrums are shown in Figure D page 15.

Because the time-history analyses are assumed to represent the actual forces and deflections the structure would experience during a seismic event, no modification of demands is required. The demands from the seven ground motions are averaged and compared to the same acceptance criteria from the NSP. 


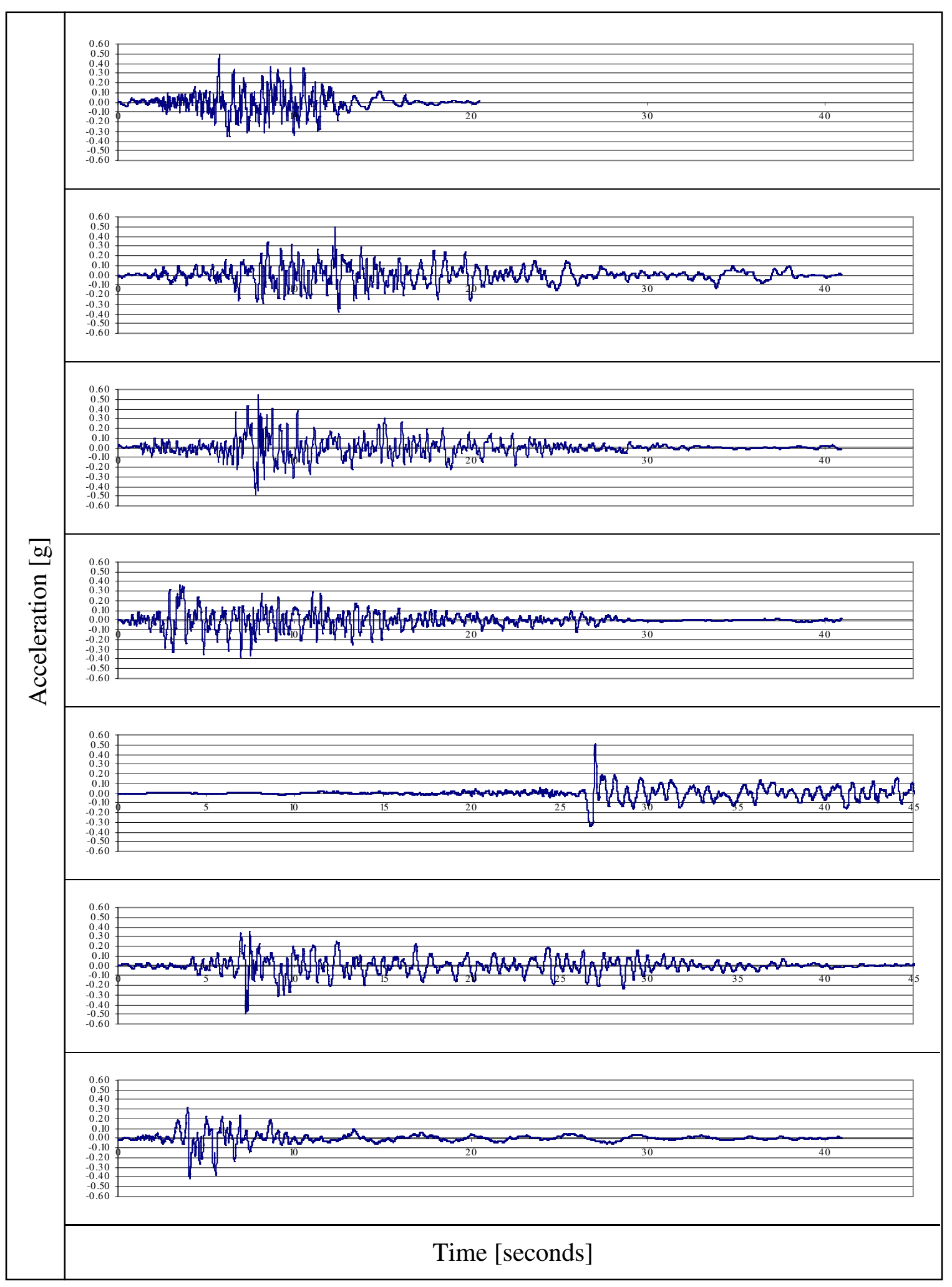

Figure C: Scaled Ground Motions

Performance Based Analysis of Steel Buildings 


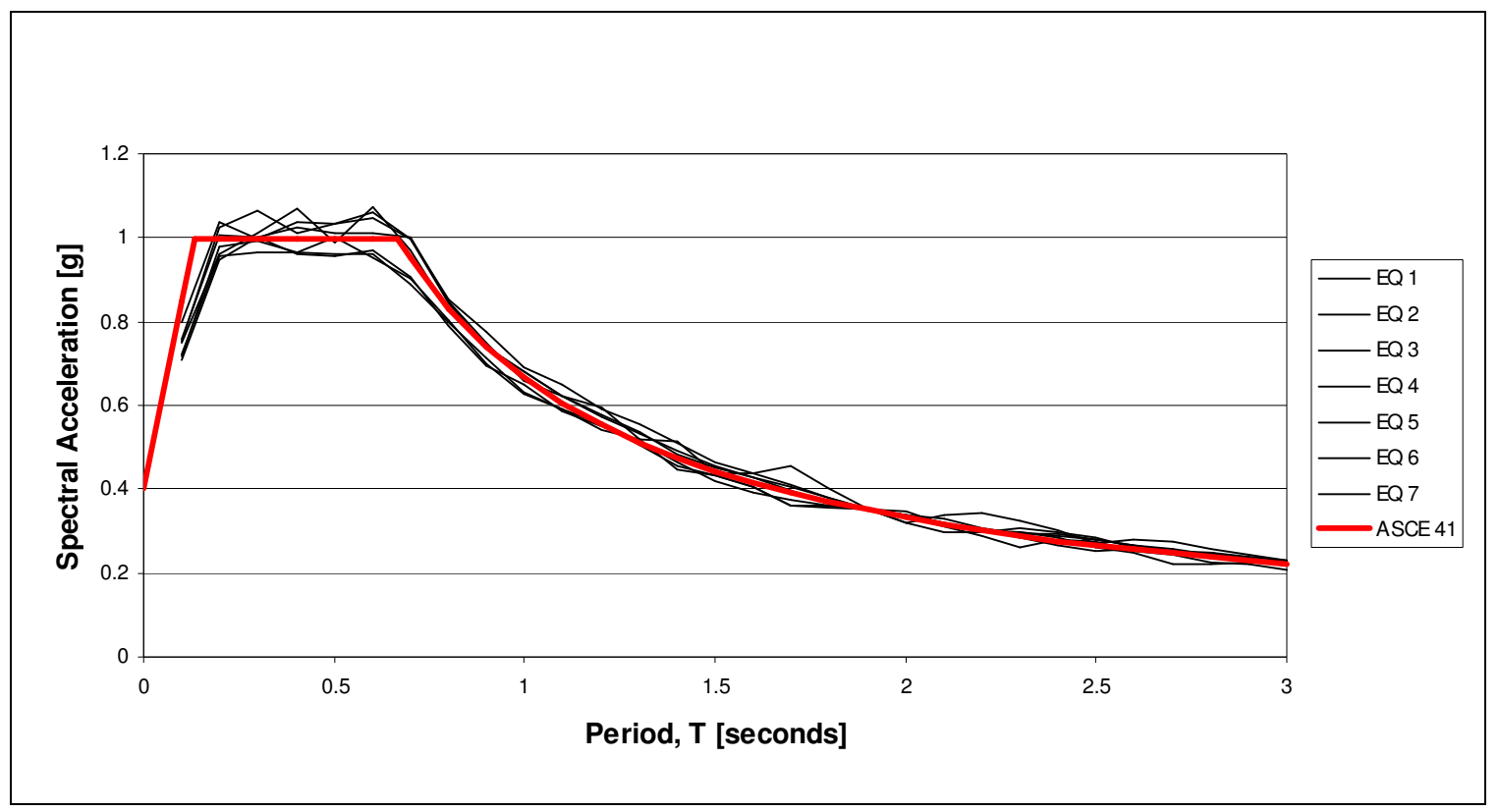

Figure D: Scaled BSE-1 Response Spectrums

\subsection{Vertical Seismic Effects and Multidirectional Effects}

Because there are no cantilever components, prestressed components, or components with demands due to gravity loads exceeding $80 \%$ of the nominal capacity, the vertical response of the structure to the ground motions need not be combined with the effects of the horizontal response per ASCE 41-06 $\S 3.2 .7 .2$ and $\S 2.6 .11$. The ASCE 41-06 analyses also did not consider multidirectional seismic effects. Because the structure has no plan irregularities and no primary columns which form part of two or more frame elements, analysis of the structure using ground motions acting nonconcurrently in the direction of each principal axis is permitted per ASCE 41-06 $\S$ 3.2.7. 


\subsection{BUILDING MODELS}

The first stage of the project was design of the building according to the 2007 California Building Code (CBC). The building has 3" steel decking topped with 31/4" $3000 \mathrm{ksi}$ lightweight concrete for a total weight of 46 psf. The weight due to mechanical units was incorporated by adding a 100 psf reducible live load to the interior bays at the roof level. The first story of the structure has 20 psf glass cladding, and all stories above have 75 psf concrete cladding. The design live load was a reducible 100 psf. Design lateral loads were calculated using "Equivalent Lateral Force Procedure" from the American Society of Civil Engineers (ASCE) Standard 7-05, Minimum Design Loads for Buildings and Other Structures. All other design loads were calculated in accordance with ASCE 7-05 load combinations in Chapters 2 and 12. The building is in Occupancy Category II per ASCE 7-05 Table 1-1. The location of the building is the intersection of Pine St. and Franklin St. in San Francisco, California. This location corresponds to a $1.500 \mathrm{~g}$ spectral response acceleration at a period of 0.2 seconds and a $0.667 \mathrm{~g}$ spectral acceleration at a 1.0 second period. The project did not directly account for soil-structure interaction due to a lack of soil information. Because no soil information was provided, Site Class "D" was chosen for the determination of lateral loads according to ASCE 7-05 $\S 11.4 .2$. All steel members in the building were designed with a minimum specified yield stress of 50 kips per square inch (ksi) and an expected yield strength of $55 \mathrm{ksi}$.

\subsection{Building Design}

The building, as seen in Figure $\mathrm{F}$ on page 17, is rectangular in plan, with six 30 '-0" bays in the East-West direction and five 30'-0" bays in the North-South direction. 
There are six stories above ground for a total height of $83^{\prime}-2$ " and two basement levels below ground for a total depth of $27^{\prime}-6 "$. The superstructure was designed to meet the requirements for a steel Special Moment Frame (SMF) per American Institute of Steel Construction (AISC) Specifications for Structural Steel Buildings (AISC 360-05) and the AISC Seismic Design Manual (AISC 327-05). AISC 358-05, Prequalified Connections for Special and Intermediate Steel Moment Frames for Seismic Applications, was used for the design of the reduced beam sections (RBS) in the moment frames. For the gravity system, all beams and girders were designed as composite. The basement consists of 14" concrete walls at the upper basement level and 18" concrete walls at the lower basement level.

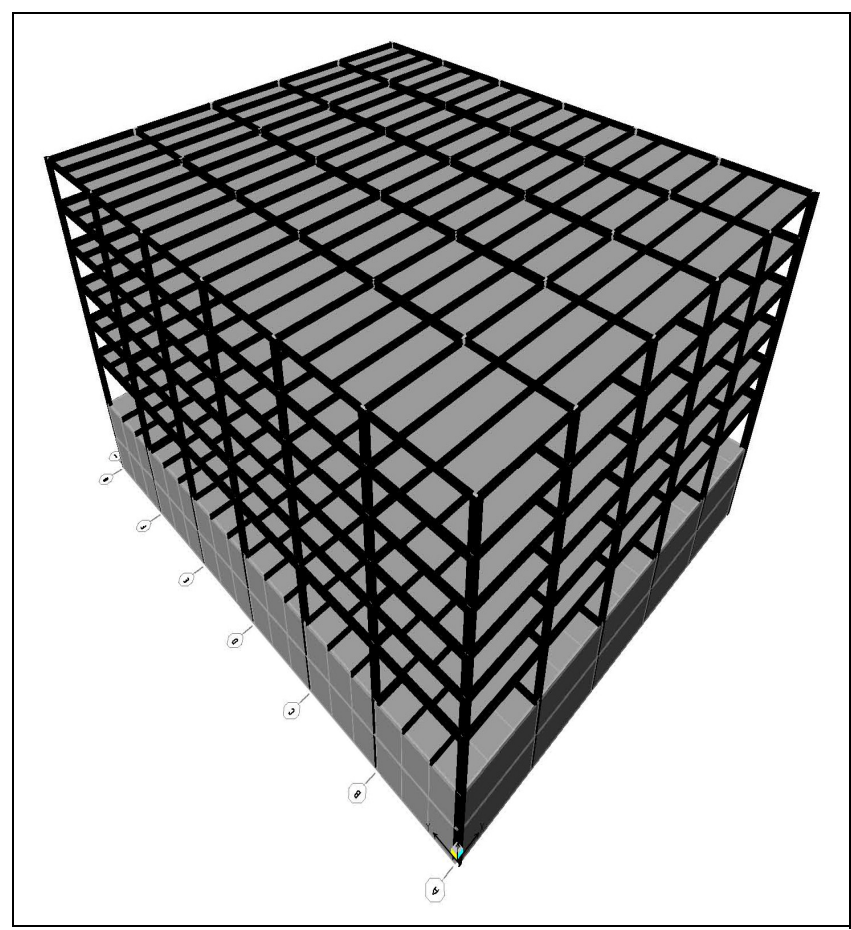

Figure E: 3D ETABS Model

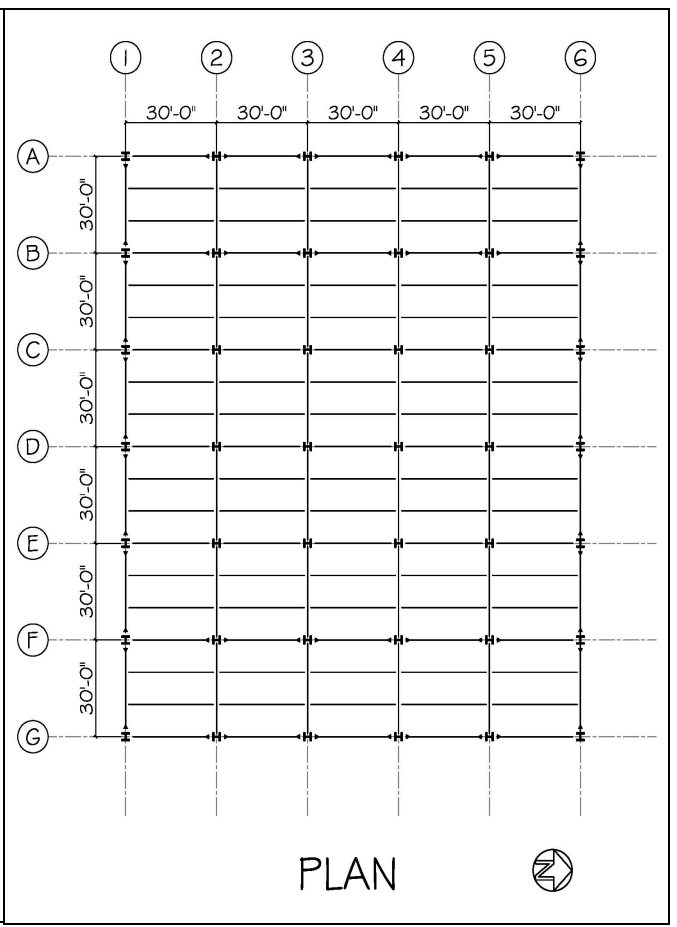

Figure F: Plan View of Superstructure 


\subsection{ETABS Model}

The building was designed and analyzed using the program ETABS v. 9.2.0, a structural analysis program distributed by Computers \& Structures, Inc (CSI). Many assumptions were made when modeling the structure:

- All column and wall base supports at the bottom of the lower basement level were idealized as pinned connections

- Columns in the plane of the basement wall were modeled as if they were continuous to the ground and encased with the concrete walls

- All beams and columns were modeled with rigid end zone factors equal to 0.5

- Beams and girders that are not part of the lateral force resisting system but are located on a column line were modeled with rotational spring restraints at the beam-to-column connections, see "4.4 Shear Tabs" on page 22

- The diaphragms were assumed to be rigid

- $5 \%$ damping was assumed (Filiatrault 2002)

In order to perform the nonlinear static procedure (NSP), or pushover analysis, plastic hinge strengths, yield rotations, and rotational capacities were modeled. All of the capacities were calculated using the prescribed methods in Chapter 5 of ASCE 41-06; the hinge yield rotations and moment capacities can be found in Table 3 on page 29. An example of the input to ETABS for a beam hinge can be seen in the Appendix on page 65. The generalized force-deformation relationship used for all steel components can be seen in Figure $\mathrm{G}$ on the following page. 


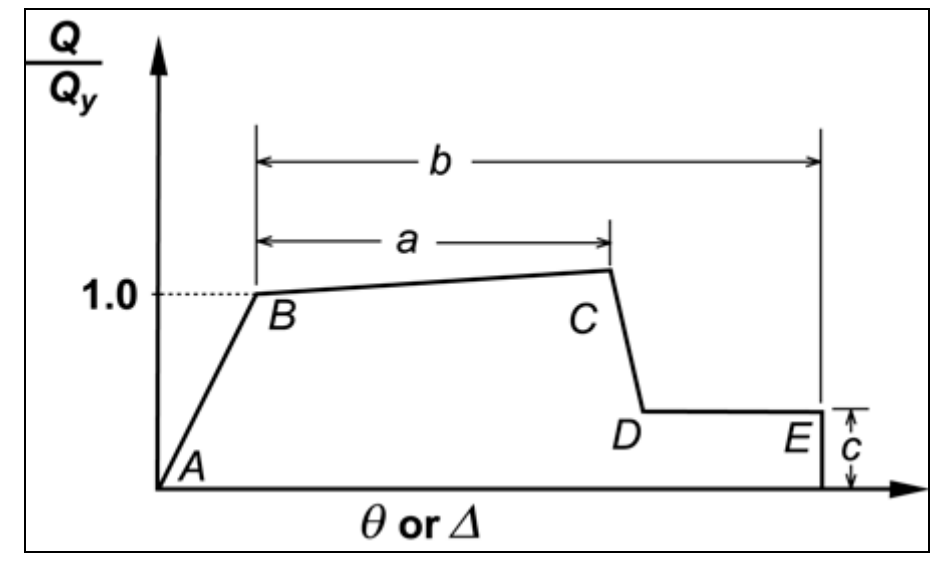

Figure G: Generalized Force-Deformation Relation for Steel Components Source: ASCE 41-06

The beam hinges were located at the centerline of the RBS and ignored the effect of axial loads. Per ASCE 41-06 $§ 5.4 .2 .3 .2$, neglecting axial load effects was permitted because the axial load in all of the beams was less than ten percent of the axial load capacity. Column hinges were placed only in the columns at ground level, at a distance of $5 \%$ of the story height off the ground. The location of the hinges was chosen to approximate a plastic hinge length equal to the depth of the column. The column hinges incorporated axial load and moment interaction through the use of ETABS P-M-M hinges, with the moment capacity defined by FEMA 273 Equation 5-4. The equation from FEMA 273 is used in ASCE 41-06, however the version of ETABS used has not updated the code reference. A three percent strain hardening value was used for all of the hinges, as permitted by ASCE 41-06 $§$ 5.4.2.2.2. An example of the input to ETABS for a P-M-M hinge can be seen in the Appendix on page 66.

\subsection{PERFORM 3D Model}

The project also employed PERFORM 3D v. 4, a nonlinear structural analysis program distributed by CSI to perform both the nonlinear static and nonlinear dynamic 
procedures. The properties and locations of all beam hinges were identical to those in the ETABS model. The column hinges were placed in the same location as the ETABS model, however PERFORM 3D defines P-M-M hinges differently. Whereas ETABS uses Equation 5-4 from FEMA 273 to define the yield moment, PERFORM 3D requires that information be input to define a yield surface for the P-M-M hinge.

The PERFORM 3D model also excluded all joists not located on gridlines. Point loads equal to the reactions from the joists were applied to girders. In addition, the area loads used in the ETABS model were distributed according the members tributary area and assigned as line loads in the PERFORM 3D model.

The concrete over metal deck diaphragms were not included in the PERFORM 3D model because they significantly and adversely affected the performance of the structure once yielding of the beams occurred. The version of PERFORM 3D used for this project allows only elastic slab sections to be modeled. Once the building approached its yield strength, the elastic stiffness of the slab became significantly stiffer than the rest of the structure and prevented the structure from yielding. Because this behavior in the slab is not in line with reality and a more accurate nonlinear model could not be used for the slab, the slab was excluded. Although the exclusion of the slab had very little impact on the elastic period of the building, it had a significant effect on allowing the building to yield. In order to simulate the rigid diaphragm the slab provides, the nodes at each story level were slaved in the PERFORM 3D model.

The method for distribution of mass also differs in the two computer programs. Whereas ETABS has many methods for determining the mass of the structure, 
PERFORM 3D requires that nodal mass be assigned. For this project, the amount of mass assigned to the PERFORM 3D model was determined from the ETABS output for mass at each story and located at the center of rigidity for each story.

Another difference between the two models was the treatment of end zones for beams and columns. For both programs, the length of the end zone was typically half the depth of the intersecting members; however the calculation for stiffness of the end zones was different. ETABS uses a rigid end zone factor. For this project, all beam and column end zones used an end zone factor of 0.5 , which equates to half the end zone being rigid and the other half being elastic. PERFORM 3D, in comparison, uses a multiple of the beam stiffness over the entire length of the end zone. The default end zone, which uses a 10 times multiplier for the stiffness in the end zone, was used for this project.

Like the ETABS model, the PERFORM 3D had a modal damping ratio of 5\%. In addition to the modal damping, the PERFORM 3D model included $0.2 \%$ Rayleigh damping at the fundamental period. A graph displaying the Rayleigh damping for the building can be seen in Figure $\mathrm{H}$ on the following page. 


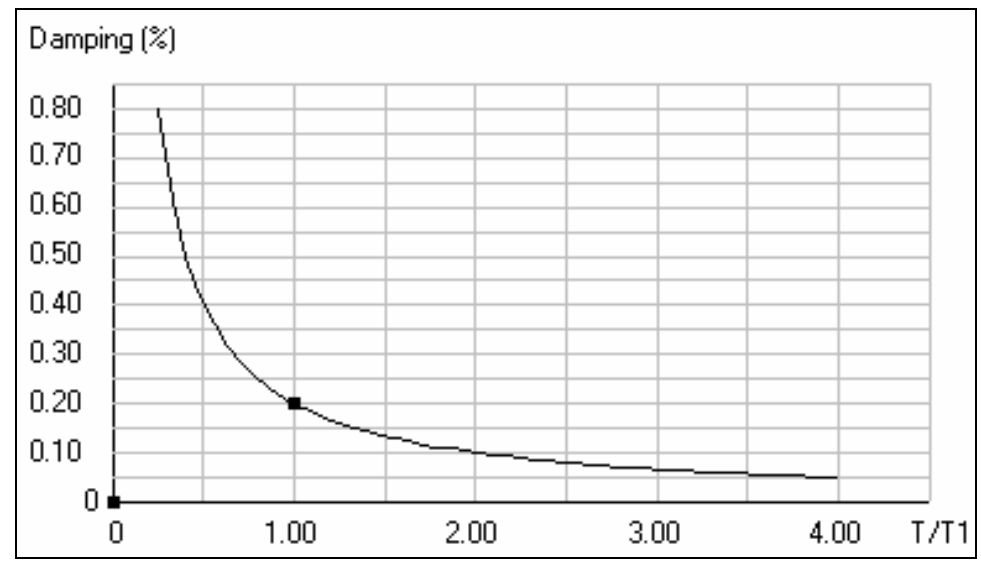

Figure H: PERFORM 3D Rayleigh Damping Source: PERFORM 3D

The Rayleigh damping was included based on a recommendation from the PERFORM 3D user guide. If only modal damping is assigned, only the displaced shapes that correspond to elastic periods will be damped. Because there are a larger number of degrees of freedom than there are mode shapes, there are displaced shapes that will not correspond to elastic period and therefore will not be damped. The addition of the small amount of Rayleigh damping provides damping for these unaccounted for displaced shapes and provides negligible damping for the included mode shapes (CSI 2006, 18-12).

\subsection{Shear Tabs}

For the design of the structure according to the CBC, all connections carrying only gravity loads were idealized as pinned connections. In order to more accurately predict the performance of the structure in the ASCE 41-06 analyses, some of the shear tabs were modeled as partially restrained moment connections instead of pinned connections. These substitutions occurred at the following locations:

- All beam-column connections that are not part of the SMF

- All girder-column connections that are not part of the SMF 
- All beam-column connections in the superstructure in the North-South direction on the intersection of gridlines $1-A, B, G, F$ and $6-A, B, G, F$. Each connection was provided with a rotational stiffness and plastic hinge. The rotational stiffness and plastic hinge properties were defined using Design of Shear Tab Connections for Gravity and Seismic Loads by Abolhassan Astaneh-Asl. In his publication, Astaneh-Asl suggests that the moment-rotation relationship for shear tabs is as depicted in Figure I.

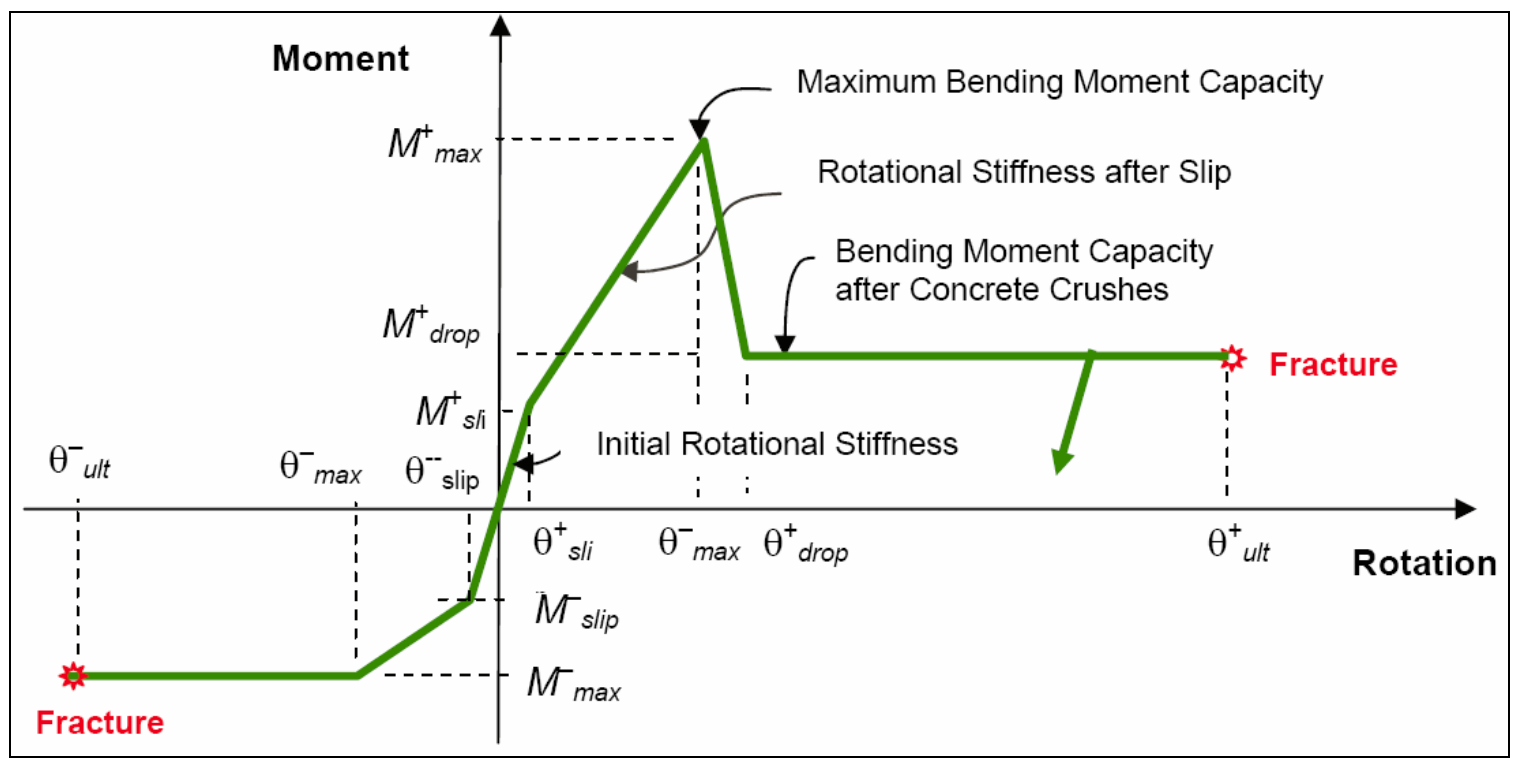

Figure I: Model of Moment-Rotation Behavior of Shear Tabs Source: Astaneh-Asl 2005

By inspection of Figure I, it can be seen that the shear tab connection has different rotational stiffness for positive and negative bending. Because ETABS and PERFORM 3D both require a single value for rotational stiffness, an average of the positive and negative rotational stiffness values was used for this project. The yield moment and rotation values input into the computer models corresponded with Astaneh-Asl's values of $\mathbf{M}_{\max }$ and $\theta_{\max }$ for both positive and negative bending. The values for the positive Performance Based Analysis of Steel Buildings 
bending moment strength degradation and the ultimate rotational capacities used for the computer models also corresponded to Astaneh-Asl's values. An example of the momentrotation relationship for a shear tab used in this project can be seen in Figure $\mathrm{J}$.

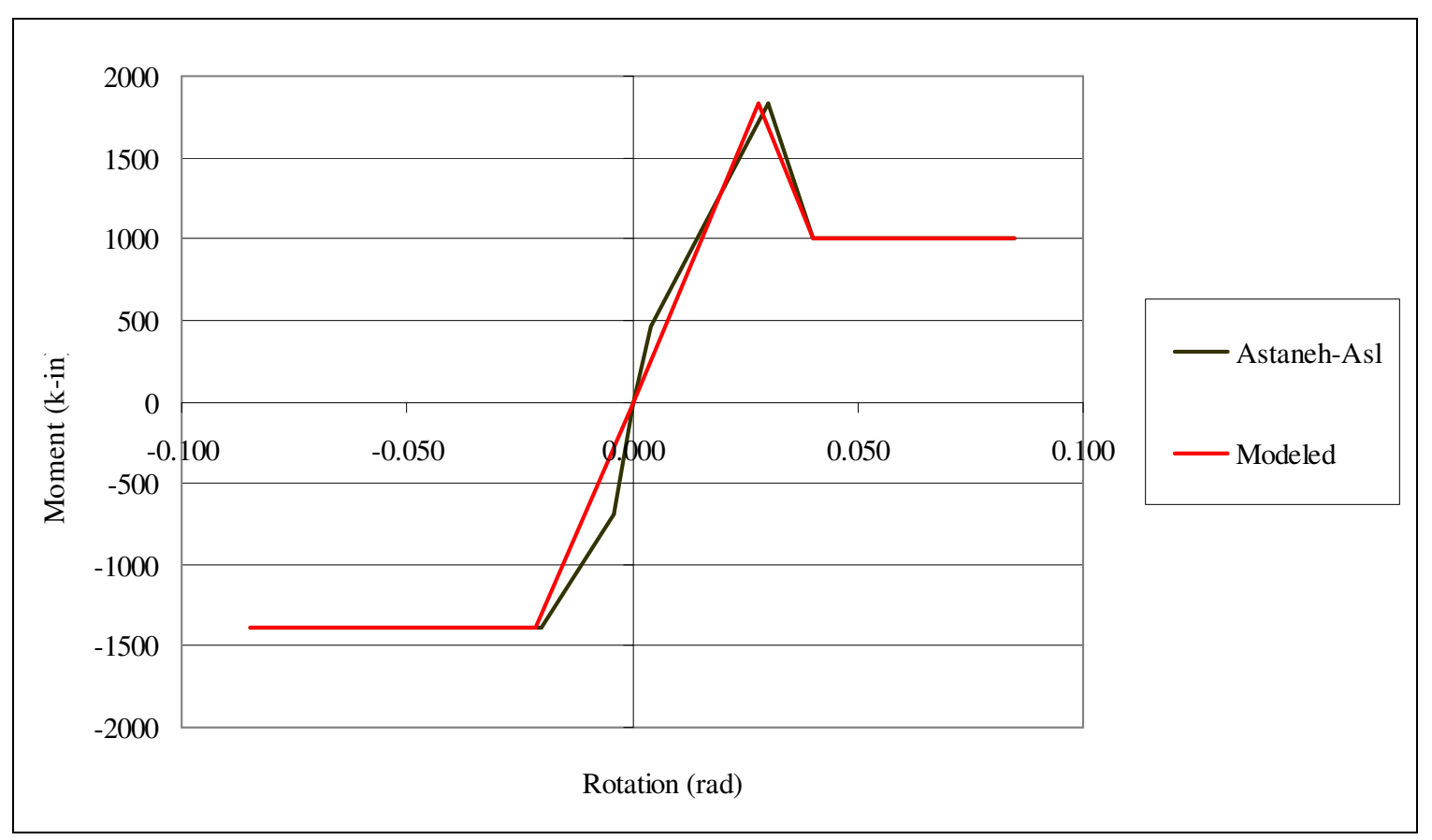

Figure J: Moment Rotation Relationship for W18x35 Beam 


\subsection{RESULTS}

Two models were constructed for use in the design of the building and the ASCE 41-06 analyses. ETABS was used for the ASCE 7-05 design of the building, the ASCE 41-06 linear static and dynamic procedures (LSP \& LDP), and the ASCE 41-06 nonlinear static procedure (NSP). PERFORM 3D was used for ASCE 41-06 NSP and the nonlinear dynamic procedure (NDP).

In order to compare the results of the analysis procedures, data had to be collected from the various components of the model. For the beams, all of the data was recorded at the centerline of the reduced beam sections (RBS). For each procedure, the maximum demand from the reduced beam sections was compared to the beam acceptance criteria. For the columns, all results were recorded at the location of the column hinge, or $5 \%$ of the height of the column above the ground level. For all of the procedures except the NDP, the maximum component moment, axial force, and hinge rotation demands in the columns occurred simultaneously. For the NDP, however, only the maximum and minimum values were recorded. It was assumed that the maximum column axial force and maximum column hinge rotation occurred simultaneously. Although this project recognizes the fact that the demands do not necessarily occur simultaneously, this assumption was found to be acceptable. After investigation, it was found that the axial force demand in the columns varied by $0 \%-10 \%$ of the maximum column axial force at the time of maximum column hinge rotation. This variation caused negligible change in the scope of the results. 
Like the column component demands, only the maximum and minimum values for story drift were recorded in the NDP, although these values do not necessarily occur simultaneously. Because the LDP used a modal analysis and the other two procedures are static, the maximum story drifts for all other procedures occur simultaneously.

For the linear procedures, the axial force in the columns reported for the ASCE 41-06 results used a limit state value as allowed by ASCE 41-06 Table 5-5.

For the nonlinear procedures, acceptance criterion for primary components was used for the SMF components. Although ASCE 41-06 allows secondary component acceptance criteria for components modeled explicitly with full backbone curves per $\S$ 3.4.3.2, it was decided that the use of the ASCE 41-06 generalized load-deformation curve did not represent modeling full backbone curves.

\subsection{ASCE 7-05 Design Results}

The project began with the design of the building according to American Society of Civil Engineers Standard 7-05 (ASCE 7-05), Minimum Design Loads for Buildings and Other Structures, and American Institute of Steel Construction (AISC) Specifications for Structural Steel Buildings (AISC 360-05). The gravity system beams and girders are listed in Table 2 on page 27. The gravity columns are W12x152 at the basement levels, W12x120 at the first two stories, and W12x72 at the top four stories. Elevations of the moment frames can be seen in Figure L, Figure M, and Figure N on pages 27 and 28. Properties of the RBS can be found in Figure O and Table 3 on page 29. 


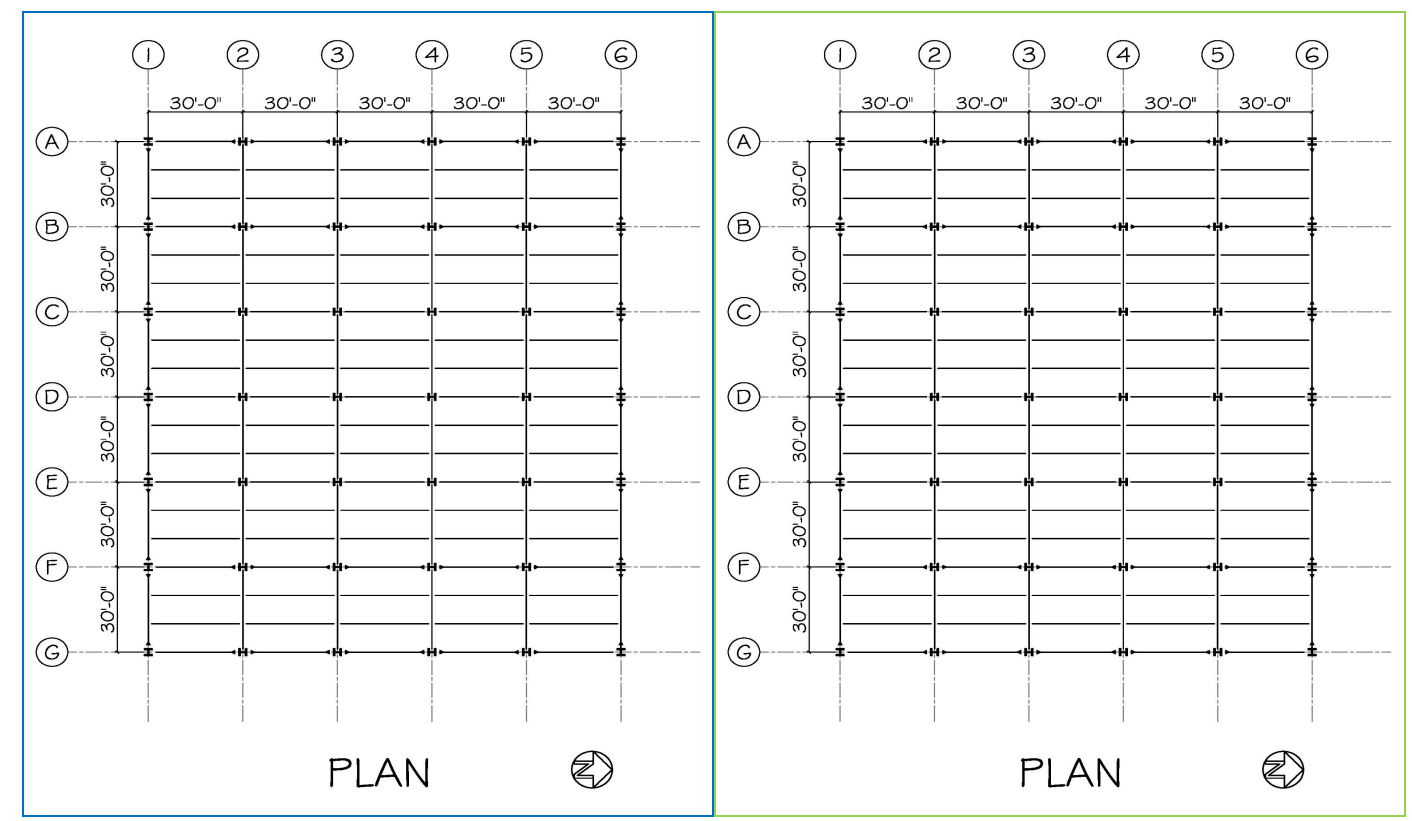

Figure K: Plan View of Superstructure

\begin{tabular}{|c|c|c|c|}
\hline \multicolumn{2}{|c|}{ Location } & Beam & Girder \\
\hline \multirow{2}{*}{ Roof } & Exterior Bays & $\mathrm{W} 18 \times 35$ & $\mathrm{~W} 18 \times 46$ \\
\cline { 2 - 4 } & Interior Bays & $\mathrm{W} 18 \times 50$ & $\mathrm{~W} 24 \times 62$ \\
\hline \multicolumn{2}{|c|}{ Lower Stories } & $\mathrm{W} 18 \times 35$ & $\mathrm{~W} 24 \times 62$ \\
\hline
\end{tabular}

Table 2: Gravity Members

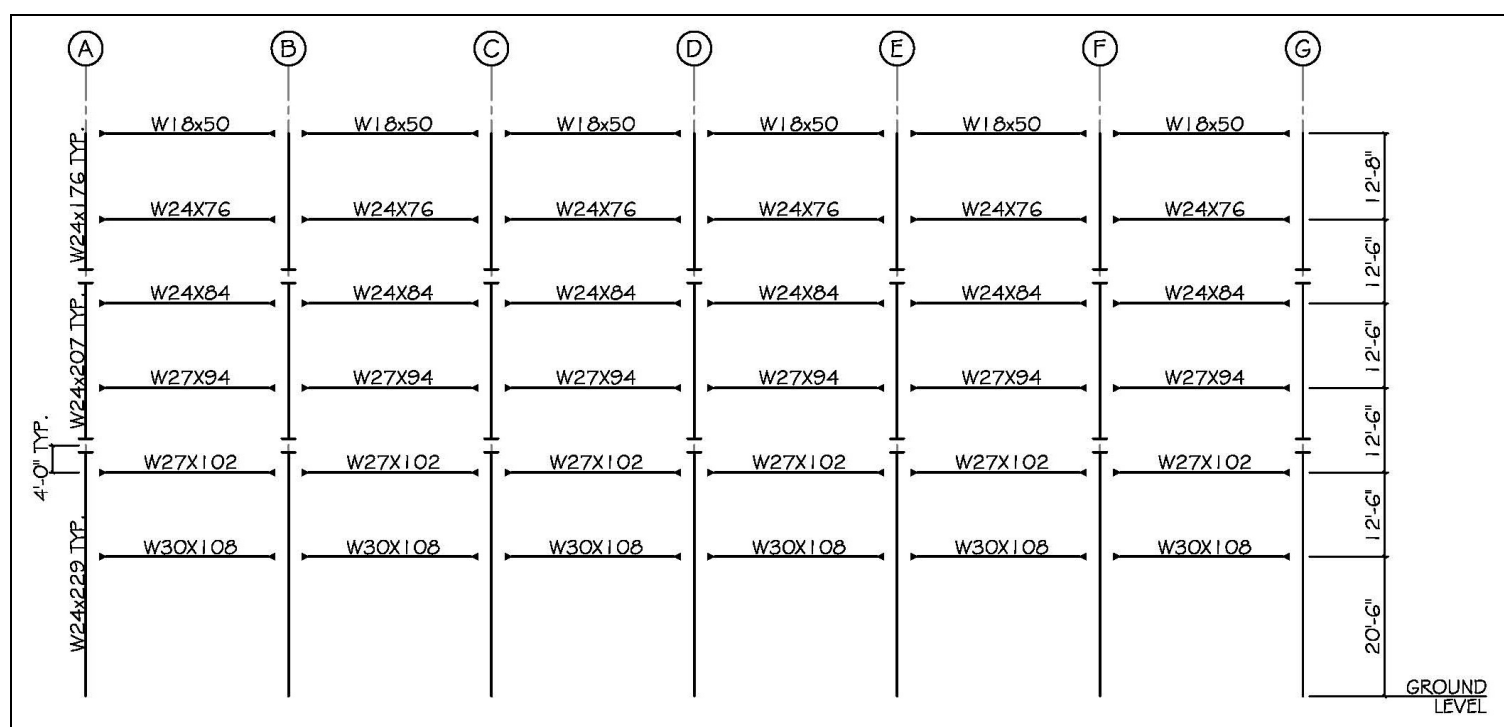

Figure L: Moment Frame Elevation on Gridlines 1 \& 6 


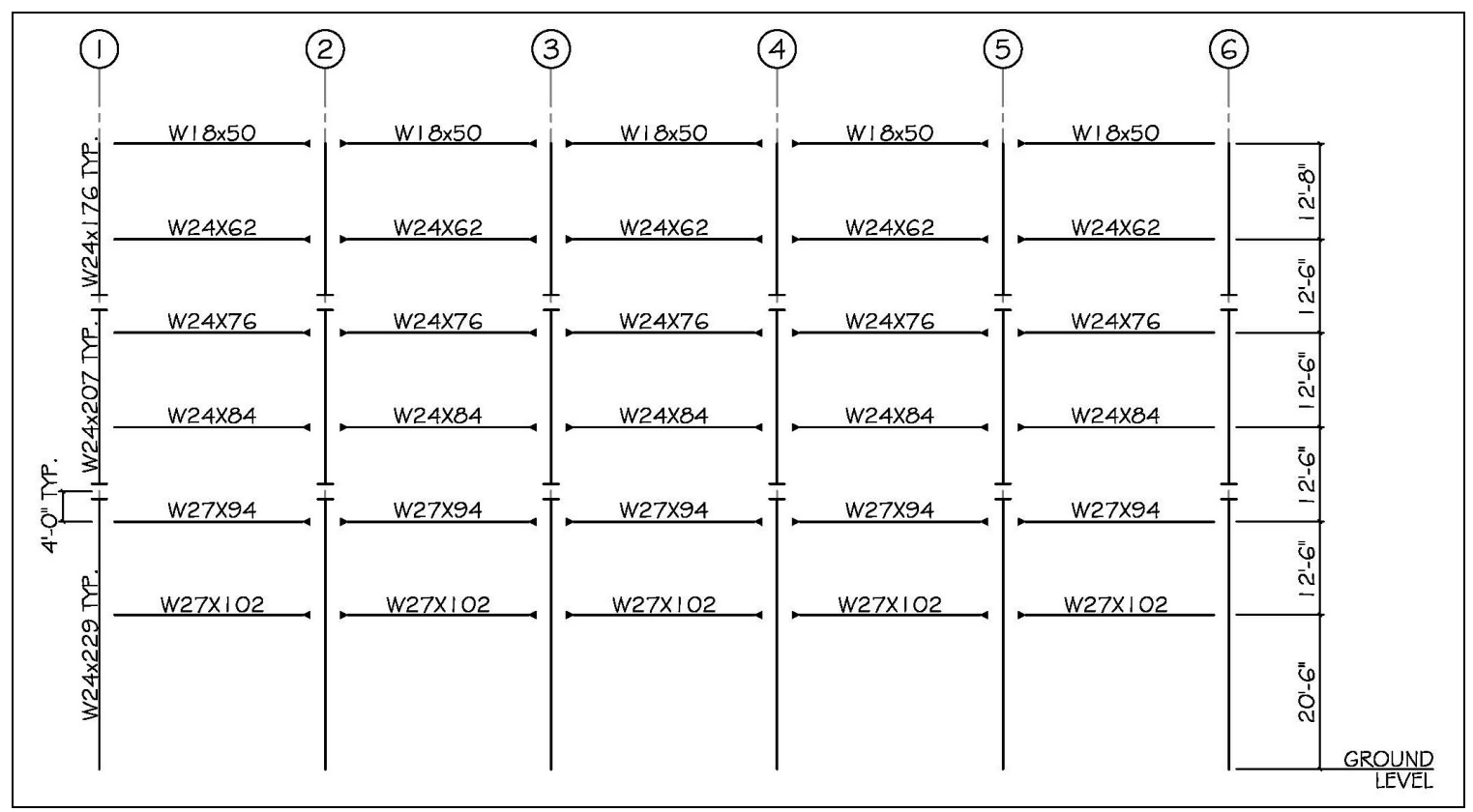

Figure M: Moment Frame Elevation on Gridlines A \& G

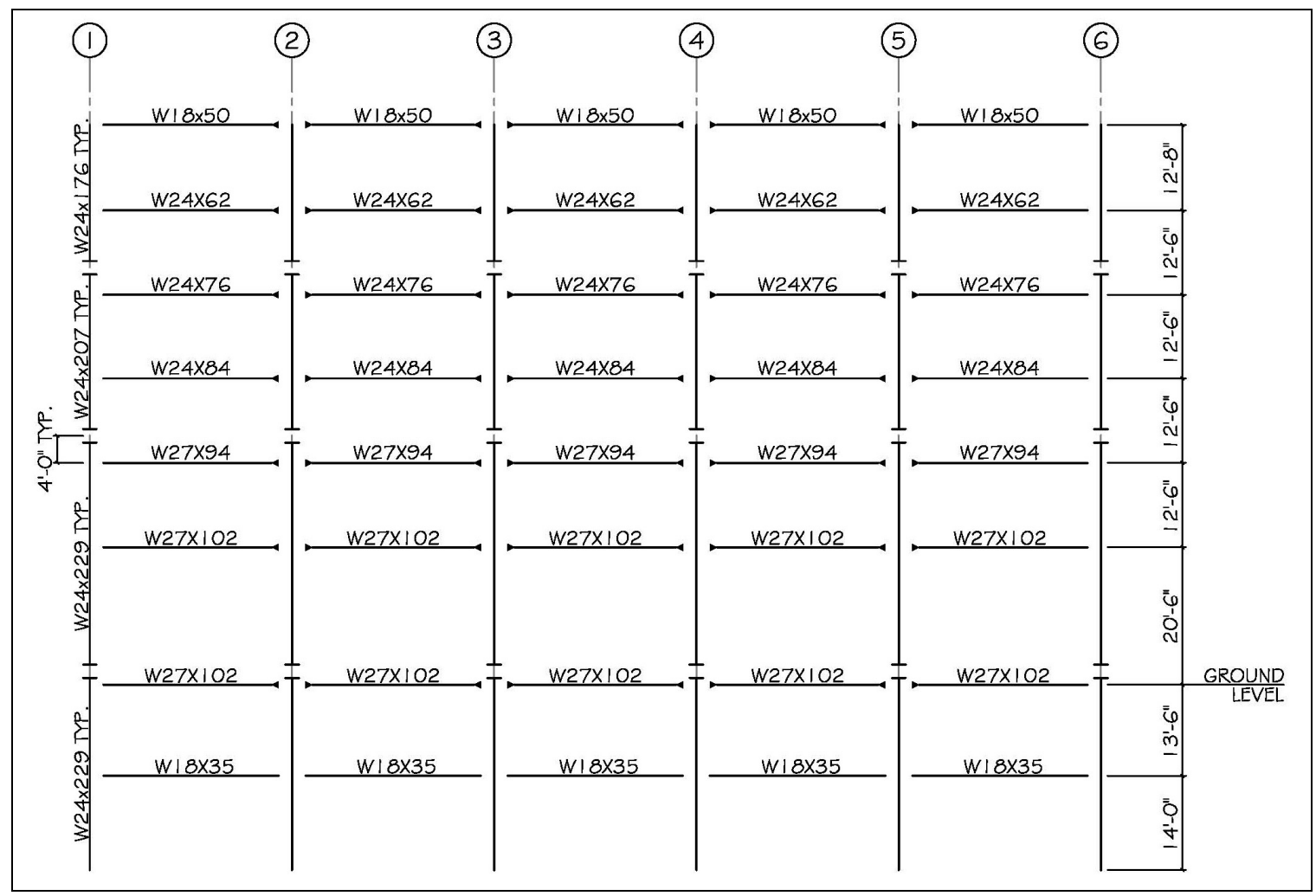

Figure N: Moment Frame Elevation on Gridlines B \& F 


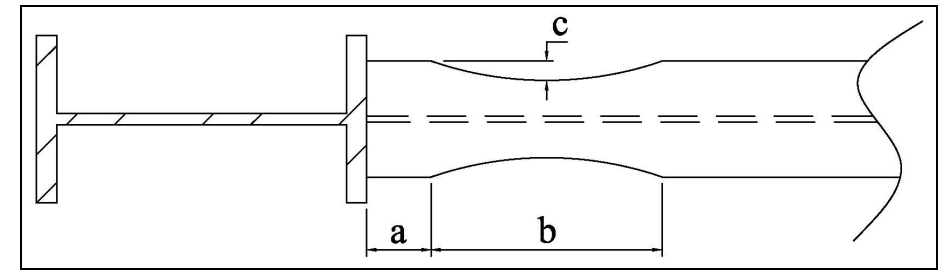

Figure O: General Plan View of RBS

\begin{tabular}{|c|c|c|c|c|c|c|}
\hline \multicolumn{7}{|c|}{ East West Frames } \\
\hline \multirow{3}{*}{ Member } & \multicolumn{4}{|c|}{ RBS Properties } & \multicolumn{2}{|c|}{ Hinge Properties } \\
\hline & $\mathrm{a}$ & $\mathrm{b}$ & $\mathrm{c}$ & $\mathrm{Z}_{\mathrm{e}}$ & $\theta_{\mathrm{y}}$ & $\mathrm{M}_{\mathrm{CE}}$ \\
\hline & [in] & [in] & [in] & {$\left[\mathrm{in}^{3}\right]$} & [rad.] & {$[\mathrm{k}-\mathrm{ft}]$} \\
\hline W18x50 & 4.00 & 12.00 & 1.500 & 71 & 0.01307 & 333 \\
\hline W24x76 & 5.00 & 16.00 & 1.750 & 145 & 0.00966 & 677 \\
\hline W24x84 & 5.00 & 18.00 & 1.500 & 170 & 0.00944 & 793 \\
\hline W27x94 & 6.00 & 18.00 & 1.875 & 205 & 0.00849 & 957 \\
\hline W27x 102 & 6.00 & 18.00 & 1.875 & 223 & 0.00840 & 1043 \\
\hline W30x108 & 6.00 & 21.00 & 2.500 & 236 & 0.00778 & 1107 \\
\hline
\end{tabular}

\begin{tabular}{|c|c|c|c|c|c|c|}
\hline \multicolumn{7}{|c|}{ North South Frames } \\
\hline \multirow{3}{*}{ Member } & \multicolumn{3}{|c|}{ RBS Properties } & \multicolumn{2}{c|}{ Hinge Properties } \\
\cline { 2 - 7 } & $\mathrm{a}$ & $\mathrm{b}$ & $\mathrm{c}$ & $\mathrm{Z}_{\mathrm{e}}$ & $\theta_{\mathrm{y}}$ & $\mathrm{M}_{\mathrm{CE}}$ \\
\cline { 2 - 7 } & {$[\mathrm{in}]$} & {$[\mathrm{in}]$} & {$[\mathrm{in}]$} & {$\left[\mathrm{in}^{3}\right]$} & {$[\mathrm{rad}]$.} & {$[\mathrm{k}-\mathrm{ft}]$} \\
\hline $\mathrm{W} 18 \times 50$ & 4.00 & 12.00 & 1.750 & 66 & 0.01320 & 312 \\
\hline $\mathrm{W} 24 \times 62$ & 4.00 & 16.00 & 1.750 & 106 & 0.01030 & 499 \\
\hline W24x76 & 5.00 & 16.00 & 2.000 & 137 & 0.00971 & 642 \\
\hline W24x84 & 5.00 & 16.00 & 2.000 & 152 & 0.00963 & 715 \\
\hline W27x94 & 6.00 & 18.00 & 2.250 & 190 & 0.00858 & 893 \\
\hline W27x102 & 6.00 & 18.00 & 2.375 & 201 & 0.00853 & 948 \\
\hline
\end{tabular}

Table 3: RBS Properties

In addition to the RBS properties, Table 3 includes three other properties:

- $\mathrm{Z}_{\mathrm{e}}$, the effective section modules measured at the ends of the middle third of the cutout section of the RBS,

- $\theta_{\mathrm{y}}$, the yield rotation for the RBS section, 
- $\mathrm{M}_{\mathrm{CE}}$, the expected yield moment of the RBS.

The effective section modulus was measured at the ends of the middle third of the cutout section of the RBS in an effort to better predict the performance of the beam. Overall, this assumption led to an approximately $3 \%$ increase in the effective section modulus when compared to the modulus at the centerline of the RBS.

A summary of the results from the design of the Special Moment Frame (SMF) structural system can be seen in Table 4. The East-West moment frames are those on gridlines 1 and 6. The North-South exterior moment frames are those on gridlines A and F. The North-South interior moment frames are those on gridlines B and G.

\begin{tabular}{|l|c|c|c|c|c|}
\hline \multicolumn{5}{|c|}{ SMF Design Results } \\
\hline \multirow{2}{*}{} & Average Beam Moment Demand-Capacity Ratio & \multicolumn{2}{c|}{ Story Drift } \\
\cline { 2 - 6 } & E-W & N-S Exterior & N-S Interior & E-W & N-S \\
\hline Roof & $93 \%$ & $74 \%$ & $78 \%$ & $1.74 \%$ & $1.70 \%$ \\
\hline 5th & $91 \%$ & $89 \%$ & $76 \%$ & $1.89 \%$ & $1.89 \%$ \\
\hline 4th & $89 \%$ & $87 \%$ & $77 \%$ & $1.97 \%$ & $1.95 \%$ \\
\hline 3rd & $89 \%$ & $87 \%$ & $77 \%$ & $1.97 \%$ & $1.93 \%$ \\
\hline 2nd & $88 \%$ & $82 \%$ & $74 \%$ & $1.91 \%$ & $1.86 \%$ \\
\hline 1st & $88 \%$ & $77 \%$ & $74 \%$ & $1.56 \%$ & $1.56 \%$ \\
\hline
\end{tabular}

\begin{tabular}{|l|c|c|c|}
\hline \multirow{2}{*}{} & \multicolumn{3}{|c|}{ Average Column P-M Interaction Demand-Capacity Ratio } \\
\cline { 2 - 4 } & E-W & N-S Exterior & N-S Interior \\
\hline 1 st & $73 \%$ & $70 \%$ & $70 \%$ \\
\hline
\end{tabular}

Table 4: Summary of SMF Design Results

The building was designed using the ASCE 7-05 Equivalent Lateral Force Method and was governed by story drift. The lateral forces used in the determination of story drift were calculated using the ETABS fundamental period of the structure as allowed by ASCE 7-05 $§ 12.8 .6 .2$. The lateral forces used to design the SMF were 
calculated using the upper bound building period value of $\left(\mathrm{C}_{\mathrm{u}}\right)\left(\mathrm{T}_{\mathrm{a}}\right)$ discussed in ASCE 7$05 \S 12.8 .2$. Because story drift governed the design, beam sizes were chosen to maximize depth, reduce weight, and decrease the demand capacity ratio of the RBS from the top to the bottom of the SMF. Column sizes were chosen to meet the story drift and panel zone requirements.

\subsection{ASCE 41-06 BSE-1 Results}

As mentioned previously in this paper, the Basic Safety Objective (BSO) in ASCE 41-06 is used to define the earthquake risk to life safety traditionally considered acceptable in the United States. Under the BSE-1 Hazard Level, the building is expected to perform to a Life Safety (LS) performance level. Because of this, the graphs used in this section will compare the demands from the ASCE 41-06 analysis procedures to the maximum allowable demand within the Life Safety performance level.

\subsubsection{Beam Results}

The figures on the following pages show the results for the beams in the SMF for all analyses. The beam demands from the linear procedures are moments and the demands from the nonlinear procedure are hinge rotations. The figures plot the beam demands as a percentage of the total allowable demand within the LS performance level at each story level. The demands at each level represent an average of the demands from all beams in the specified frame at each level. Because all of the beams at each level in each frame experienced similar demands, an average value is a good representation of the performance of the beams under each loading. 
As seen in Figure $\mathrm{P}$, the maximum beam moment and hinge rotation demands in the East-West direction as a percentage of the allowable demand within the LS performance level are approximately $42 \%$ for the linear procedures and $35 \%$ for the nonlinear procedures. As the elevation of the beams increase, the demands decrease, with approximately $5 \%$ of LS beam hinge rotation demand for the nonlinear procedures at the roof level.

Like the beams in the East-West direction, the beam moment and hinge rotation demands in the North-South direction also were well within the acceptable range for the LS performance level. The demand-capacity ratios from the ASCE 41-06 analyses are smaller in the North-South direction than in the East-West direction because the yield strength of the building is greater in the North-South direction.

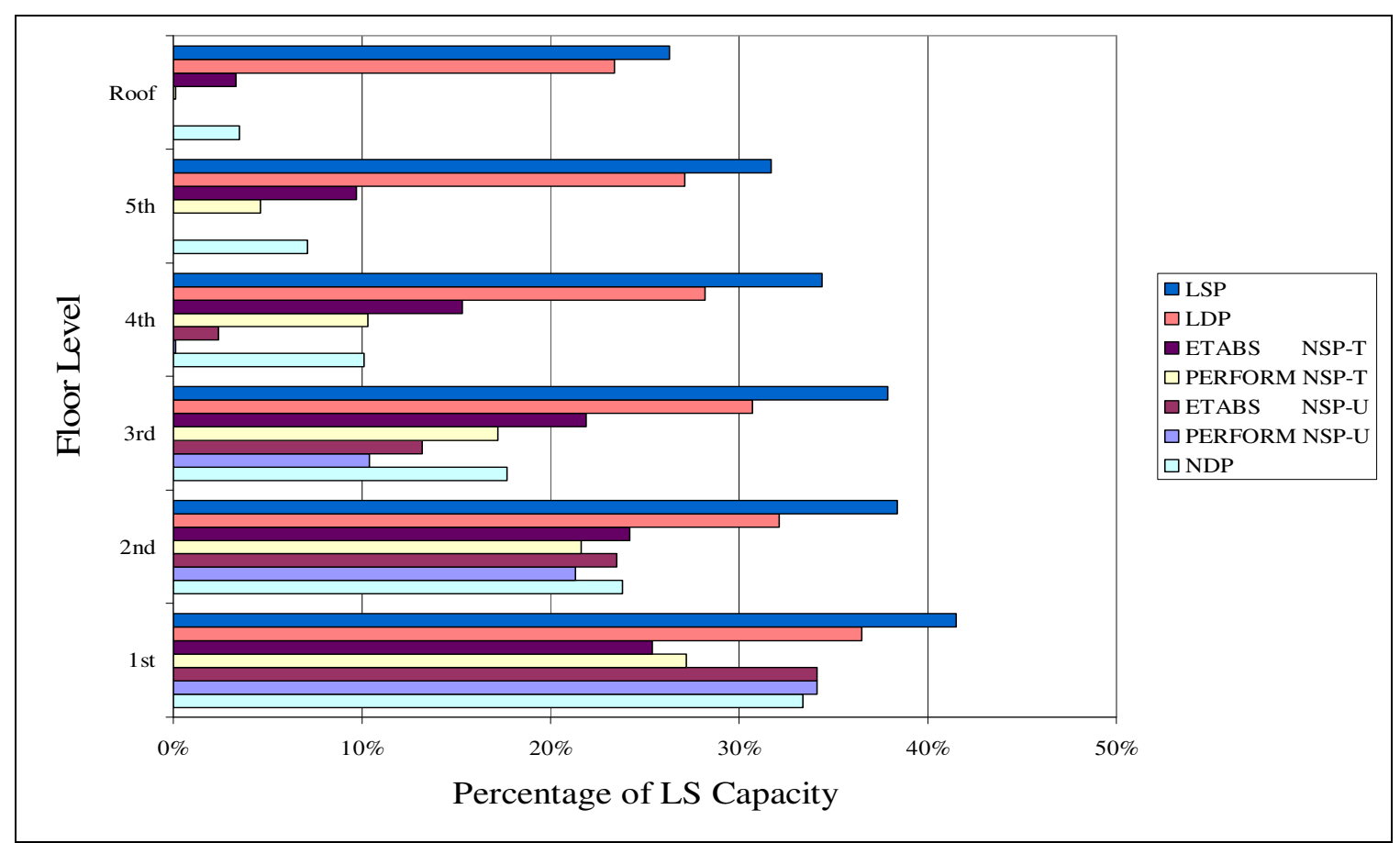

Figure P: SMF Beams in East-West Direction 


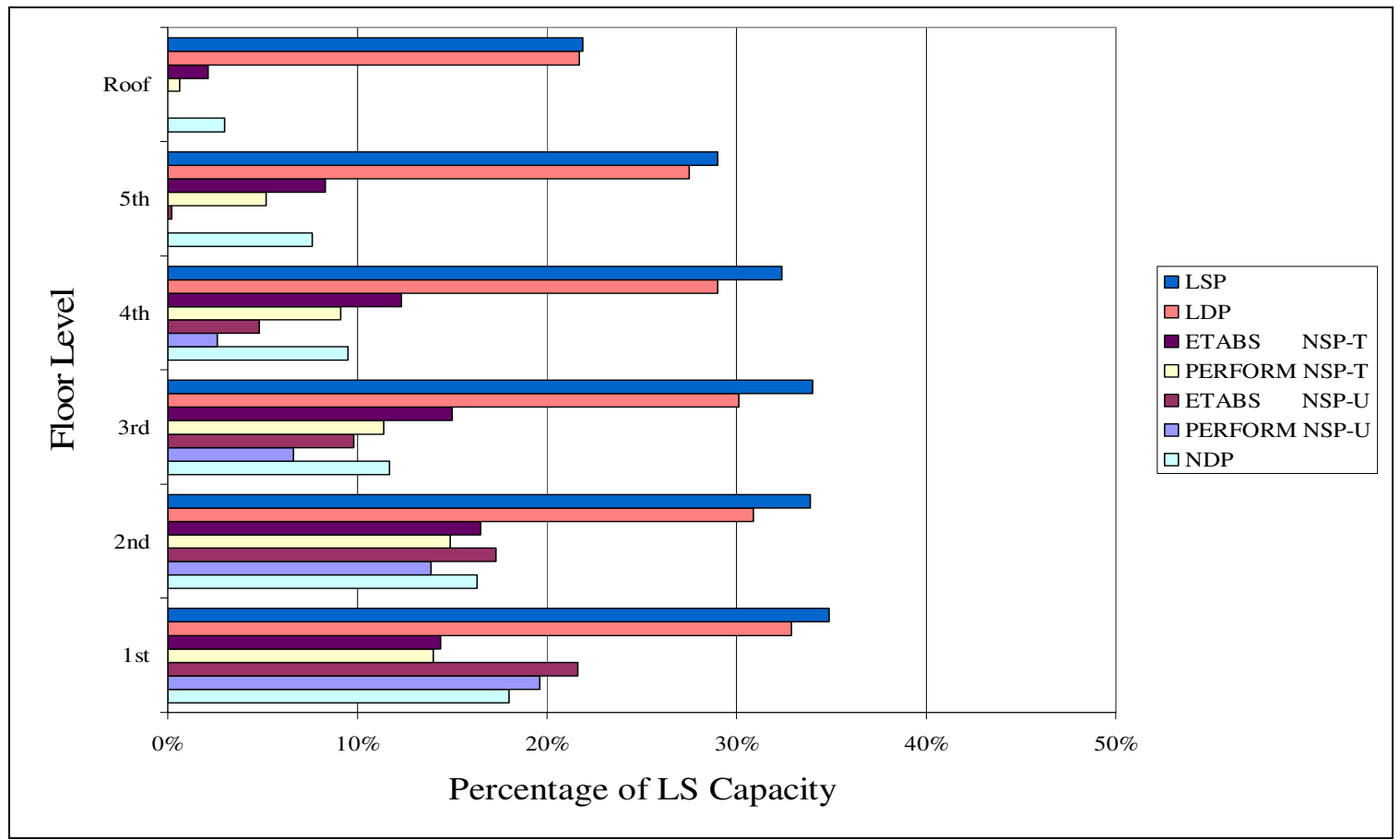

Figure Q: SMF Exterior Beams in North-South Direction

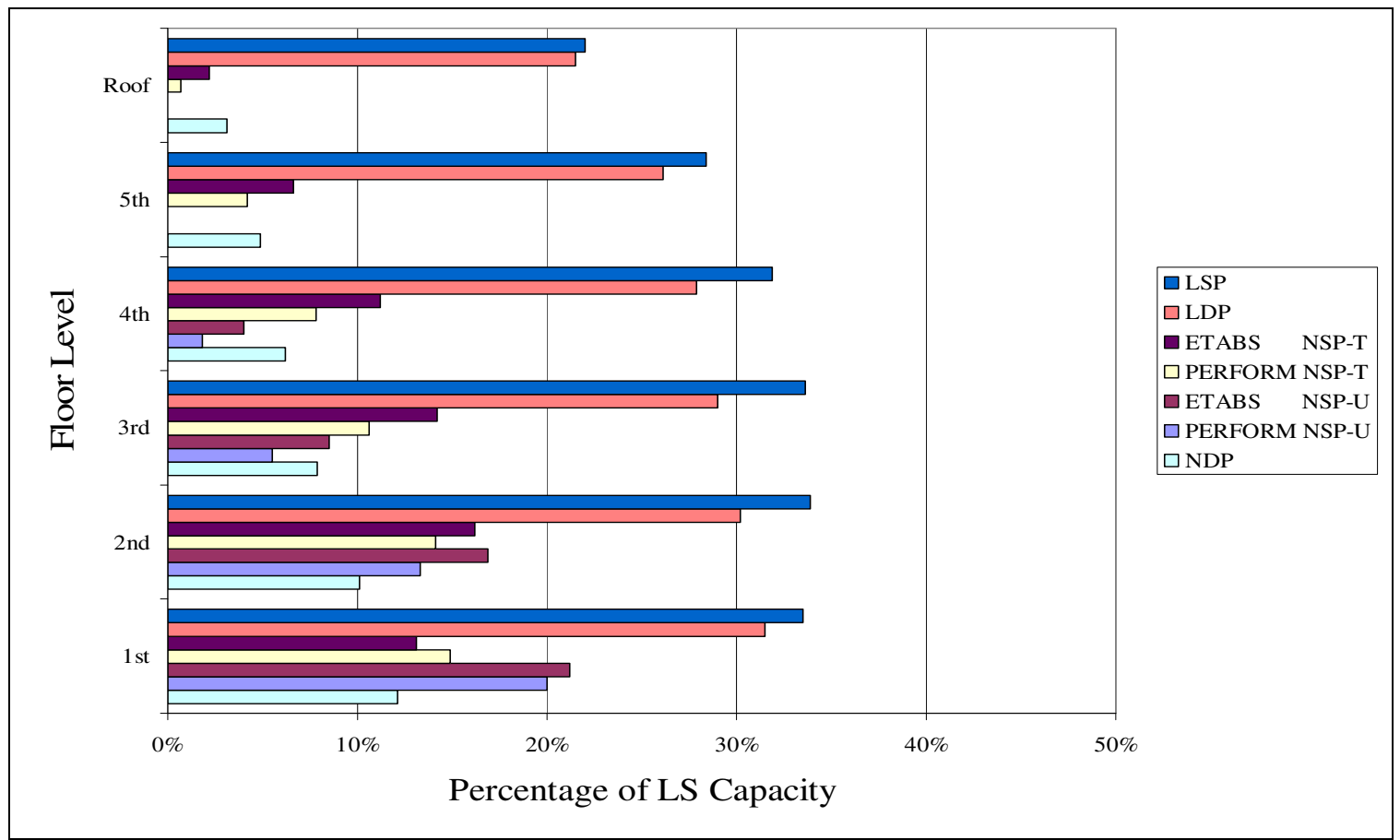

Figure R: SMF Interior Beams in North-South Direction 


\subsubsection{Column Results}

The following figures show the results for the columns in the SMF for all analysis procedures. The column demands from the linear procedures are moments and the demands from the nonlinear procedures are hinge rotations. The figures plot the column demands as a percentage of the total allowable moment and hinge rotation demands within the LS performance level. The figures show results for only the columns at the first story because plastic hinges occur only at the first story for the nonlinear procedures. The figures show both the average demands and the maximum demands for the columns in the specified SMF for each procedure.

For all procedures, the maximum demand occurs in only a single column in each frame. Because the lateral forces on the building create a tension-compression couple in the end columns of the frames, one end column in each frame experiences higher compression forces that result in larger demands. The average value listed in the figures is an accurate representation of the demands for the remaining columns in the frames.

The column hinge demands from the nonlinear procedures indicate that the building performs well within the LS performance level, with a maximum column hinge rotation demand-capacity ratio of $40 \%$ of the LS capacity. The column moment demands from the linear analyses, however, indicated that the building performed slightly better than the CP performance level. The maximum column moment demand-capacity ratios are approximately $80 \%-100 \%$ of the LS capacity. 


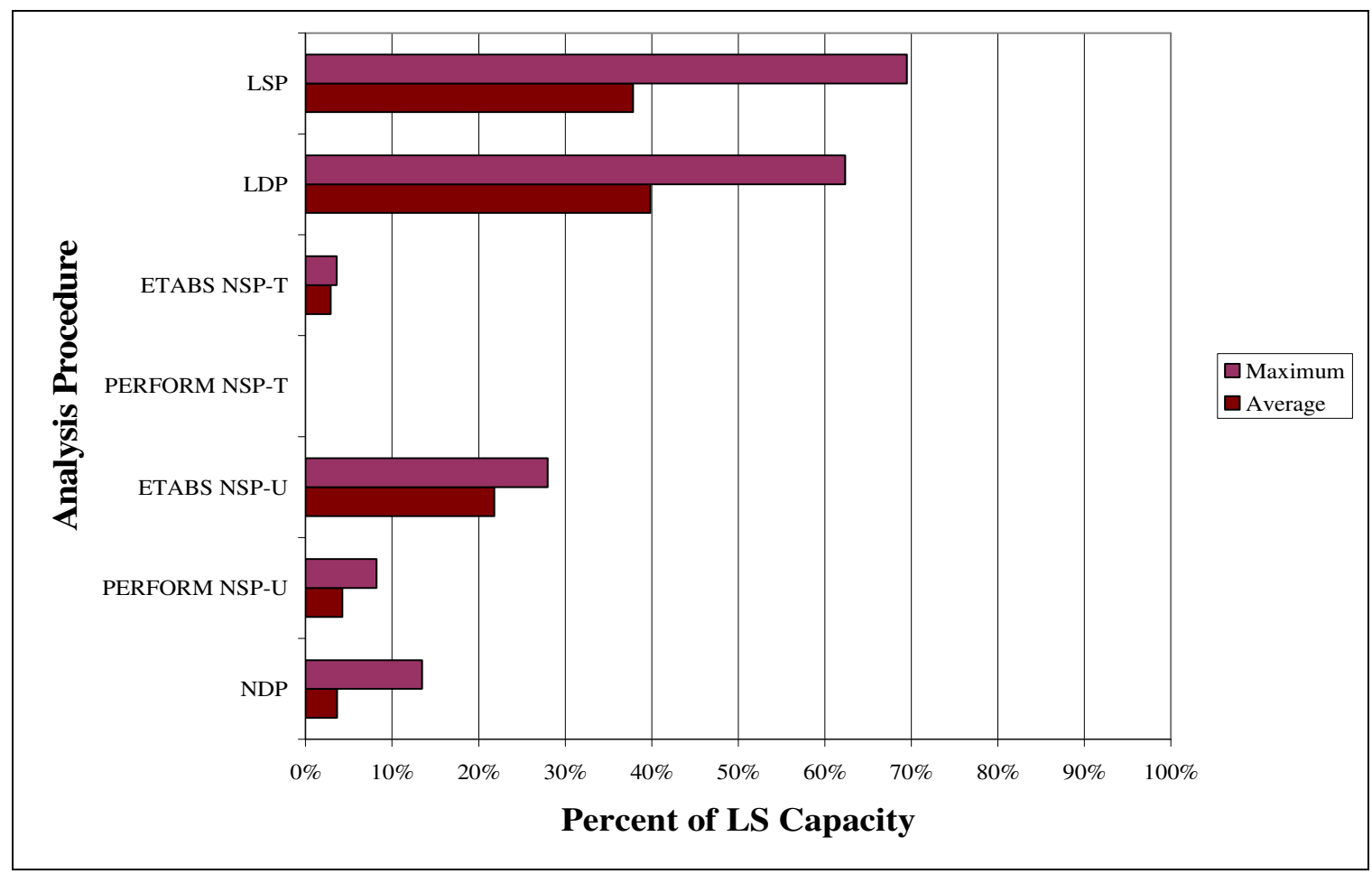

Figure S: SMF Columns in East-West Direction

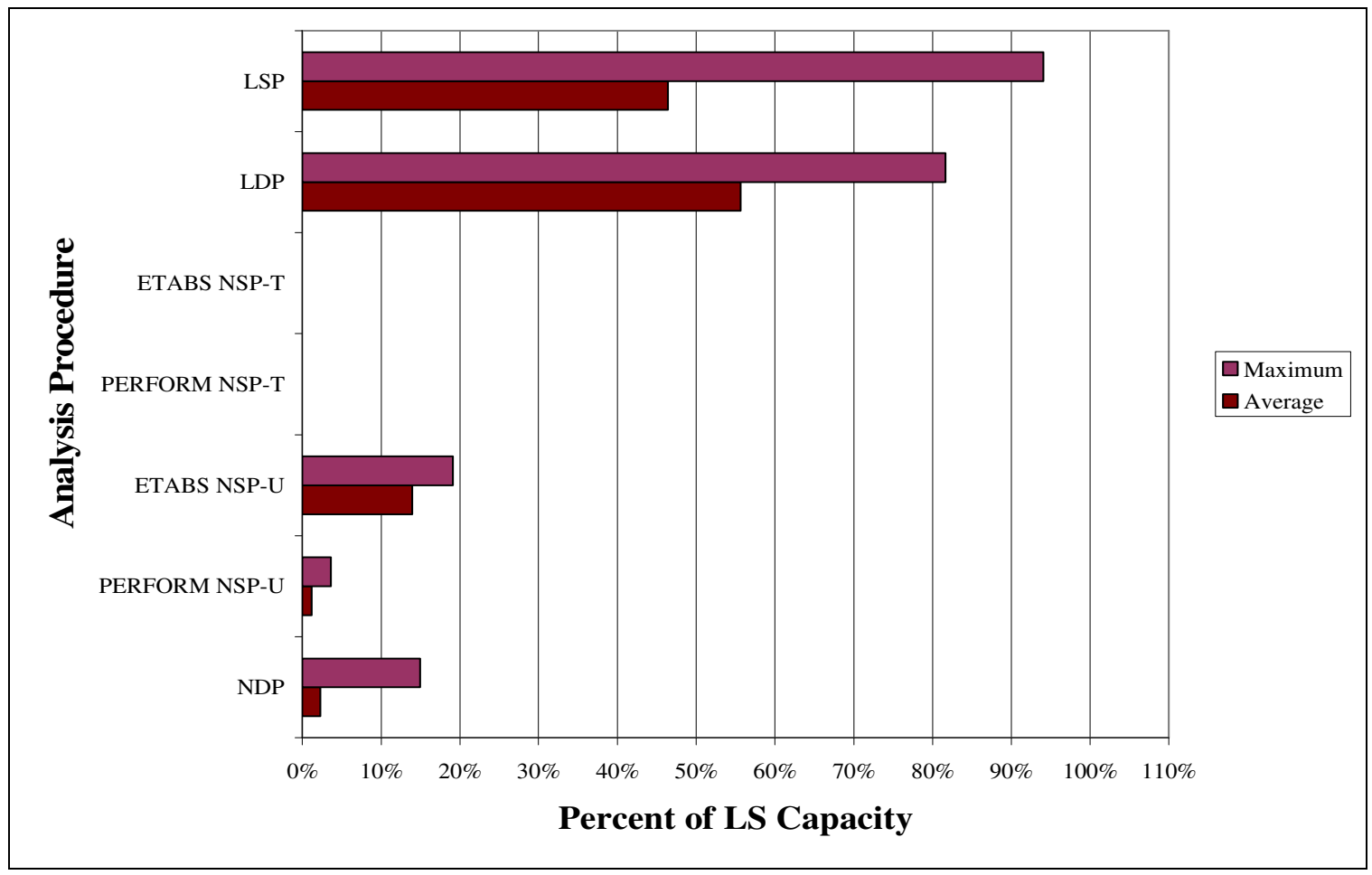

Figure T: SMF Exterior Columns in North-South Direction 


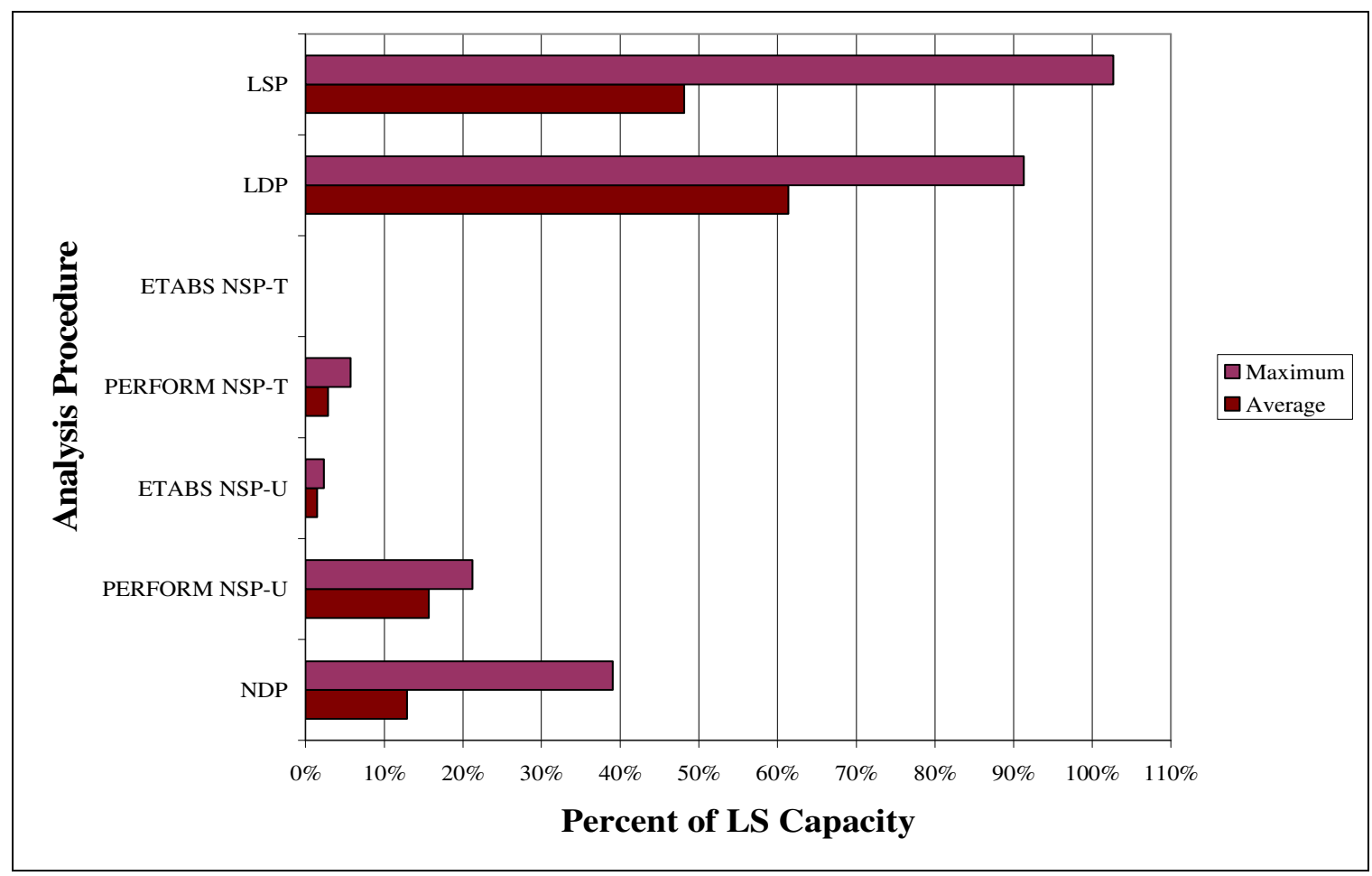

Figure U: SMF Interior Columns in North-South Direction

\subsubsection{Story Drift and Roof Displacement}

The figures on the following pages show the results for story drift at all stories in the superstructure and the maximum roof displacements for all analyses. If the nonlinear static procedures are enveloped to incorporate the degradation of the structure throughout the analyses, it can be seen that both the enveloped NSP and the NDP indicate similar story drifts. The linear procedures also have similar story drifts to the nonlinear procedures at the lower stories, with the difference between the linear and nonlinear procedures story drifts increasing at the higher stories.

Throughout the project, pushover analyses performed using PERFORM 3D consistently indicated differing story drifts than similar analyses performed using ETABS. Although the ETABS and PERFORM 3D models were defined to be as similar 


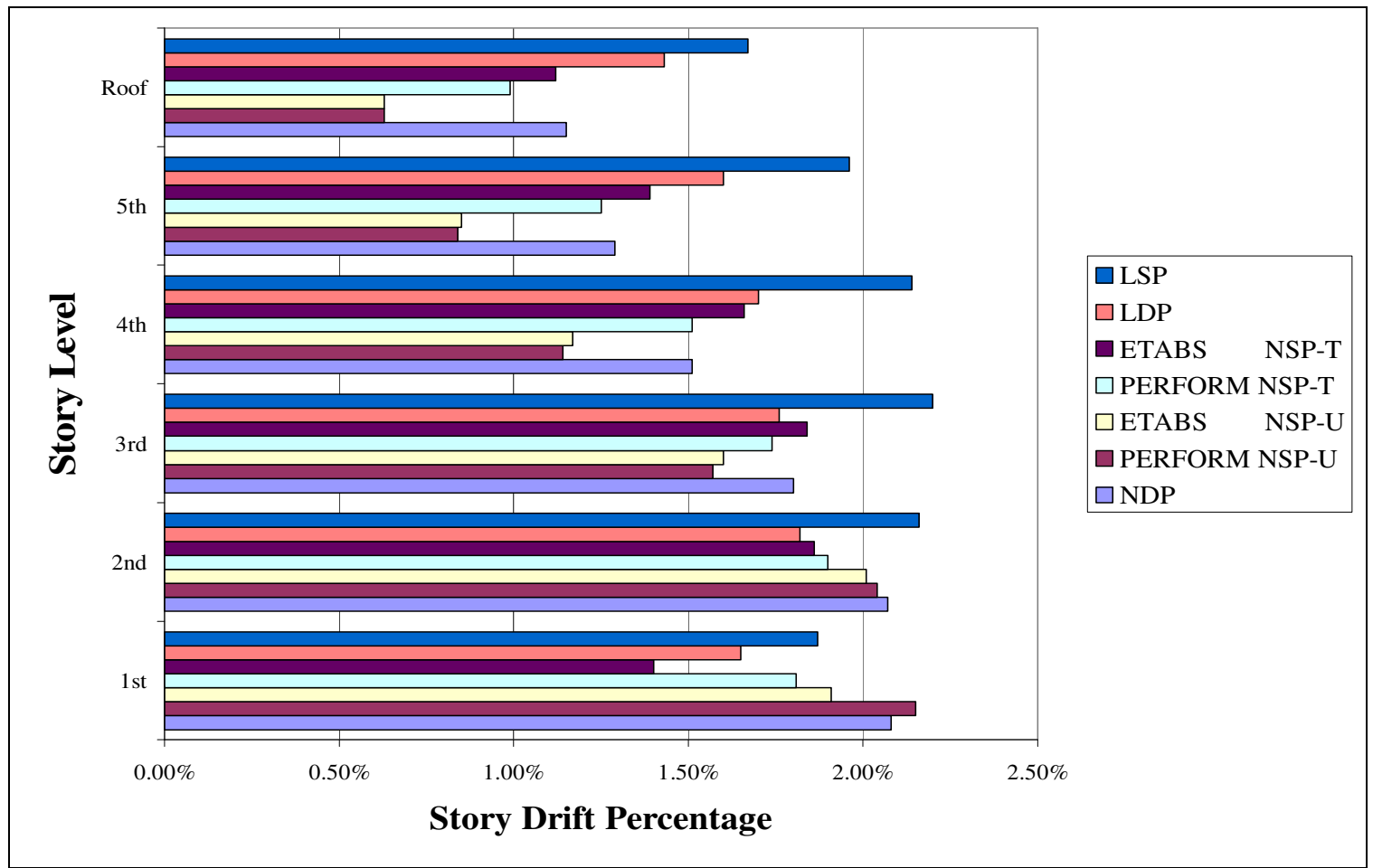

Figure V: East-West Story Drift

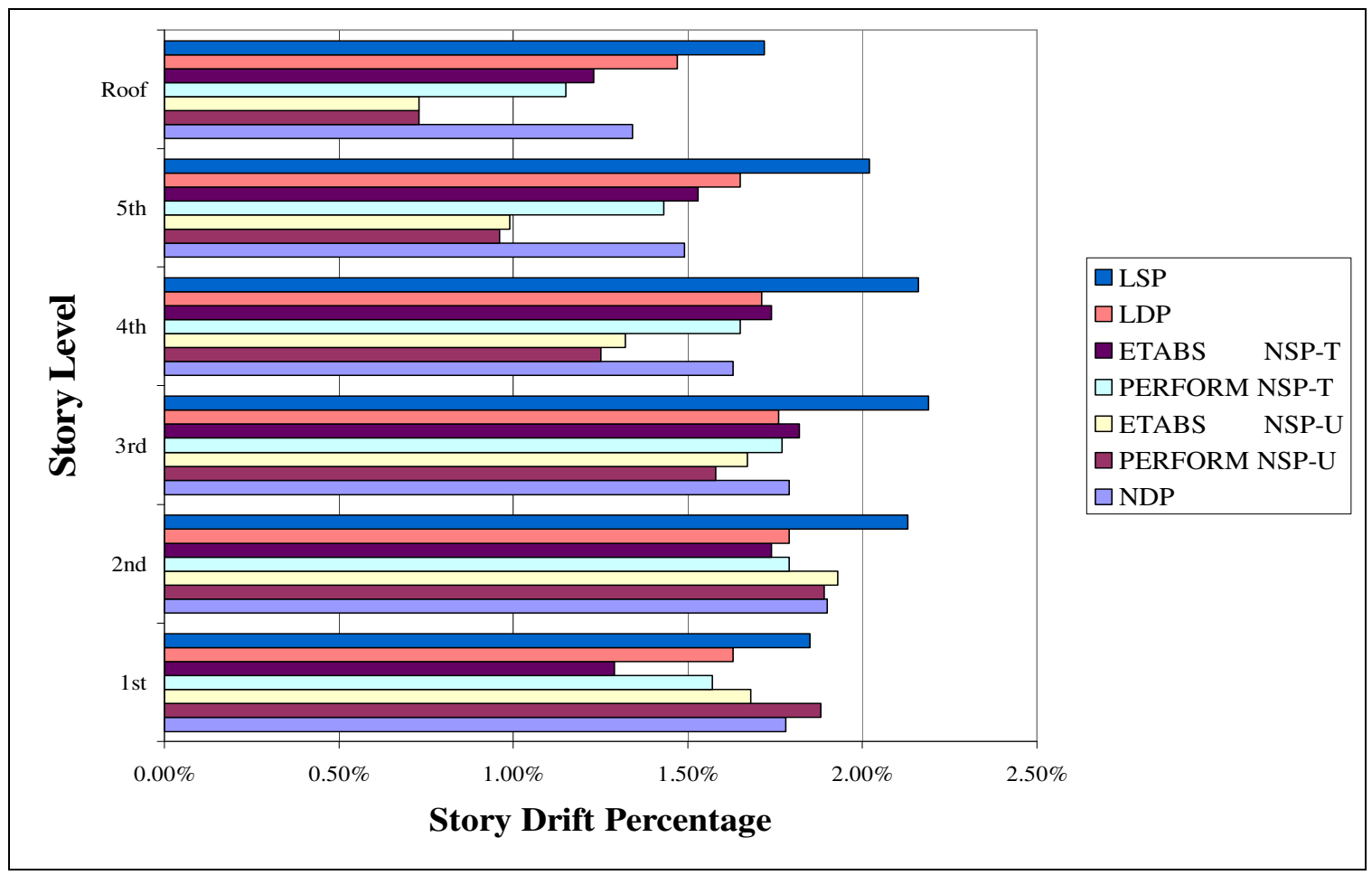

Figure W: North-South Story Drift

Performance Based Analysis of Steel Buildings 


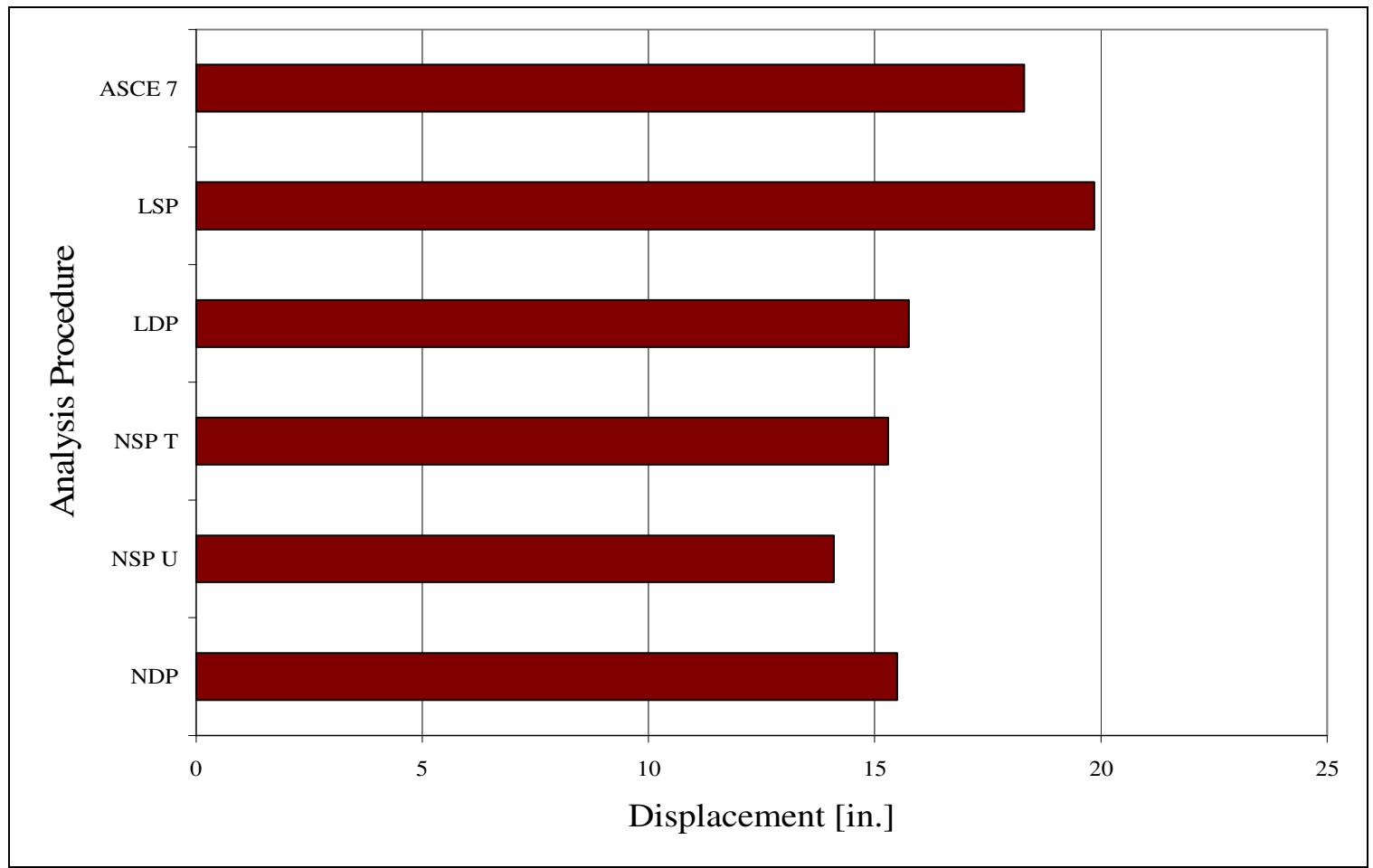

Figure X: Maximum Roof Displacements in East-West Direction

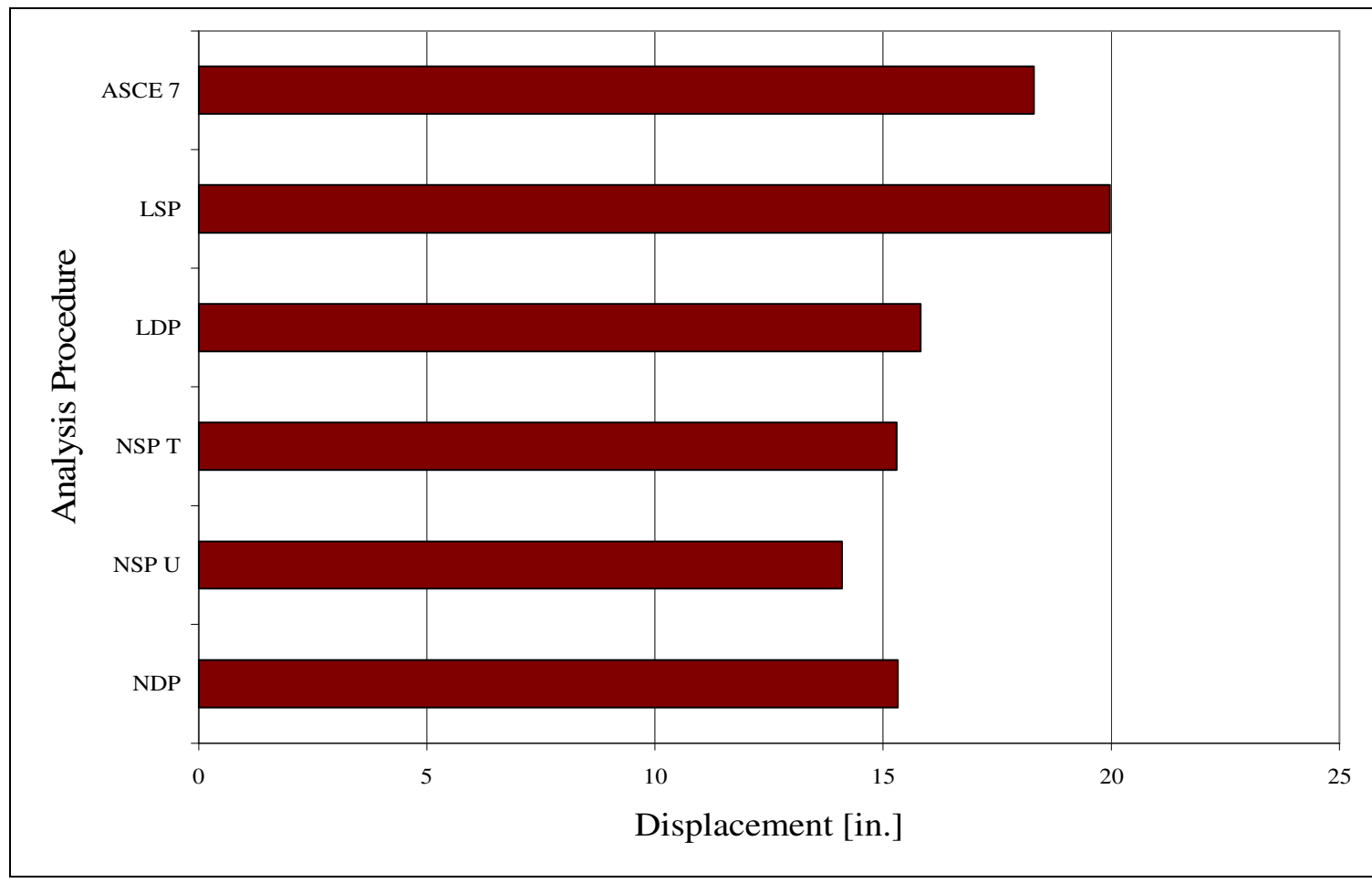

Figure Y: Maximum Roof Displacements in North-South Direction

Performance Based Analysis of Steel Buildings 
as possible, a notable difference in story drift at the first story resulted from the same loading pattern and target displacement in the pushover analyses. This difference was due to the formation of plastic hinges in the columns occurring at different displacement levels in the two programs.

Overall, the story drifts from the ASCE 41-06 analyses were similar to ASCE 705 design story drifts. ASCE 7-05 has a maximum allowable story drift of $2 \%$ for this building. Because story drift controlled the design of the building and the story drift was calculated using the actual building period, the building should experience approximately $2 \%$ story drifts.

As seen in Figure $\mathrm{X}$ and Figure $\mathrm{Y}$ on the previous page, all of the ASCE 41-06 procedures except the LSP indicated lower maximum roof deflections than the ASCE 705 maximum roof deflection. Also, for this structure, the target displacement for the triangular load pattern calculated in accordance with ASCE 41-06 matched the average maximum roof deflections from the NDP.

\subsection{ASCE 41-06 BSE-2 Results}

In order to achieve the Basic Safety Objective (BSO), the structure must meet a Collapse Prevention (CP) performance level when analyzed with the BSE-2 Hazard Level. Although the components in the structure can perform beyond the limit for a Life Safety (LS) performance level, many of the figures in this section show moment and hinge rotation demands as a percentage of the LS acceptance criterion. The demands are shown as a percentage of the LS capacity to facilitate comparison of the BSE-1 and BSE2 Hazard Level results. 


\subsubsection{Beam Results}

The figures on the following pages show the SMF beam results from the BSE-2 Hazard Level analyses. The beam demands are moments for the linear procedures and hinge rotations for the nonlinear procedures. The results show the average demands for all beams at each level in the specified frame.

As the figures illustrate, the beam moment and hinge rotation demands from the BSE-2 Hazard Level analyses are significantly lower than their capacity. For all SMF in the building, the moment and hinge rotation demands from the BSE-2 Hazard Level analyses do not exceed $60 \%$ of their LS capacity.

For the BSE-2 Hazard Level analyses, the properties of the shear tabs on the intersections of gridlines 1-A,B,G,F and 6-A,B,G,F were changed. Some of the time history analyses caused the rotations in the shear tabs to exceed the initial definitions for the ultimate rotation of the shear tab. Because the ultimate rotation for the shear tabs is directly related to the gap between the beam flange and the column face, it was assumed the gap was increased to accommodate rotation and increase the ultimate rotation for the shear tab. This change was negligible to all other aspects of the project. 


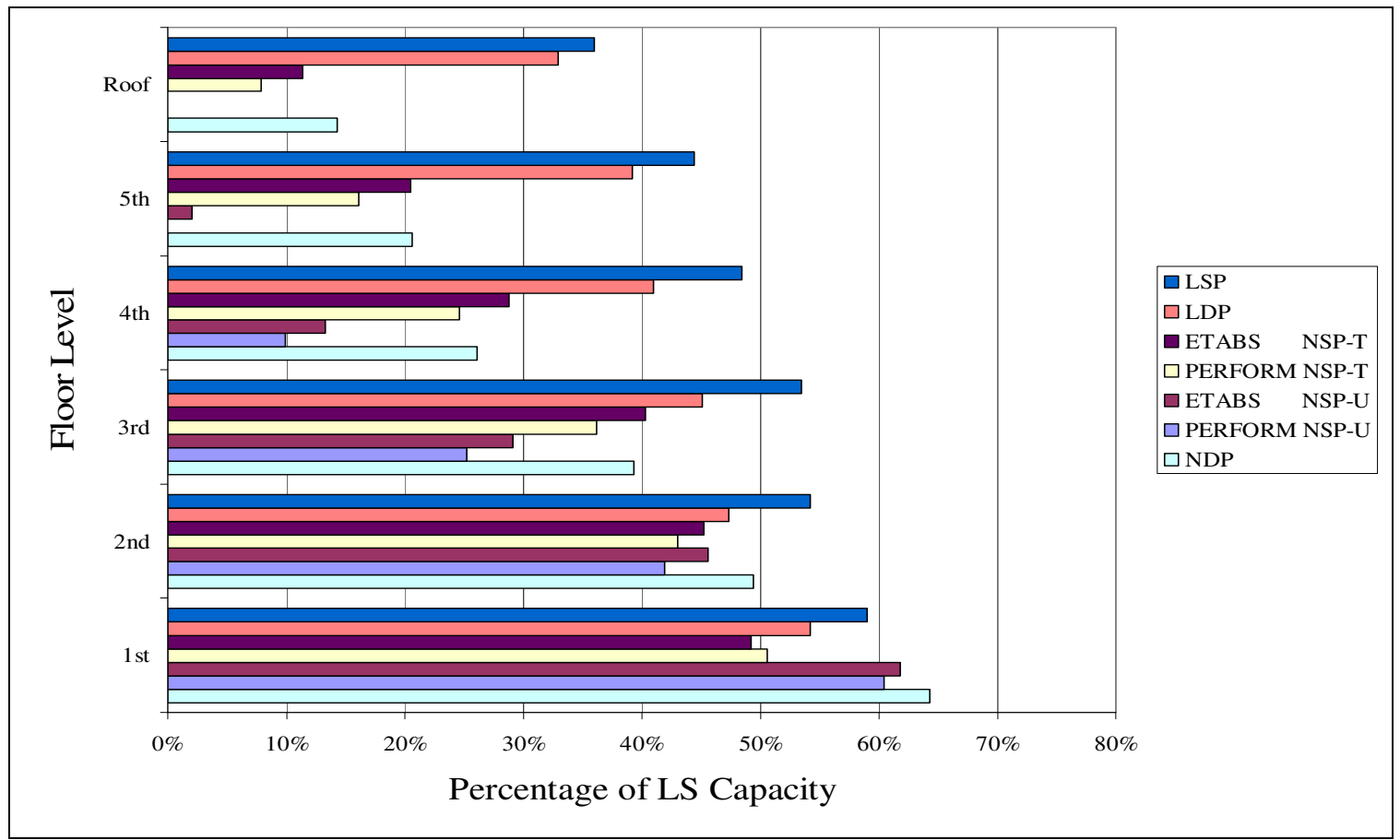

Figure Z: SMF Beams in the East-West Direction

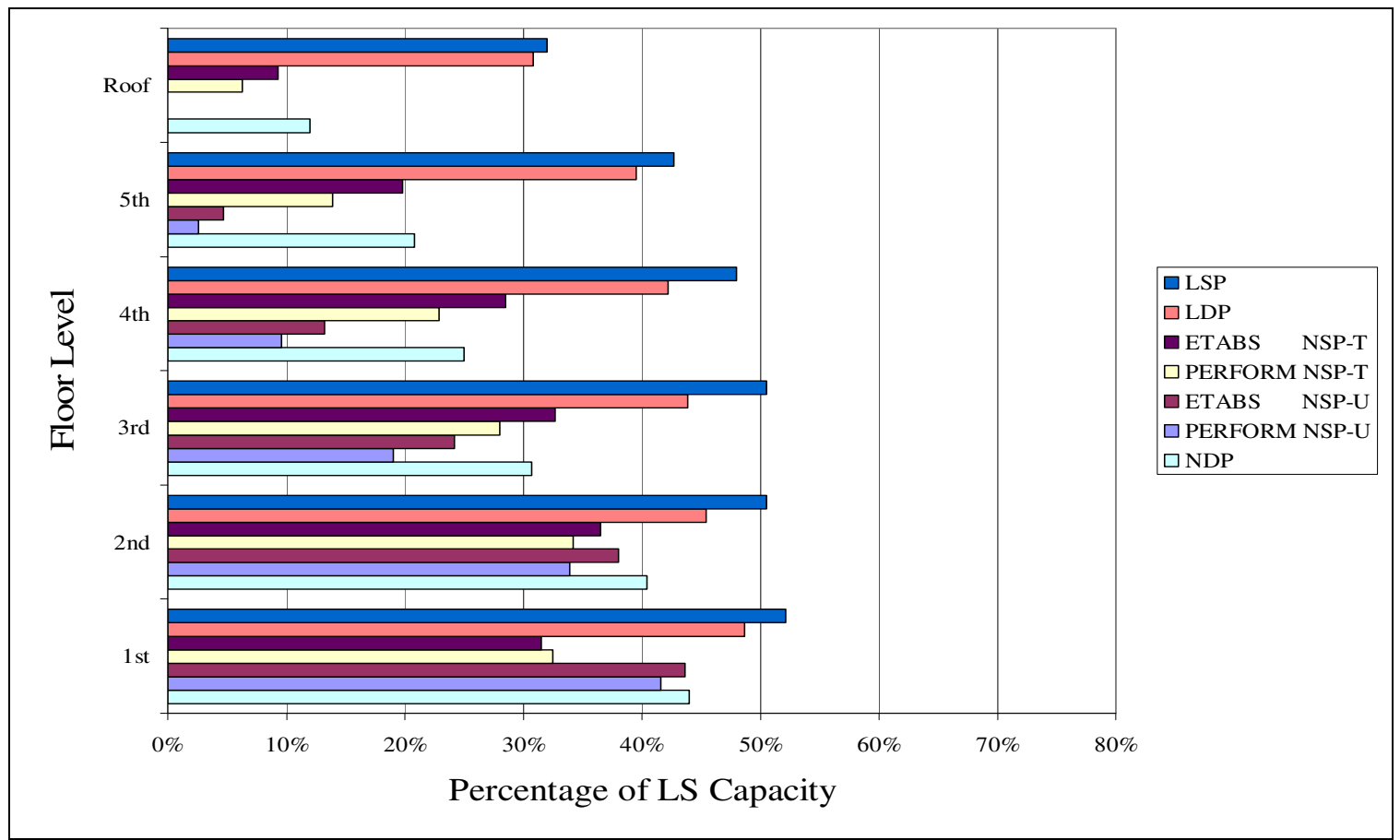

Figure AA: SMF Exterior Beams in the North-South Direction 


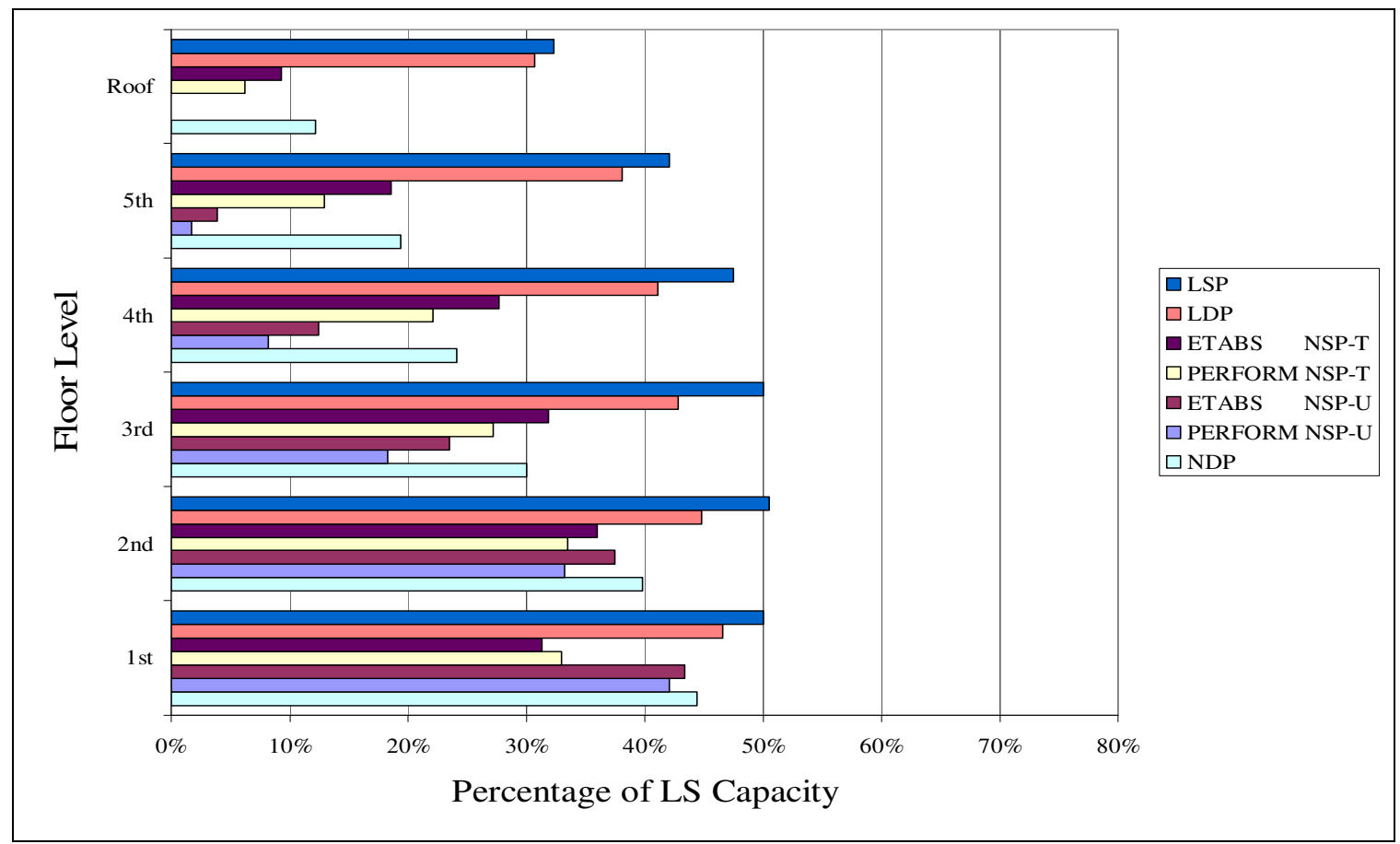

Figure BB: SMF Interior Beams in the North-South Direction

\subsubsection{Column Results}

The column results for the BSE-2 Hazard Level analyses are shown on the following pages. The column demands are moments for the linear procedures and hinge rotations for the nonlinear procedures. The results were compiled for the columns at the first story only because hinging does not occur at any other story for the nonlinear procedures. Like the BSE-1 Hazard Level analyses, the average moment and hinge rotation demands in the BSE-2 Hazard Level analyses were well within the acceptable range to meet the BSO. Although the average demands are within the acceptable range, the maximum moment demands from some of the linear analyses are greater the Collapse Prevention acceptance criteria. This maximum demand occurs in only one column in each frame for the analyses. 


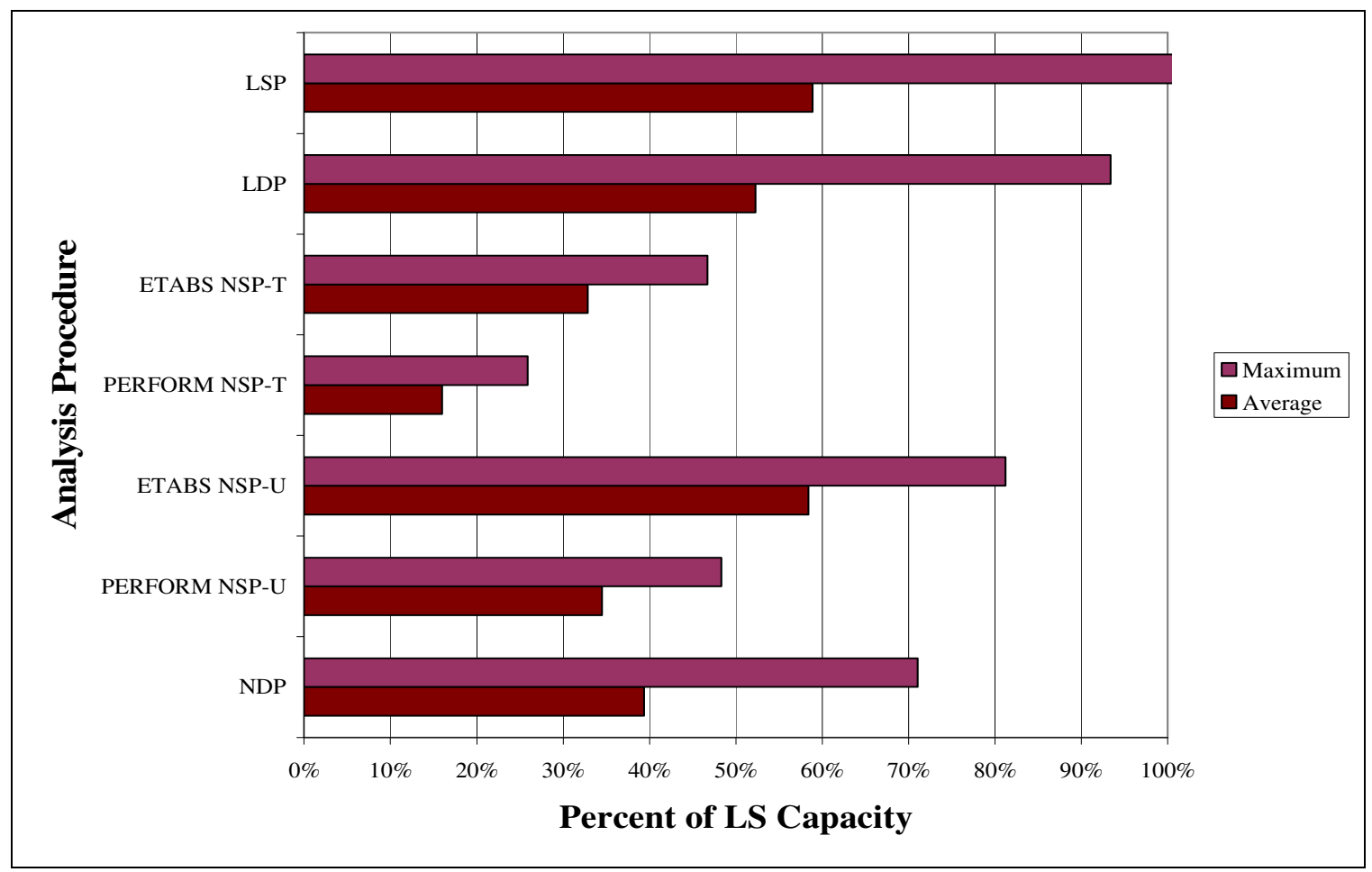

Figure CC: SMF Columns in the East-West Direction

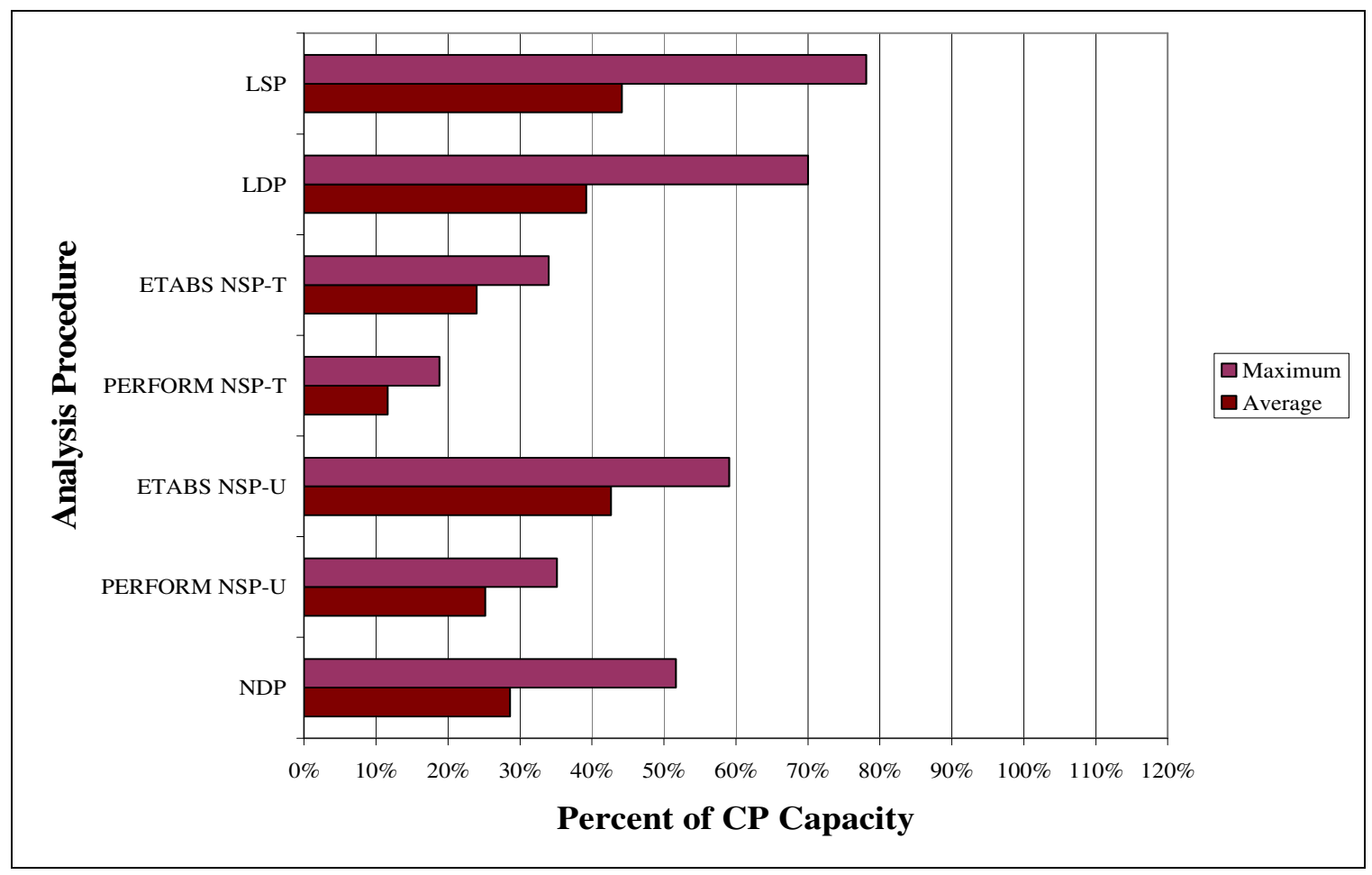

Figure DD: SMF Columns in East-West Direction 


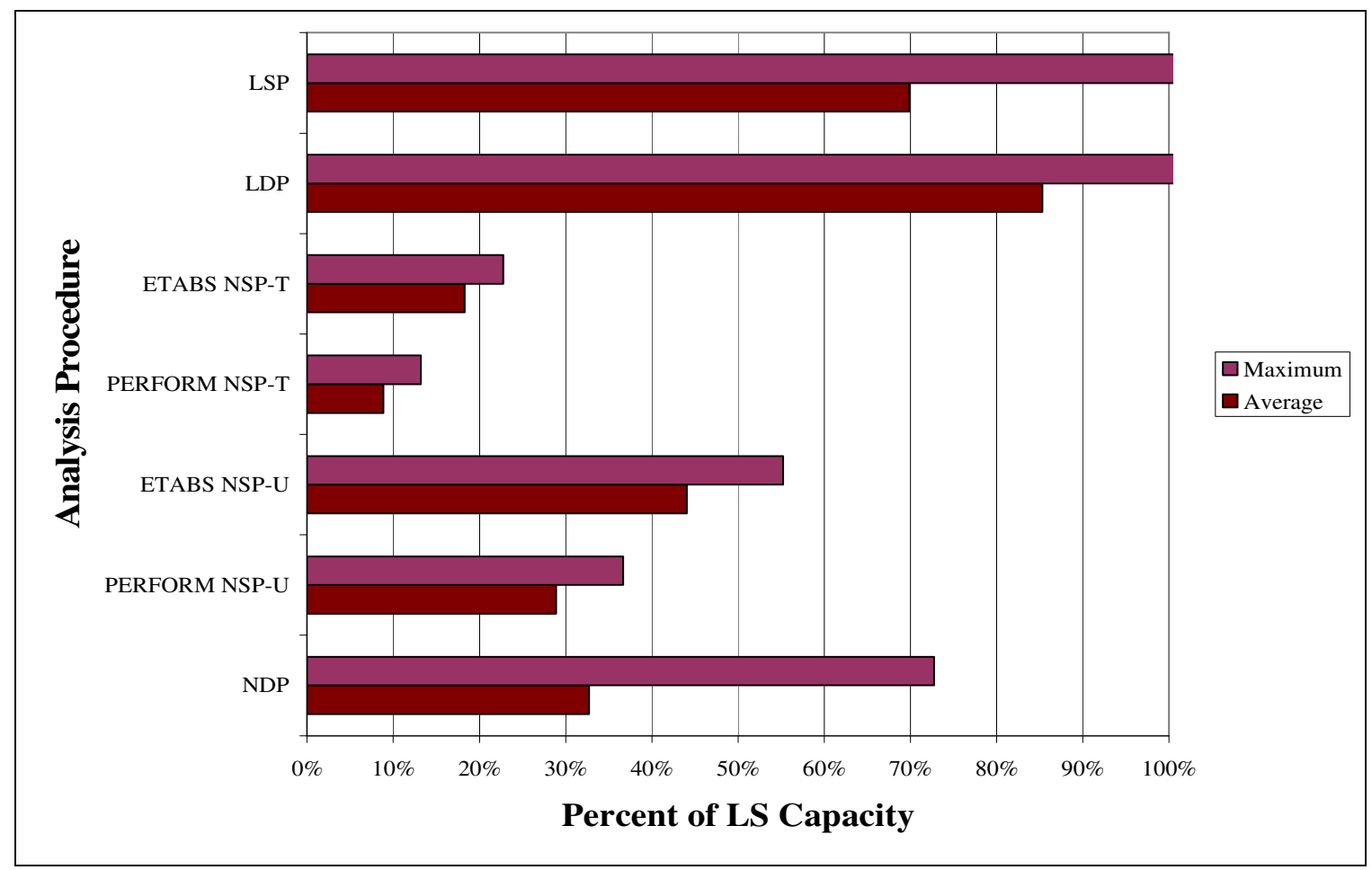

Figure EE: SMF Exterior Columns in North-South Direction

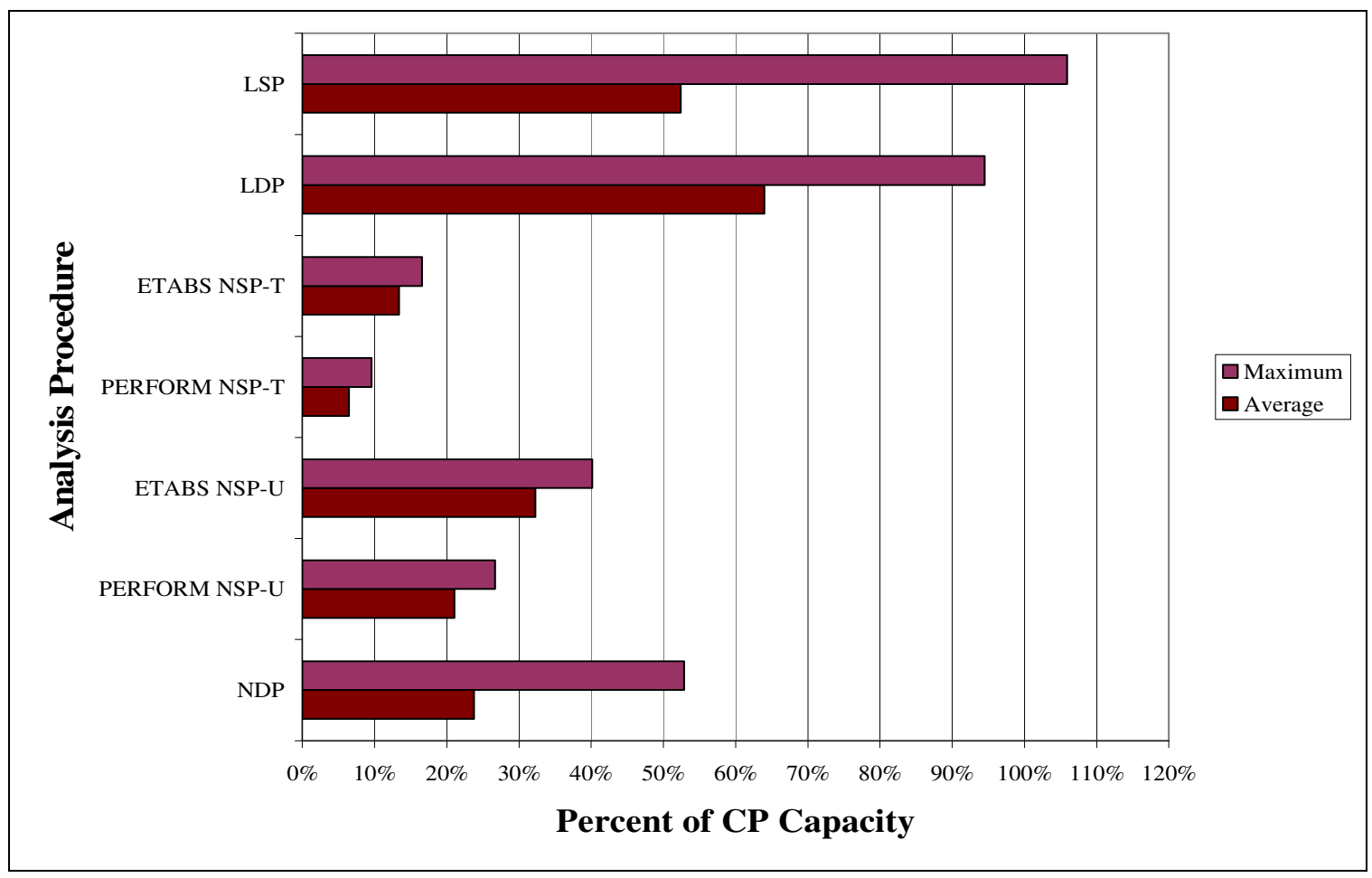

Figure FF: SMF Exterior Columns in North-South Direction

Performance Based Analysis of Steel Buildings 


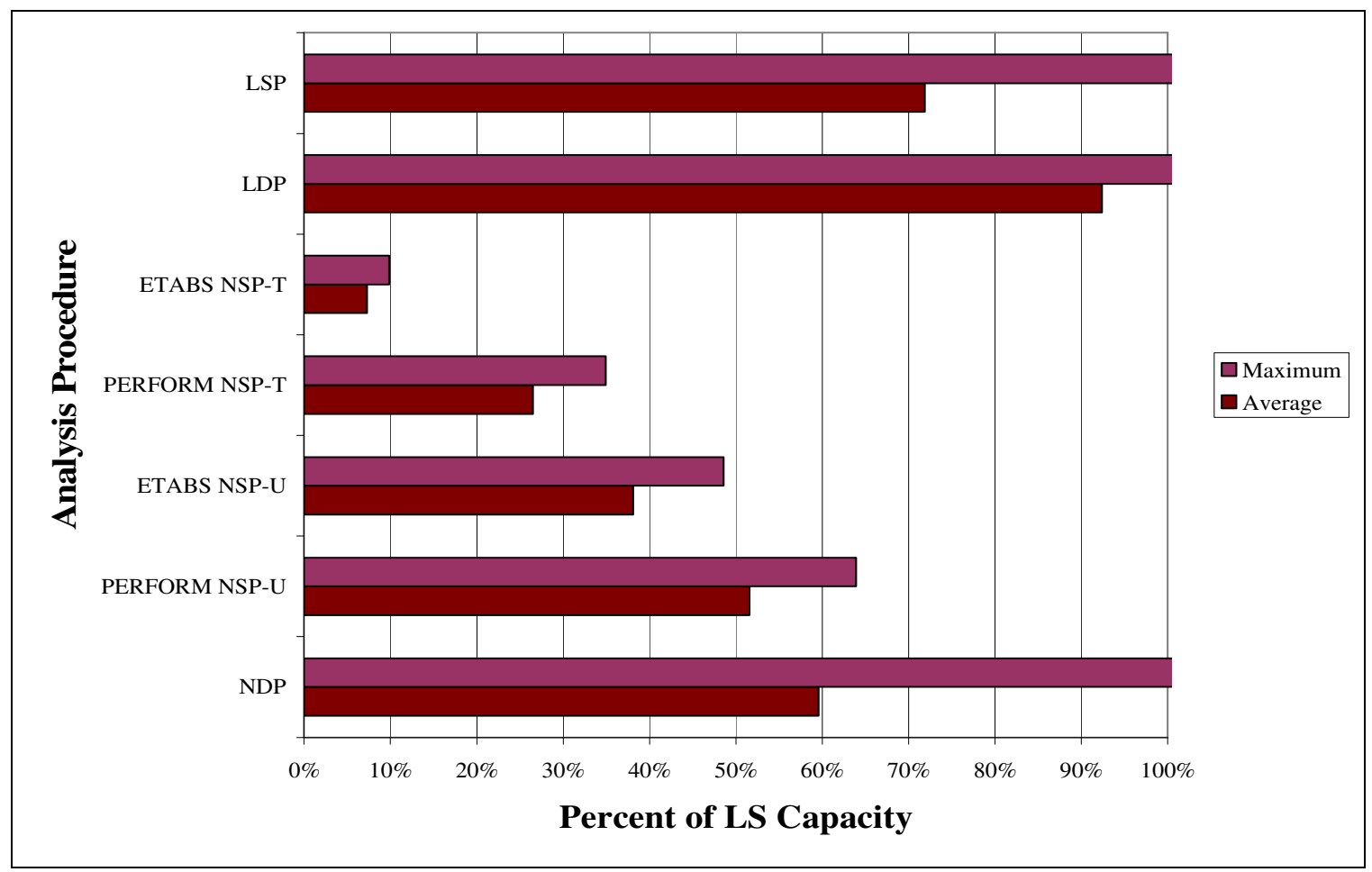

Figure GG: SMF Interior Columns in the North-South Direction

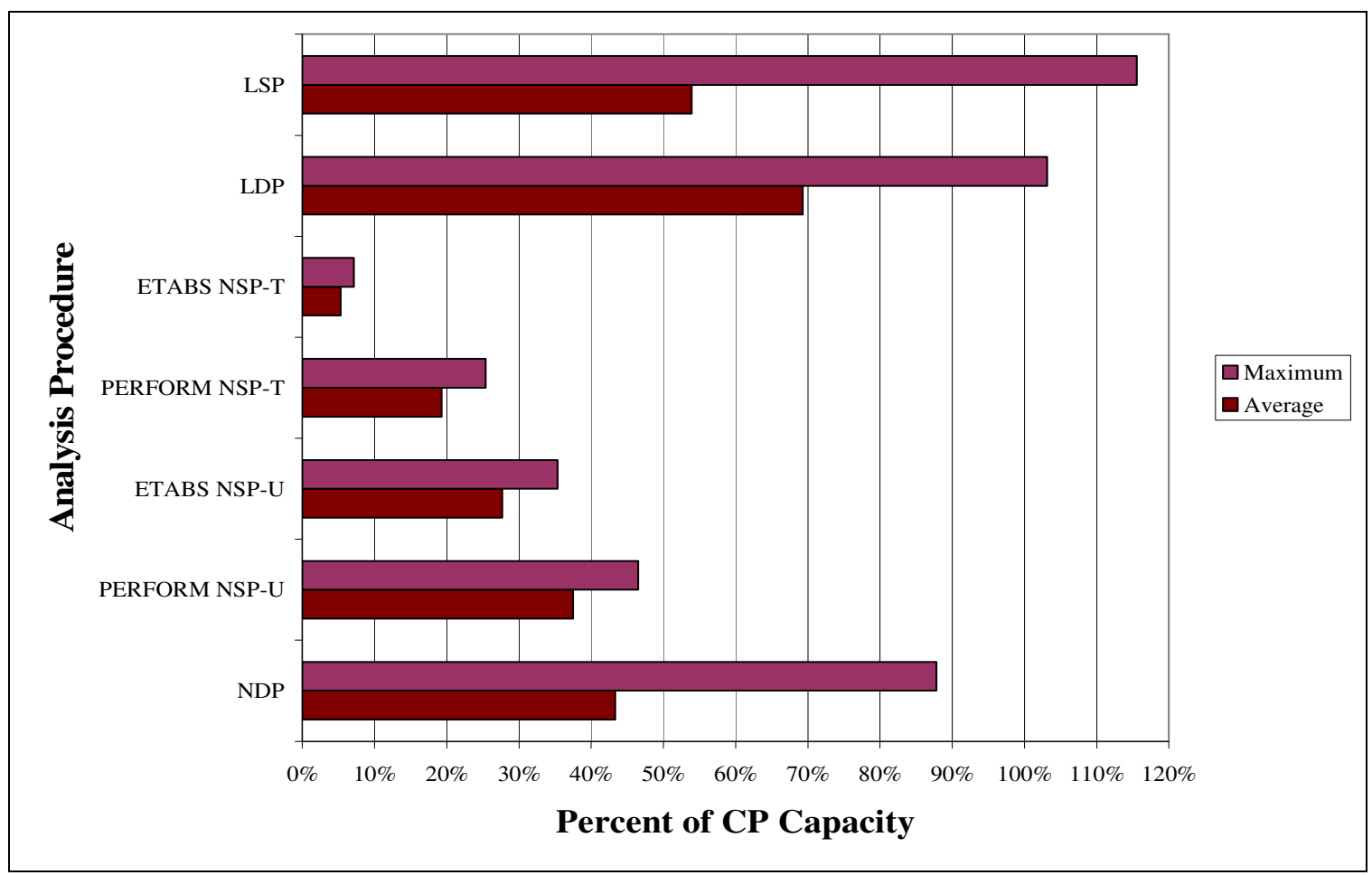

Figure HH: SMF Interior Columns in North-South Direction

Performance Based Analysis of Steel Buildings 


\subsubsection{Story Drift and Roof Displacement}

The story drifts and maximum roof displacements from the BSE-2 Hazard Level analyses can be seen on the following pages. At the lower stories, the enveloped NSP and the NDP result in story drifts that are greater than the linear procedures, however the resulting story drifts at the higher stories are much larger in the linear procedures. This is due to the fact that plastic hinges form in the first story columns in the nonlinear procedures, whereas the building responds elastically in the linear procedures. According to ASCE 41-06, typical story drifts for a building with a steel SMF structural system are $2.5 \%$ permanent and $1 \%$ transient for a LS performance level, and 5\% transient or permanent for a CP performance level. As can been seen in the figures, an average story drift of approximately $3 \%$ was experienced at the bottom three stories of the building in the nonlinear analyses. An average $0.5 \%$ permanent drift resulted from the NDP, whereas no permanent drift occurred in the BSE-1 Hazard Level analysis. Although ASCE 41-06 does not intend for the story drifts to be used as acceptance criteria, the story drifts from the BSE-2 Hazard Level analyses represent story drifts for a LS performance level according to the ASCE 41-06 typical values.

The figures showing the maximum roof displacement do not include a value for ASCE 7-05. This omission resulted from the fact that ASCE 7-05 produces a maximum roof displacement that corresponds only to an ASCE 41-06 LS performance level. Unlike the BSE-1 Hazard Level analyses, the average maximum roof displacement indicated by the NDP was greater than the both target displacements for the NSP and the maximum roof displacement from the LDP. 


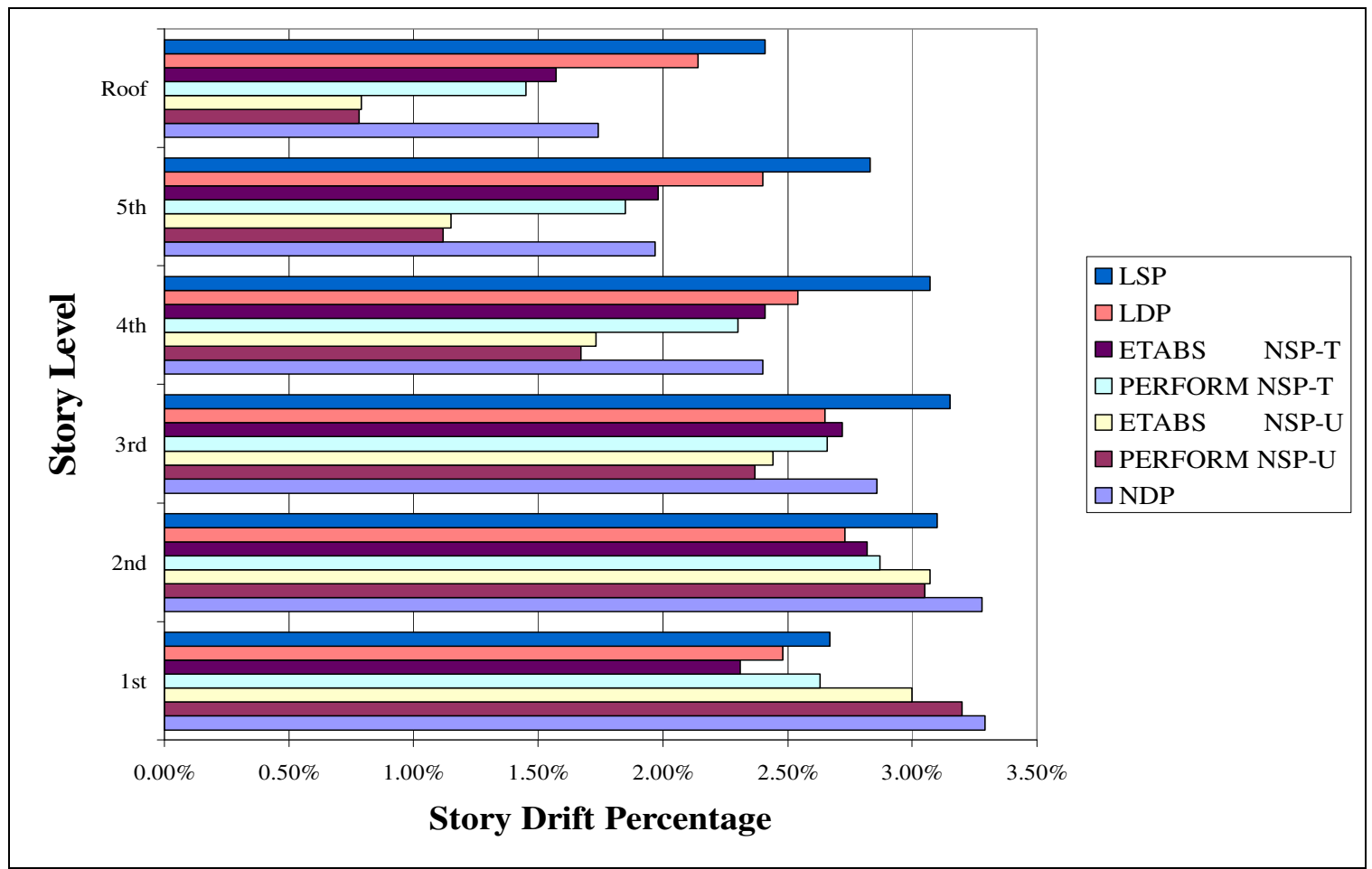

Figure II: East-West Story Drift

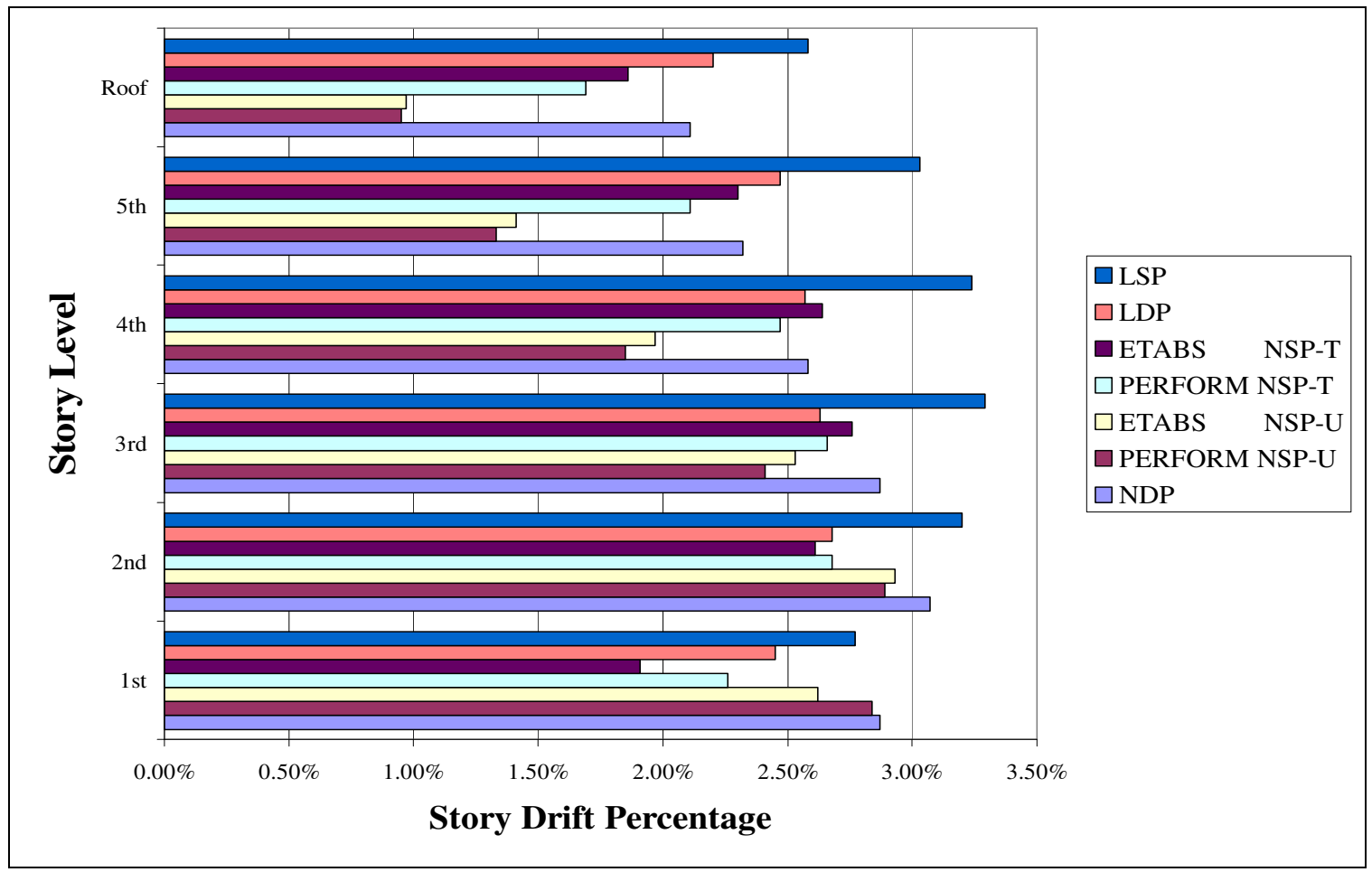

Figure JJ: North-South Story Drift

Performance Based Analysis of Steel Buildings 


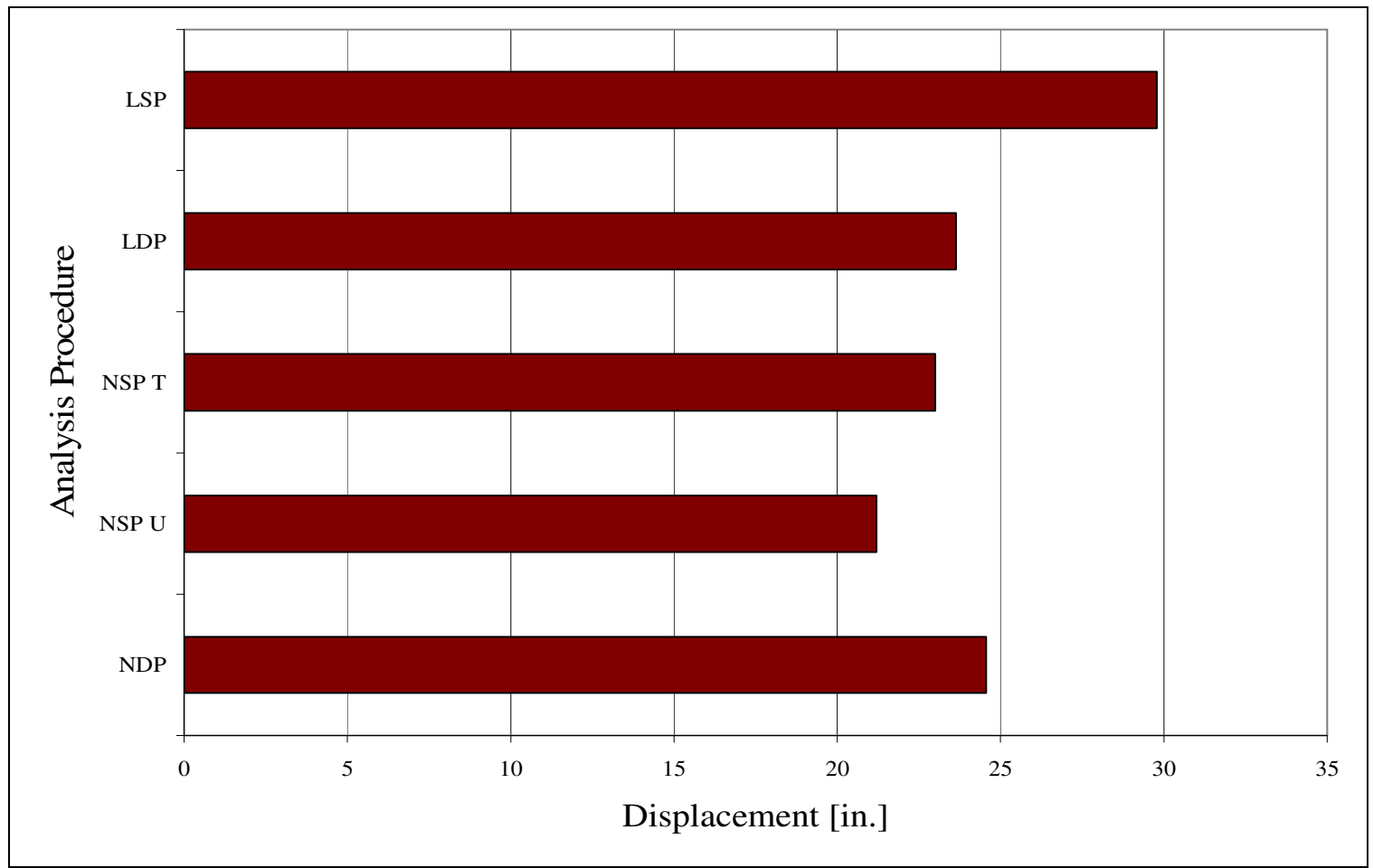

Figure KK: Maximum Roof Displacements in East-West Direction

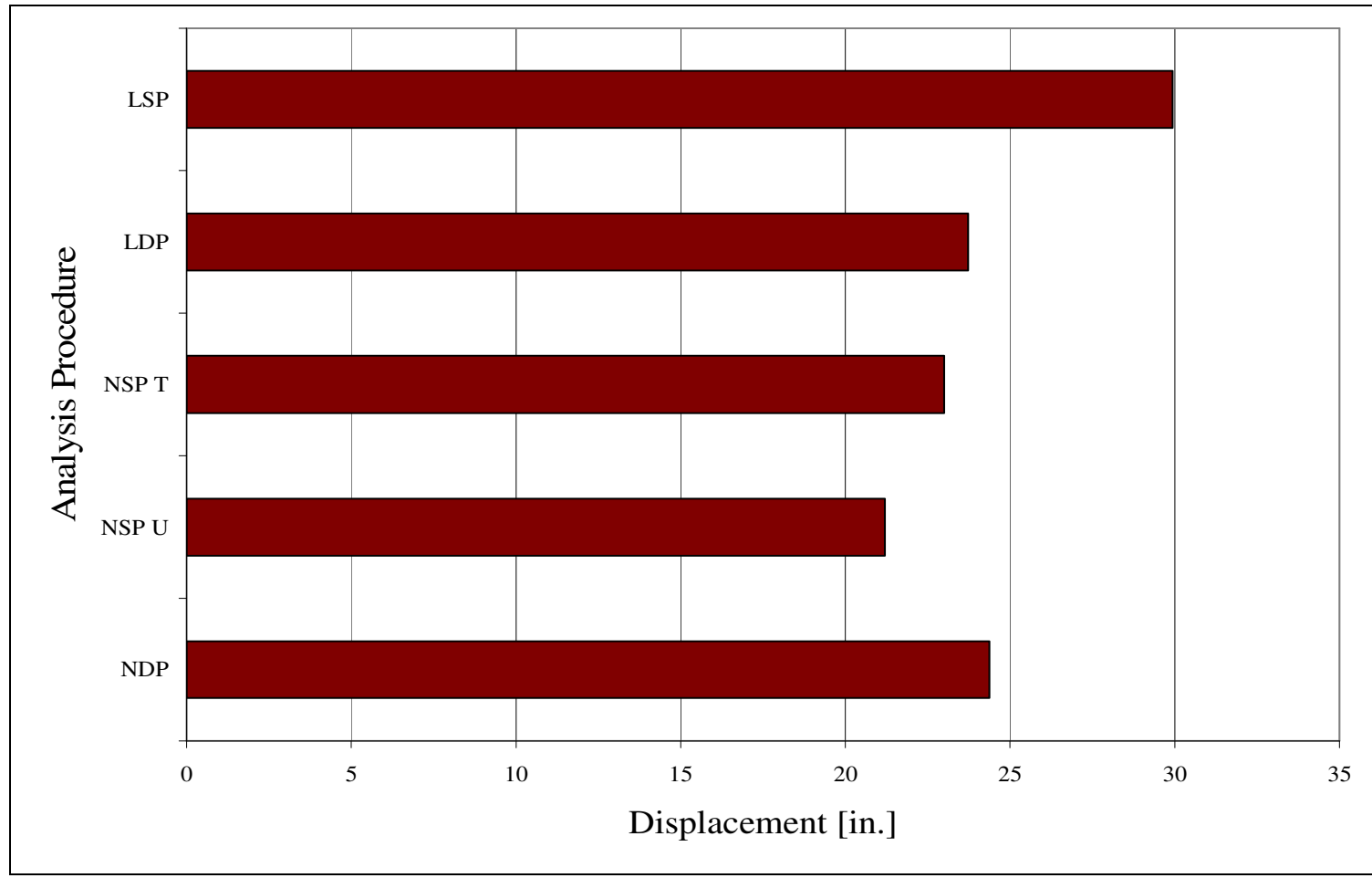

Figure LL: Maximum Roof Displacements in North-South Direction

Performance Based Analysis of Steel Buildings 


\subsection{Pushover Curves}

The figures on the page 51 show the force-displacement curves produced using the nonlinear static procedure. The maximum displacement reached on the curves represents both $150 \%$ of the BSE-1 Hazard Level target displacement and $100 \%$ of the BSE-2 Hazard Level target displacement. As can be seen in the figures, the ETABS model is stiffer than the PERFORM 3D model. Because the PERFORM 3D model excluded the concrete over metal deck for the reasons discussed on page 20, it was initially thought that the absence of the concrete over metal deck was the cause for this difference in building stiffness. After further investigation, however, this was not the reason for the difference in stiffness between the two models. This conclusion was made because modifying the stiffness values for the concrete over metal deck in ETABS did not change the building period; because the building period is directly related to the stiffness of the building and the building period did not change, the building stiffness did not change.

Although the exclusion of the concrete over metal deck in the PERFORM 3D model did not affect the results of the analyses, modeling differences between the two programs could affect the stiffness of the building. The end zones for beams and columns are treated differently in ETABS and PERFORM 3D and could contribute to the difference in elastic stiffness. In addition to the end zones, the PERFORM 3D model includes definitions for elastic panel zones at the SMF connections. PERFORM 3D uses the Krawinkler model for panel zone components, as shown in Figure MM on the following page. 


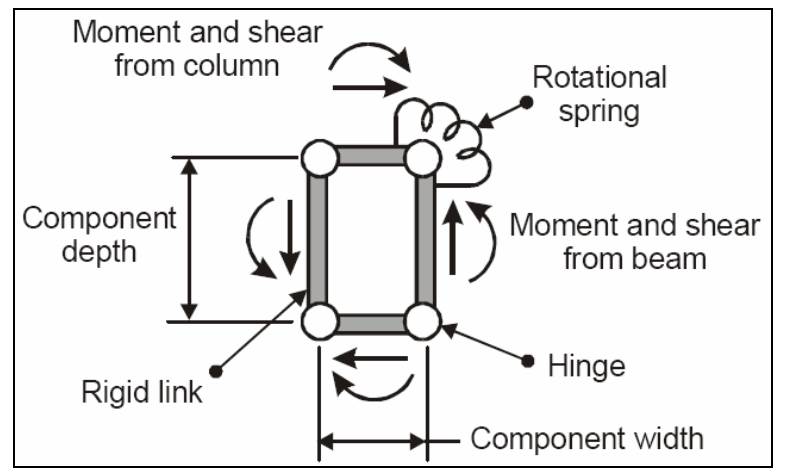

Figure MM: Krawinkler Model for Panel Zones

Source: CSI 2006, 8-2

Because the panel zones were defined as elastic, the PERFORM 3D model accounted for elastic panel zone deformations. Since the ETABS model treats the panel zones as rigid and the PERFORM 3D model allowed the panel zones to elastically deform, the PERFORM 3D model was more flexible than the ETABS model. The results of this project correlate well with the suggestions of FEMA 350, Recommended Seismic Design Criteria for New Steel Moment-Frame Buildings. FEMA 350 recommends that frames be modeled with centerline-to-centerline dimensions for the purpose of calculating stiffnesses of beams and columns. By using the centerline-to-centerline dimensions, the effect of the panel zone is approximated and results in estimates of drift similar to a buildings modeled with panel zones (FEMA $350 § 2.8 .2 .3,2-15$ ). Because rigid end and panel zones were used in the ETABS model, the building period was lower than in the PERFORM 3D model, which used elastic panel zones. 


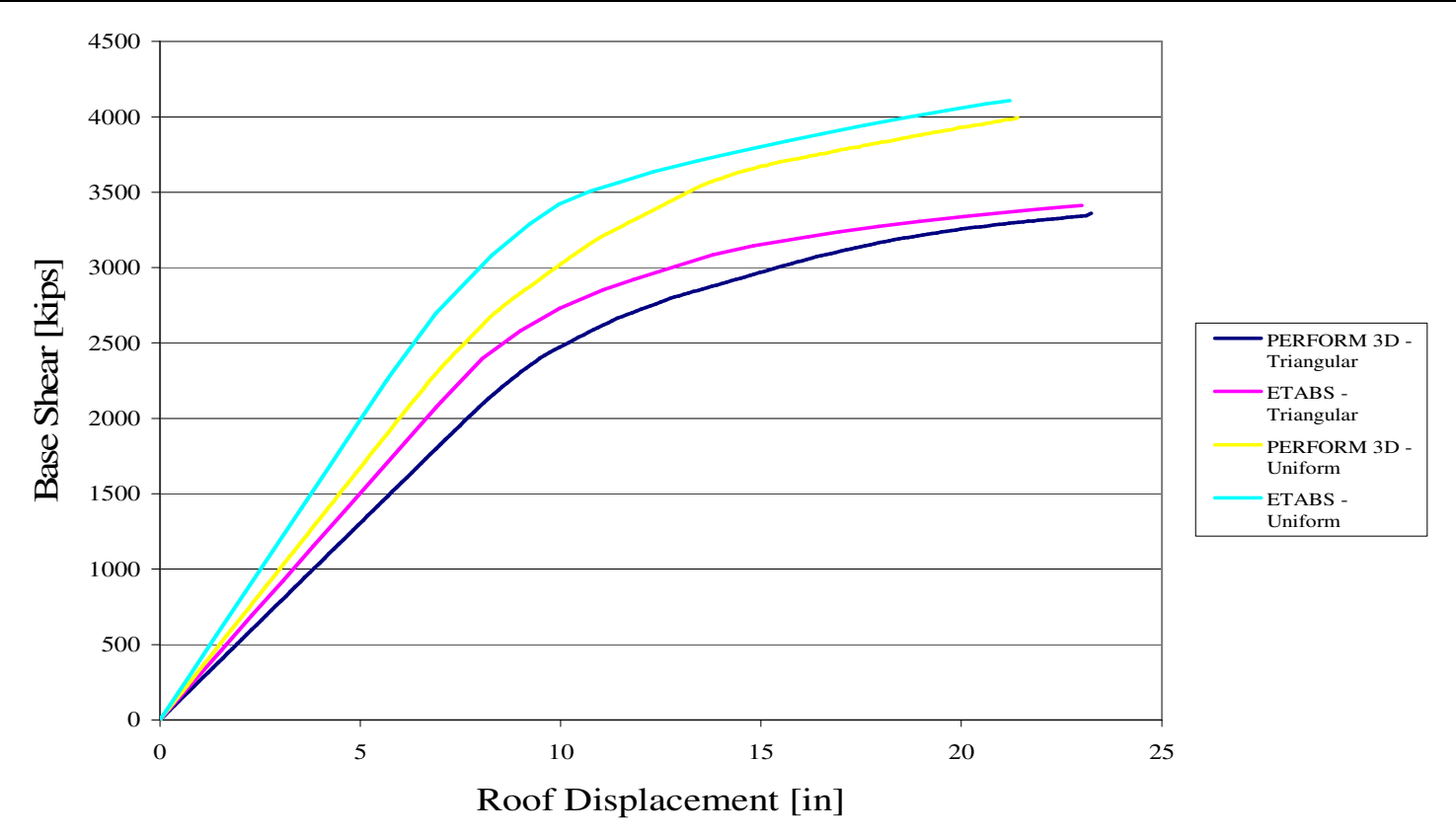

Figure NN: Pushover Curve in East-West Direction

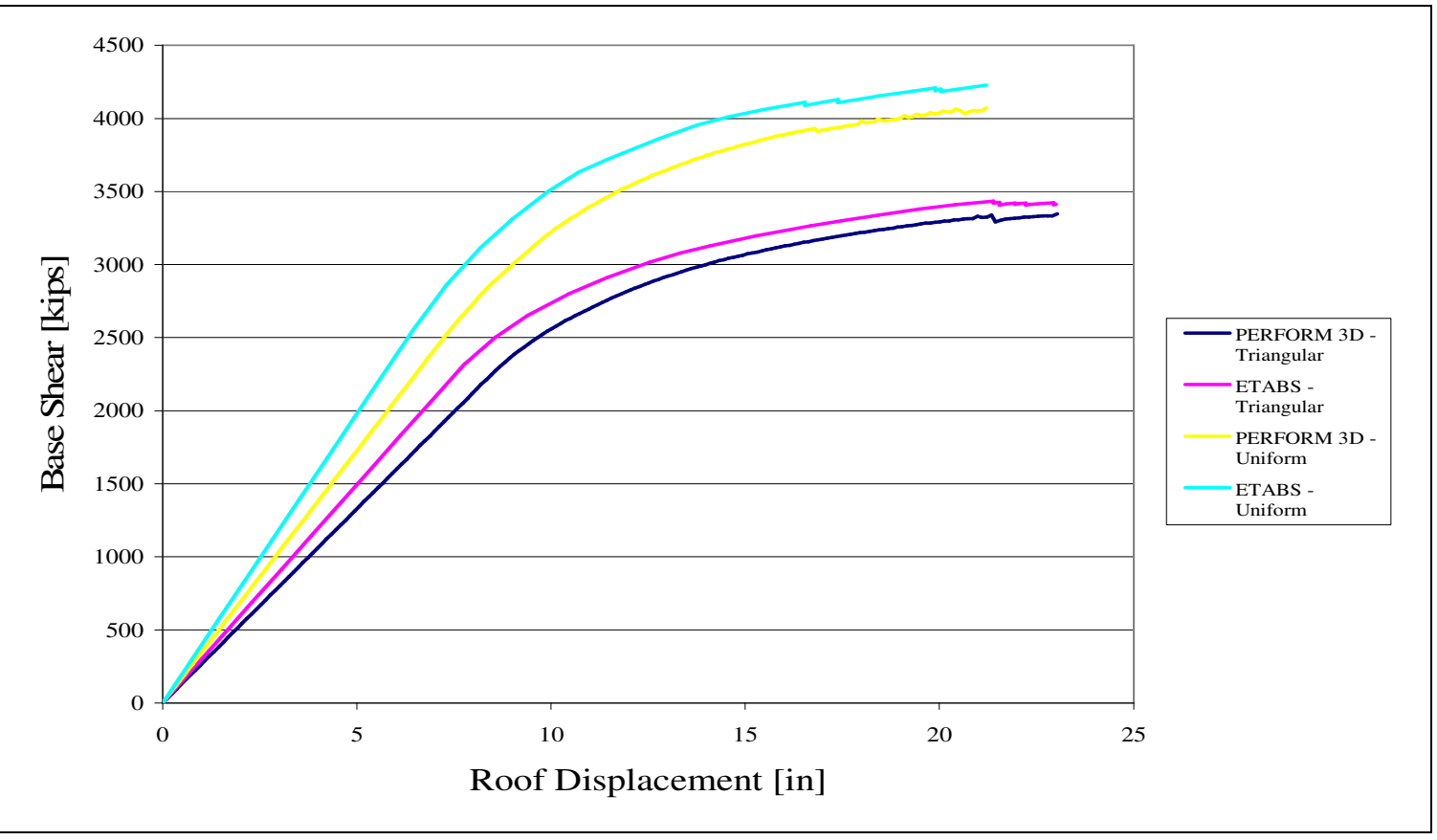

Figure OO: Pushover Curve in North-South Direction 


\subsection{Design Checks}

In order to ensure the models were performing as expected, several simple checks were performed. The first check performed on the building was a building period check. The building period was calculated using Eq. 1 from ASCE 7-05 §15.4.4,

$$
T=2 \pi \sqrt{\frac{\sum_{i=1}^{n} w_{i} \delta_{i}^{2}}{g \sum_{i=1}^{n} f_{i} \delta_{i}}},
$$

where $\quad w_{i}$ is the weight at level $i$,

$\delta_{i}$ is the elastic deflection due to the applied lateral forces, $f_{i}$,

$f_{i}$ is any lateral force distribution in accordance with the principles or structural mechanics, and

$g$ is the acceleration due to gravity.

Using the BSE-1 Hazard Level lateral forces, the calculated building period of 1.81 seconds matched exactly the ETABS value for the first mode of vibration in both directions.

In addition to checking the building period in ETABS, the P-M-M hinges in the PERFORM 3D model were checked. The following three figures show time history plots of the P-M relationship for three separate column hinges in the East-West direction under loading from the first ground motion. The green lines on the plots represent the generalized yield surface for the hinge and the red dashed lines represent the generalized failure surface for the hinge. The term generalized is used because PERFORM 3D allows the user to input coefficients to adjust the shape of the lines connecting the maximum axial forces and moments, whereas the hand checks used straight line approximations. 


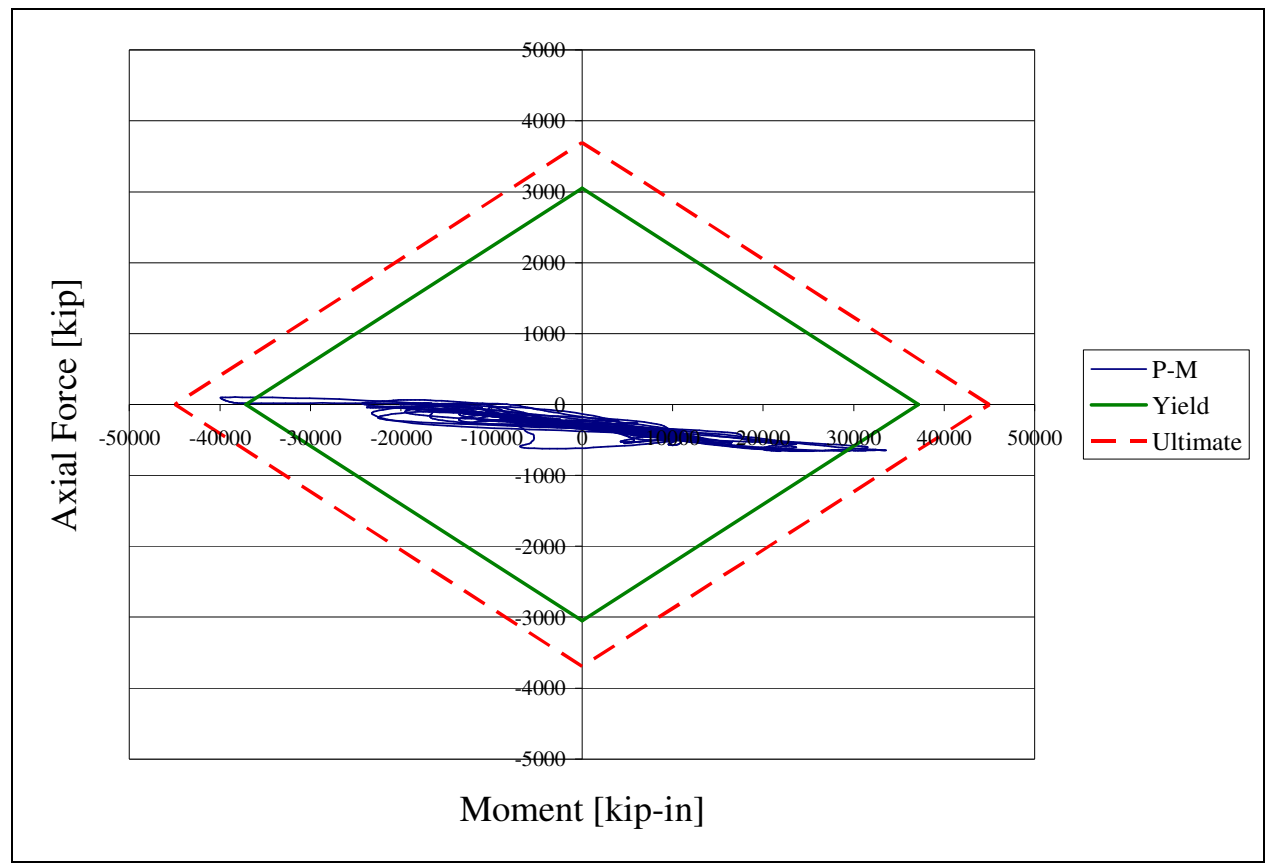

Figure PP: Column Hinge at 1-A

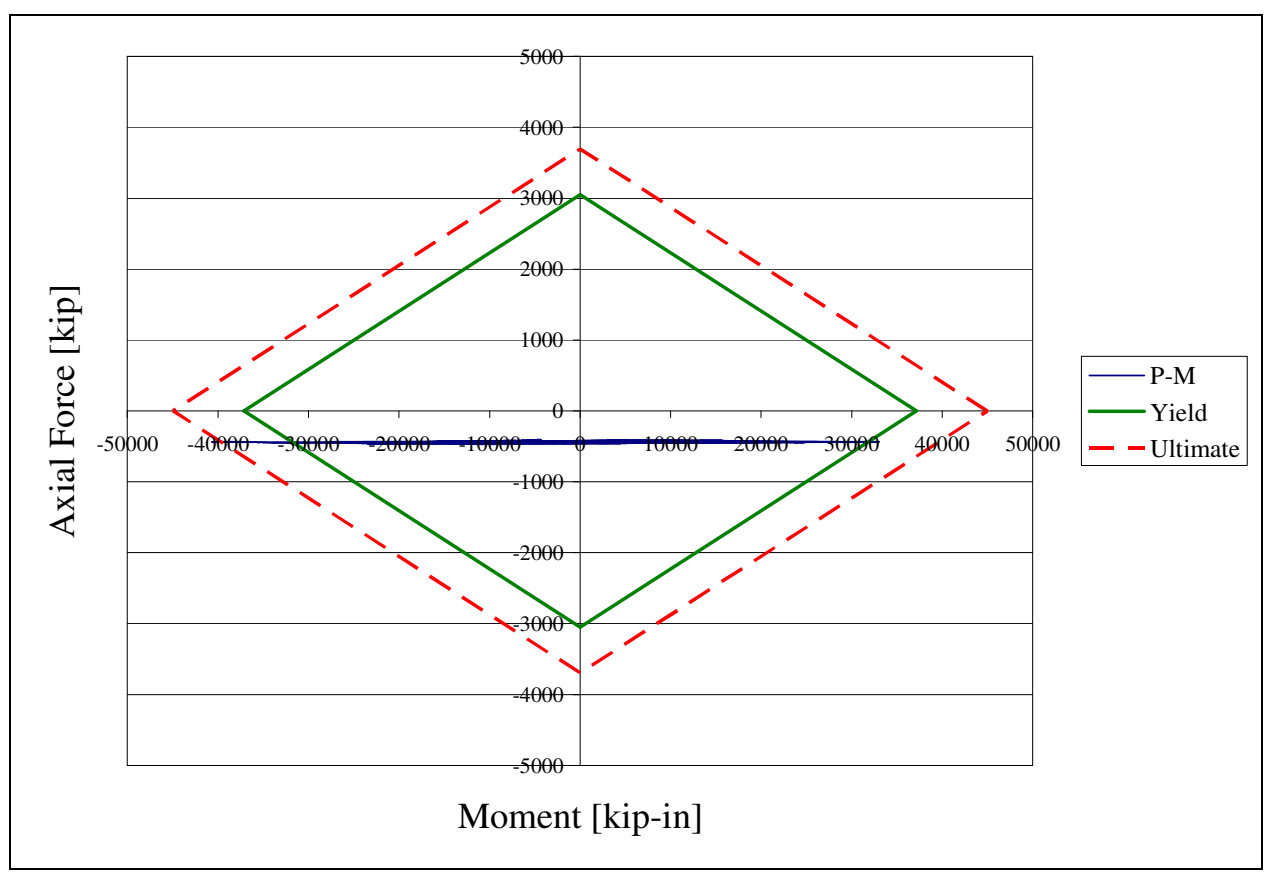

Figure QQ: Column Hinge at 1-B 


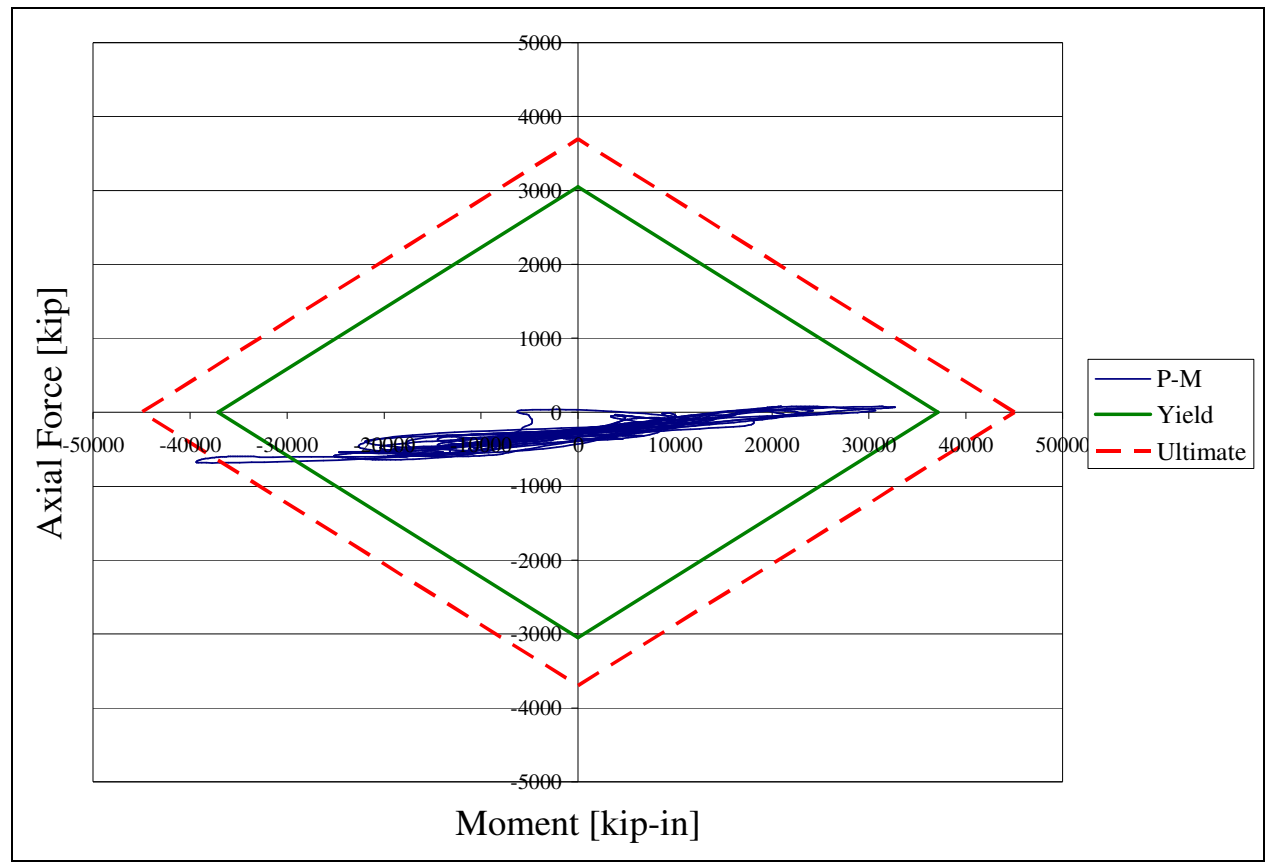

Figure RR: Column Hinge 1-F 


\subsection{CONCLUSIONS}

The project began with the design of a steel Special Moment Frame (SMF)

building according to the current building codes and standards, including American Society of Civil Engineers (ASCE) Standard 7-05, Minimum Design Loads for Buildings and Other Structures. The building was then analyzed using the four analysis procedures prescribed in ASCE 41-06, Seismic Rehabilitation of Existing Structures. The results from the ASCE 41-06 analyses were compared to the expected structural performance level of Life Safety (LS) to determine the adequacy of the ASCE 7-05 design.

A summary of the results from the research can be seen in Table 5. The table shows the structural building performance level and maximum story drift for each of the four analysis procedures and two hazard levels. Unless noted otherwise, performance level references the structural performance level.

\begin{tabular}{|l|c|c|c|c|}
\hline \multirow{2}{*}{ Analysis Procedure } & \multicolumn{2}{|c|}{ Performance Level } & \multicolumn{2}{c|}{$\begin{array}{c}\text { Max. Story } \\
\text { Drift }\end{array}$} \\
\cline { 2 - 5 } & $\begin{array}{c}\text { BSE-1 Hazard } \\
\text { Level }\end{array}$ & $\begin{array}{c}\text { BSE-2 Hazard } \\
\text { Level }\end{array}$ & BSE-1 & BSE-2 \\
\hline Linear Static Procedure & LS & Post CP & $2.20 \%$ & $3.29 \%$ \\
\hline $\begin{array}{l}\text { Linear Dynamic } \\
\text { Procedure }\end{array}$ & LS & CP & $1.82 \%$ & $2.73 \%$ \\
\hline $\begin{array}{l}\text { Nonlinear Static } \\
\text { Procedure }\end{array}$ & $\begin{array}{c}\text { Slightly Exceeded } \\
\text { IO }\end{array}$ & LS & $1.90 \%$ & $2.87 \%$ \\
\hline $\begin{array}{l}\text { Nonlinear Dynamic } \\
\text { Procedure }\end{array}$ & $\begin{array}{c}\text { Slightly Exceeded } \\
\text { IO }\end{array}$ & LS & $2.08 \%$ & $3.29 \%$ \\
\hline
\end{tabular}

\section{Table 5: Summary of Building Performance Level Results}

The two Hazard Levels used for this project are the BSE-1 ( 500 year earthquake) and BSE-2 ( 2500 year earthquake). In order to meet the Basic Safety Objective of ASCE 41-06, the building should perform to a LS performance level for the 
BSE-1 Hazard Level and to a Collapse Prevention (CP) performance level for the BSE-2 Hazard Level. Because the BSE-1 Hazard Level corresponds to a LS performance level, the performance of the building under the BSE-1 Hazard Level loading was compared to the expected ASCE 7-05 performance of LS.

The worst structural performance level was predicted using the Linear Static Procedure (LSP). For the BSE-1 Hazard level, the maximum beam moment demands were approximately $40 \%$ of their LS capacity; however, the maximum column moment demands were approximately $100 \%$ of their LS capacity. For the BSE-2 Hazard Level, the beams again performed well, with maximum moment demands of approximately $60 \%$ of their LS capacity. The maximum column moment demands, however, exceeded the CP performance level capacity by approximately $10 \%$, causing the structural performance level to exceed $\mathrm{CP}$.

The building performance achieved using the Linear Dynamic Procedure (LDP) was similar to the performance from the LSP. As a general trend, the moment demands from the LDP were reduced $0 \%-10 \%$ when compared to the LSP; however, this variation generally had negligible effects on the overall performance of the building. The only significant difference between the LSP and the LDP was the maximum column moment demands for the BSE-2 Hazard Level. The reduction in column moment demands was significant enough to cause all columns to perform to a CP performance level, therefore improving the building performance level to $\mathrm{CP}$.

The nonlinear analyses produced significantly better results than the linear analyses. The Nonlinear Static Procedure (NSP) incorporated two load patterns: a code 
based load distribution and a uniform load distribution. The results discussed for the NSP are an envelope of the results for the two load patterns. For both the NSP and Nonlinear Dynamic Procedure (NDP), the beam hinge rotation demands at the bottom two stories slightly exceeded the IO performance level and the remainder of the beams remained within the IO performance level for the BSE-1 Hazard Level. Like the beams, the majority of the columns remained within the IO performance level in the nonlinear analyses under the BSE-1 Hazard Level loading, with only 4 columns slightly exceeding the IO performance level. For the BSE-2 Hazard Level NSP and NDP, all beam hinge rotation demands were within the LS performance level capacity and all but 2 columns were within the LS performance level.

The results of this research illustrate that for this building, the use of the NDP did not change the overall assessment of the building performance. Although the NDP identified some locations with increased hinge rotation demands when compared to the NSP, the overall performance of the building from the NSP and NDP was very similar for the BSE-1 and BSE-2 Hazard Levels.

Although the BSE-1 Hazard Level beam and column performance levels from the ASCE 41-06 nonlinear analyses were better than the intended result of LS, the story drifts from the ASCE 41-06 analyses indicated that the building performed closer to the ASCE 7-05 intended result of LS. Because ASCE 41-06 does not provide acceptance criteria for building drift, however, the drift was not used to determine the structural building performance level. The similarity between the ASCE 7-05 drift check and the ASCE 41- 
06 analysis results did indicate that the ASCE 7-05 drift check is more accurate when the building period calculated using the Rayleigh-Ritz method is used.

The overall building performance was evaluated based on the collective performance of the building's beams and columns. The beam and column hinge rotation demands indicate that the building slightly exceeded an Immediate Occupancy (IO) performance level for the BSE-1 Hazard Level nonlinear analyses. The results from the BSE-1 Hazard Level nonlinear analyses indicate that the beams slightly exceeded the IO performance level at the first and second stories and were within the IO performance level at all the stories above. The columns on the exterior of the building all experienced average hinge rotation demands well below the IO performance level, and the maximum hinge rotation demands from the SMF columns on the interior of the building exceeded the IO performance level but were less than $40 \%$ of the LS capacity. Based on the beam and column hinge rotation demands from the NDP, it was determined that the structural building performance level slightly exceeded the defined IO performance level for the BSE-1 Hazard Level. The building drift was not used to determine the structural building performance level

Although the building achieved nearly an IO structural performance level, the building would not necessarily receive the same nonstructural performance level. Although this research focused on the effects of story drift to the structural system, story drift is also a major indicator of damage to the nonstructural systems. Because the story drift was approximately $2 \%$, the nonstructural performance level would likely indicate more damage than the structural performance level. 
In addition to differences in the structural and nonstructural performance levels, an inconsistency in the definitions for the beam acceptance criteria and the typical values for story drift provided in ASCE 41-06 was also indicated by this research. The story drifts at the lower levels of the building for the BSE-2 Hazard Level nonlinear analyses were approximately $2.5 \%$. ASCE $41-06$ states that a $2.5 \%$ story drift is typical of a building achieving a LS performance level. The beam hinge rotation demand-capacity ratios, however, were approximately $65 \%$ and $45 \%$ of the LS capacity in the East-West and North-South directions. Because beam hinge rotations and story drifts should be closely correlated, it is expected that these values should correspond better.

This research also investigated the difference between the ETABS and PERFORM 3D models. This investigation was performed by comparing the results from the nonlinear static procedure. For both pushover loading patterns and hazard levels, the maximum rotations in the beam hinges from the two programs were very similar. The column hinge rotation demands and story drifts varied, however, with approximately 10\%-20\% difference in column demands and 15\%-20\% difference in story drift. This difference in column demands and story drift was likely due to the fact that the programs calculated the relative stiffness of the exterior to interior frames in the North-South direction differently as well as the difference in the P-M-M hinge modeling for each program. Despite the differences in the two programs, the performance level achieved by the building using the NSP was not significantly affected.

In addition to the research presented in this paper, a similar project was completed using steel Special Concentric Braced Frames (SCBF) instead of steel Special Moment 
Frames (SMF). The research found the building designed using the SCBF performed worse than the expected result of LS when analyzed using BSE-1 Hazard Level nonlinear procedures. For the BSE-1 Hazard Level linear analyses, the building maintained a LS performance level. After completing the BSE-1 Hazard Level NSP and NDP analyses, however, the building achieved a CP performance level (Adams 2010). In contrast to the SMF building, the performance level achieved for the SCBF building designed using ASCE 7-05 was worse than the expected result of LS. This difference in performance between the steel SMF and SCBF was likely due to the fact that the majority of the inelastic deformation in the SCBF was confined to the compression braces, whereas the tension braces, beams, and columns in the SCBF experienced little to no inelastic deformation. This concentration of inelastic deformation caused the compressions braces to exceed the LS performance level while the remainder of the components in the building, including the tension braces, performed to closer to an IO performance level. Because the performance level is based on the collective performance of the building components, however, the building achieved performance levels worse than the expected results. There were a total of 24 compression braces in each direction for the SCBF building; however, there were 72 beams and 12 columns in each direction for the SMF building. Because the inelastic deformations in the SMF building were distributed among three times as many components, the hinge rotation demand-capacity ratios in the SMF building were smaller than the compression brace axial load demand-capacity ratios in the SCBF building. 
This research was completed to investigate the performance of two separate building types, designed using ASCE 7-05, using the analysis procedures from ASCE 4106. The conclusions from the research are based on one building representing each building type. A design using the AISC specifications for a steel SMF and the lateral loads from ASCE 7-05 resulted in a building that slightly exceeded an Immediate Occupancy structural performance level for the BSE-1 Hazard Level. In comparison, a design using the AISC specifications for steel SCBF resulted in a building that performed to a Collapse Prevention structural performance level for the BSE-1 Hazard Level. ASCE 7-05, however, is intended to result in designs that perform to a Life Safety structural performance level regardless of the building type.

Future work to verify and expand on these conclusions should include analyses performed using different building configurations and occupancy types. Additional ground motions and seismic design parameters could also be included. The addition of soil-structure interaction to the analyses would also broaden the applicability of the results and conclusions. 


\subsection{REFERENCES}

(Adams 2010) Adams, Scott. "Performance Based Analysis of Steel Buildings.” MS thesis California Polytechnic State University, San Luis Obispo, 2010. Print.

(ASCE 41-06) American Society of Civil Engineers. ASCE 41-06 Seismic Rehabilitation of Existing Buildings. Reston, Virginia. 2007.

(Astaneh-Asl 2005) Astaneh-Asl, Abolhassan. "Design of Shear Tab Connections for Gravity and Seismic Loads." Steel Tips. Structural Steel Education Council. 1 June 2005. June 2009. < http://www.steeltips.org/steeltips/tip_details.php?id=90>

(FEMA 274) United States Department of Homeland Security's Federal Emergency Management Agency. NEHRP Commentary on the Guidelines for the Seismic Rehabilitation of Buildings. Washington, D.C.: US Dept. of Homeland Security, 1997.

(FEMA 350) United States Department of Homeland Security's Federal Emergency Management Agency. Recommended Seismic Design Criteria for New Steel Moment-Frame Buildings. Washington, D.C.: US Dept. of Homeland Security, 2000.

(FEMA 356) United States Department of Homeland Security's Federal Emergency Management Agency. Prestandard and Commentary for the Seismic Rehabilitation of Buildings. Washington, D.C.: US Dept. of Homeland Security, 2000.

(FEMA 440) United States Department of Homeland Security's Federal Emergency Management Agency. Improvement of Nonlinear Static Seismic Analysis Procedures. Washington, D.C.: US Dept. of Homeland Security, 2005.

(FEMA 445) United States Department of Homeland Security's Federal Emergency Management Agency. Next-Generation Performance-Based Seismic Design Guide. Washington, D.C.: US Dept. of Homeland Security, 2006.

(Filiatrault 2002) Filiatrault, André. Elements of Earthquake Engineering and Structural Dynamics. Canada: National Library of Canada, 2002. 123

(Ghobarah 2001) Ghobarah, Ahmed. "Performance-based design in earthquake engineering: state of development." Engineering Structures. 23 (2001) 878-884.

(IBC 2006) International Code Council. International Building Code. USA: International Code Council, 2006 
(Vision 2000) Structural Engineers Association of California. Vision 2000: Performance Based Seismic Engineering of Buildings. Sacramento, CA.: SEAOC, 1995

(USGS 2008) "Deaths in the United States from Earthquakes". Earthquake Hazards Program. United States Geological Service. 16 July 2008. 12 Nov 2008. $<$ http://earthquake.usgs.gov/regional/states/us_deaths.php>

(CSI 2006) Computers and Structures, Inc. PERFORM-3D Users Guide. Berkeley, CA: CSI, 2006 


\section{LIST OF ACRONYMS}

$\begin{array}{ll}\text { AISC } & - \text { American Institute of Steel Construction } \\ \text { ASCE } & - \text { American Society of Civil Engineers } \\ \text { ATC } & - \text { Applied Technology Council } \\ \text { BSE-1 } & - \text { Basic Safety Earthquake 1 } \\ \text { BSE-2 } & - \text { Basic Safety Earthquake } 2 \\ \text { BSO } & - \text { Basic Safety Objective } \\ \text { CBC } & - \text { California Building Code } \\ \text { CP } & - \text { Collapse Prevention } \\ \text { CSI } & - \text { Computers and Structures, Inc. } \\ \text { FEMA } & - \text { Federal Emergency Management Agency } \\ \text { IBC } & - \text { International Building Code } \\ \text { IO } & - \text { Immediate Occupancy } \\ \text { LDP } & - \text { Linear Dynamic Procedure } \\ \text { LSP } & - \text { Linear Static Procedure } \\ \text { LS } & - \text { Life Safety } \\ \text { NDP } & - \text { Nonlinear Dynamic Procedure } \\ \text { NSP } & - \text { Nonlinear Static Procedure } \\ \text { RBS } & - \text { Reduced Beam Section(s) } \\ \text { SEAOC } & - \text { Structural Engineers Association of California } \\ \text { SMF } & - \text { Special Moment Frame } \\ \text { UBC } & - \text { Uniform Building Code } \\ \text { USGS } & - \text { United States Geological Survey } \\ & \end{array}$




\section{APPENDIX}

\begin{tabular}{|c|c|c|}
\hline Point & Moment/SF & Rotation/SF \\
\hline E- & -0.6 & -11 \\
\hline D- & -0.6 & -9 \\
\hline C- & -1.27 & -9 \\
\hline B- & -1 & 0. \\
\hline A & 0. & 0. \\
\hline B & 1. & 0. \\
\hline C & 1.27 & 9. \\
\hline D & 0.6 & 9 \\
\hline E & 0.6 & 11. \\
\hline
\end{tabular}

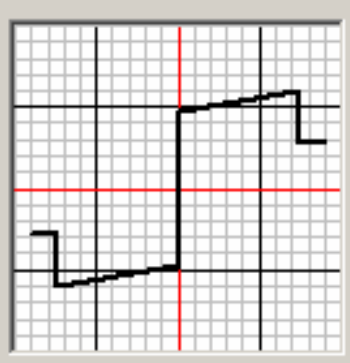

『 Hinge is Rigid Plastic

$\sqrt{\checkmark}$ Symmetric

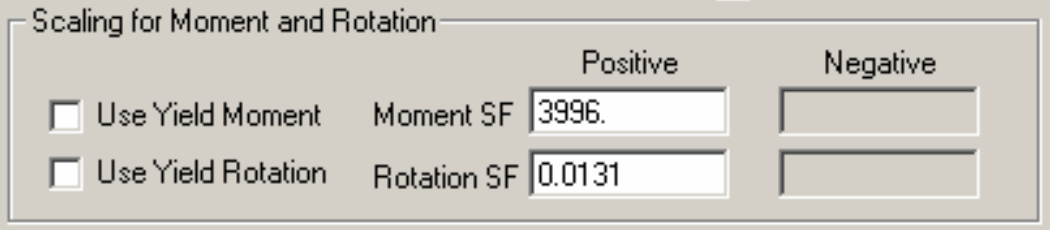

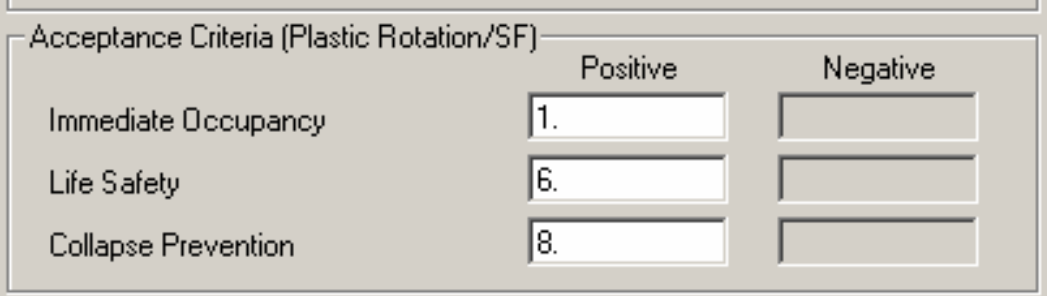

\section{DK}

Cancel 


\begin{tabular}{|c|c|c|}
\hline Point & Moment/SF & Rotation/SF \\
\hline E- & -0.2 & -10.94 \\
\hline D- & -0.2 & -7.08 \\
\hline C- & -1.212 & -7.08 \\
\hline B- & -1 & 0. \\
\hline A & 0. & 0. \\
\hline B & 1. & 0. \\
\hline C & 1.212 & 7.08 \\
\hline D & 0.2 & 7.08 \\
\hline E & 0.2 & 10.94 \\
\hline
\end{tabular}
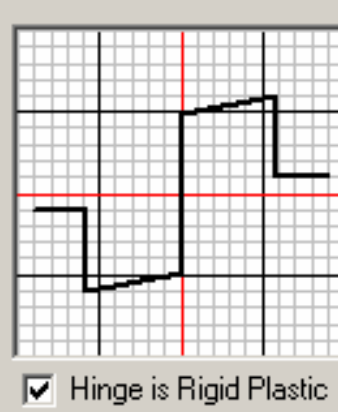

『 Symmetric
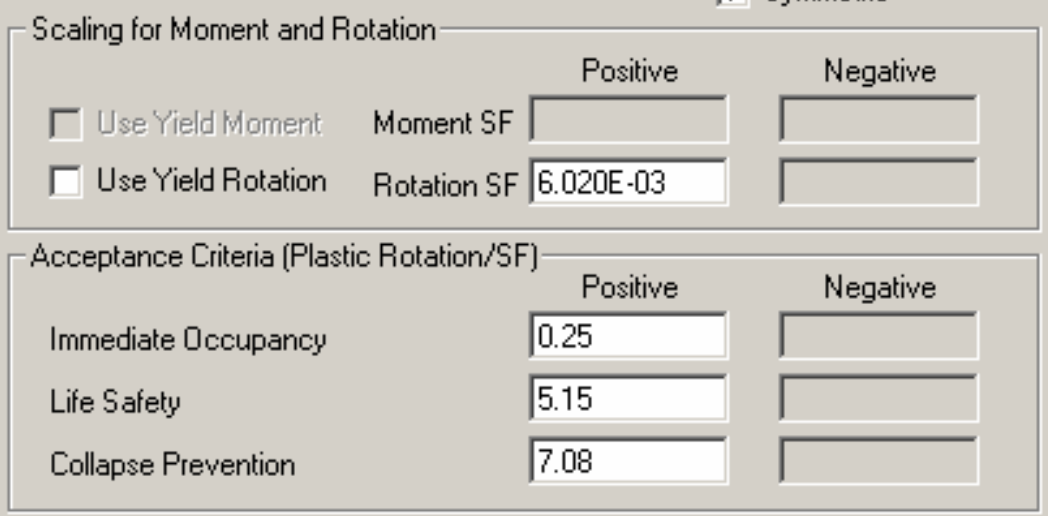

Axial Load - Displacement Relationship

c Proportional to Moment - Rotation

C Elastic-Perfectly Plastic

Define/Show Interaction...

DK

Cancel

C Steel, AISC-LRFD Equations $\mathrm{H} 1-1 \mathrm{a}$ and $\mathrm{H} 1-1 \mathrm{~b}$ with phi $=1$

Expected Yield Strength

c Steel, FEMA 273 Equation 5-4

Expected Yield Strength

55.

C Concrete, $\mathrm{ACl} 318-95$ with phi $=1$

C User Definition

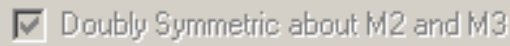

Number of Curves

Define/Show Surface.. 


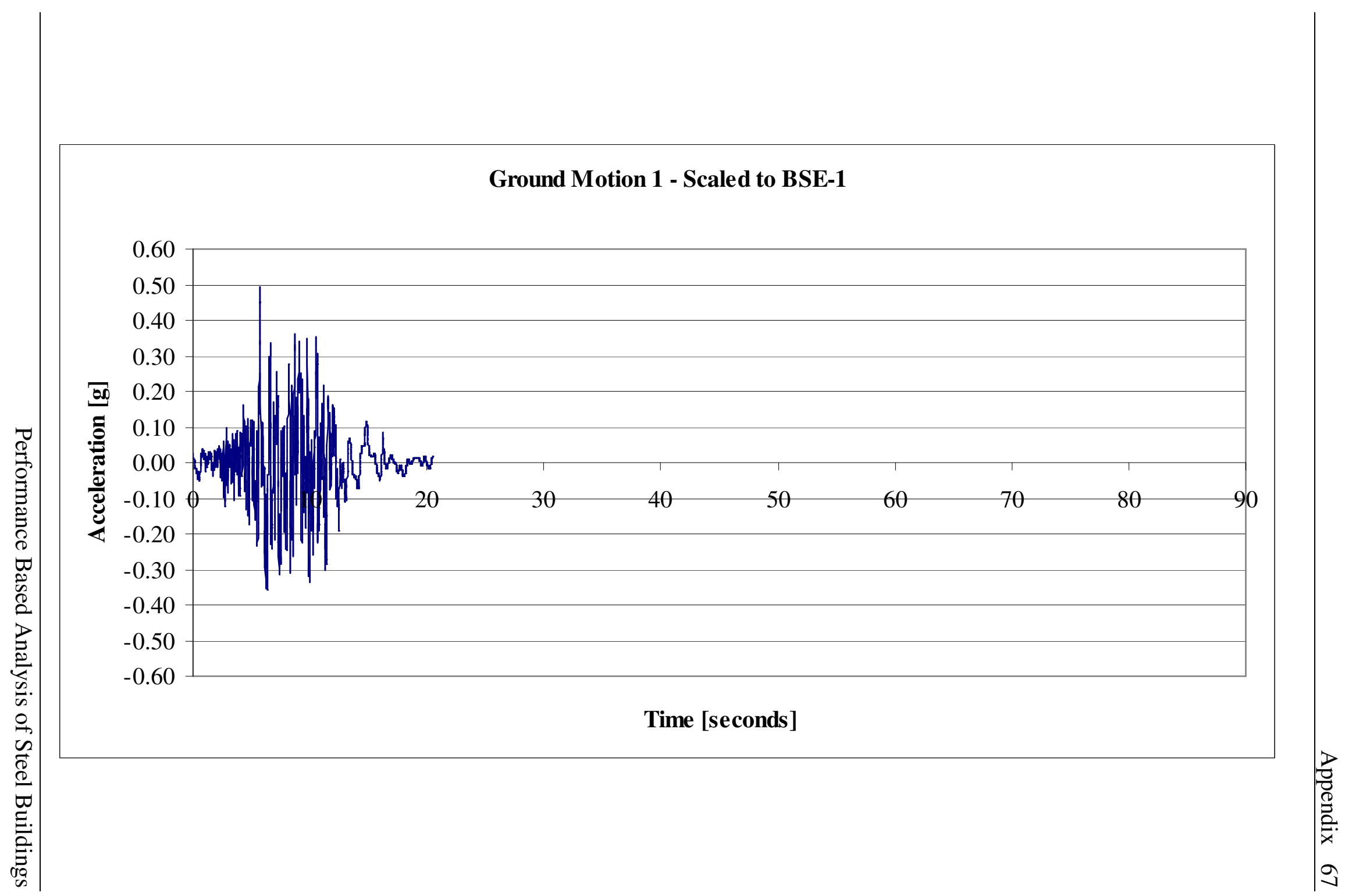




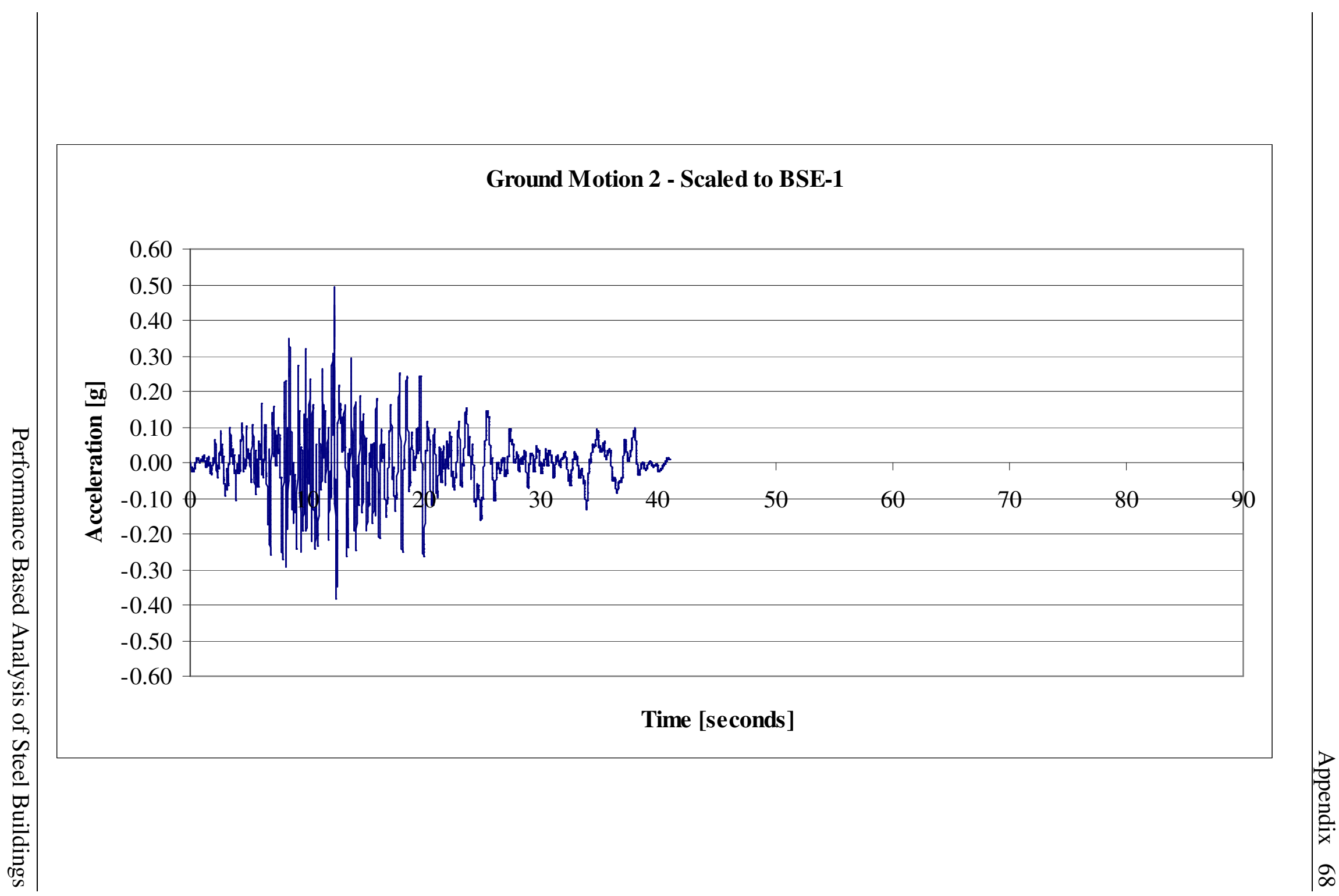




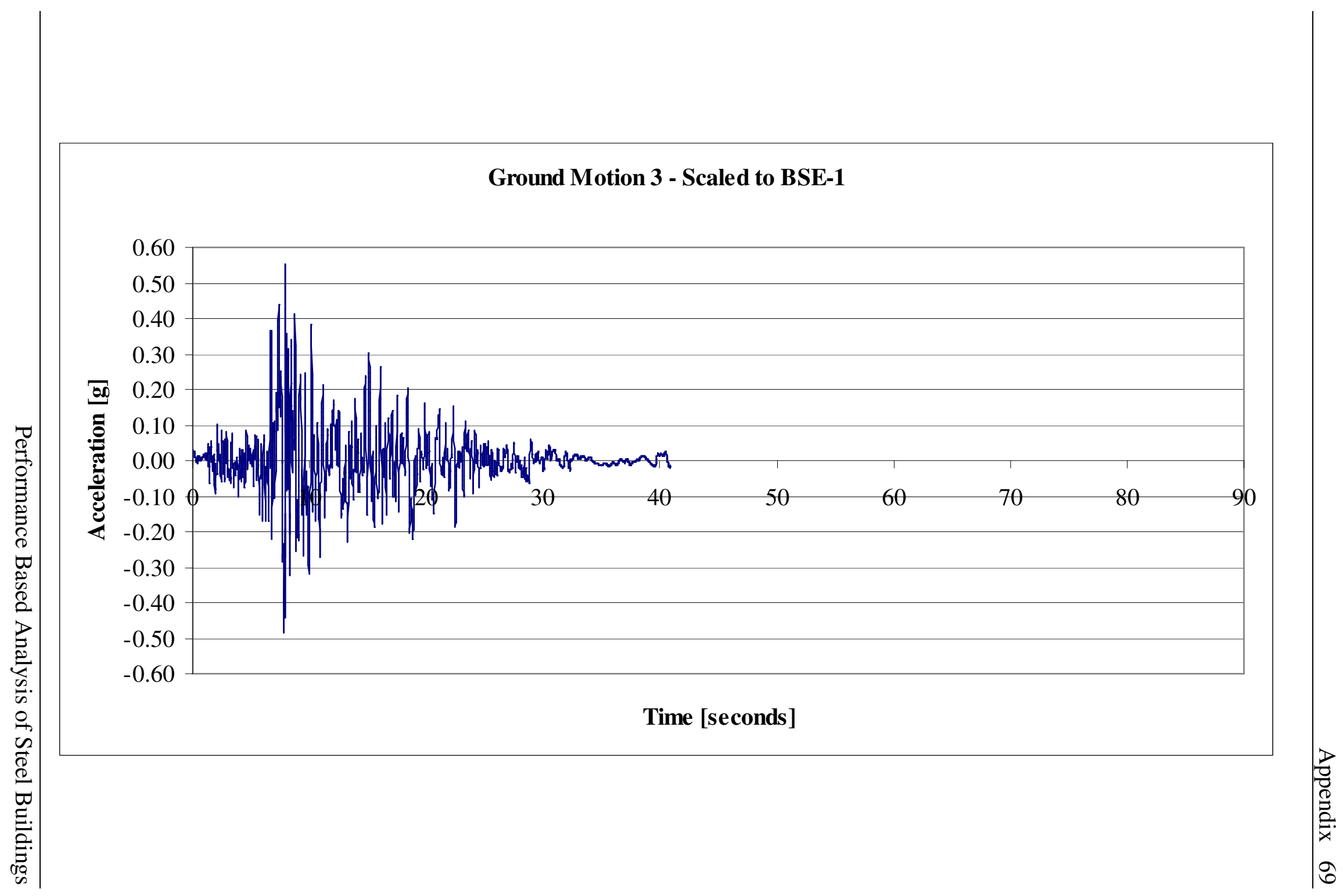




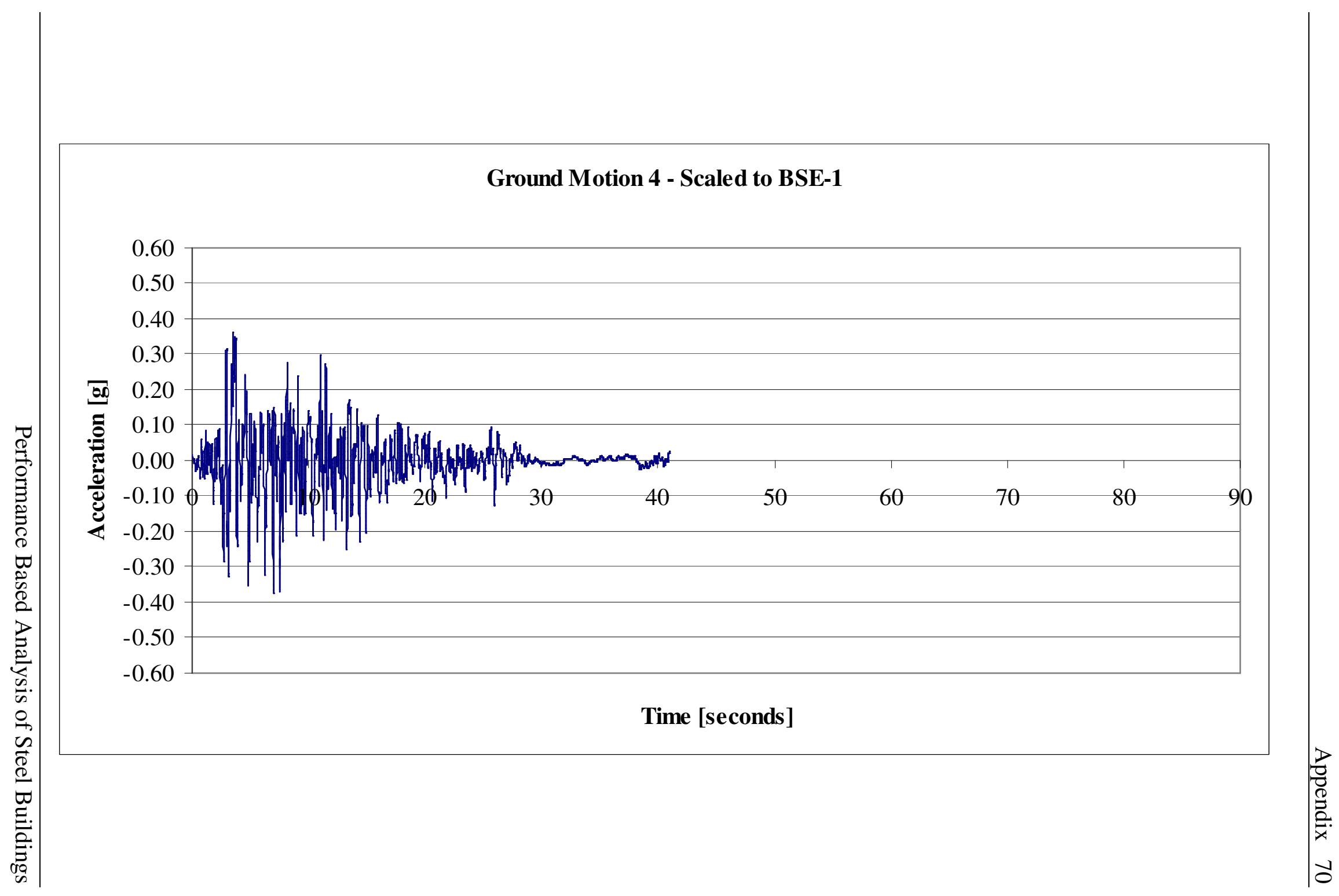




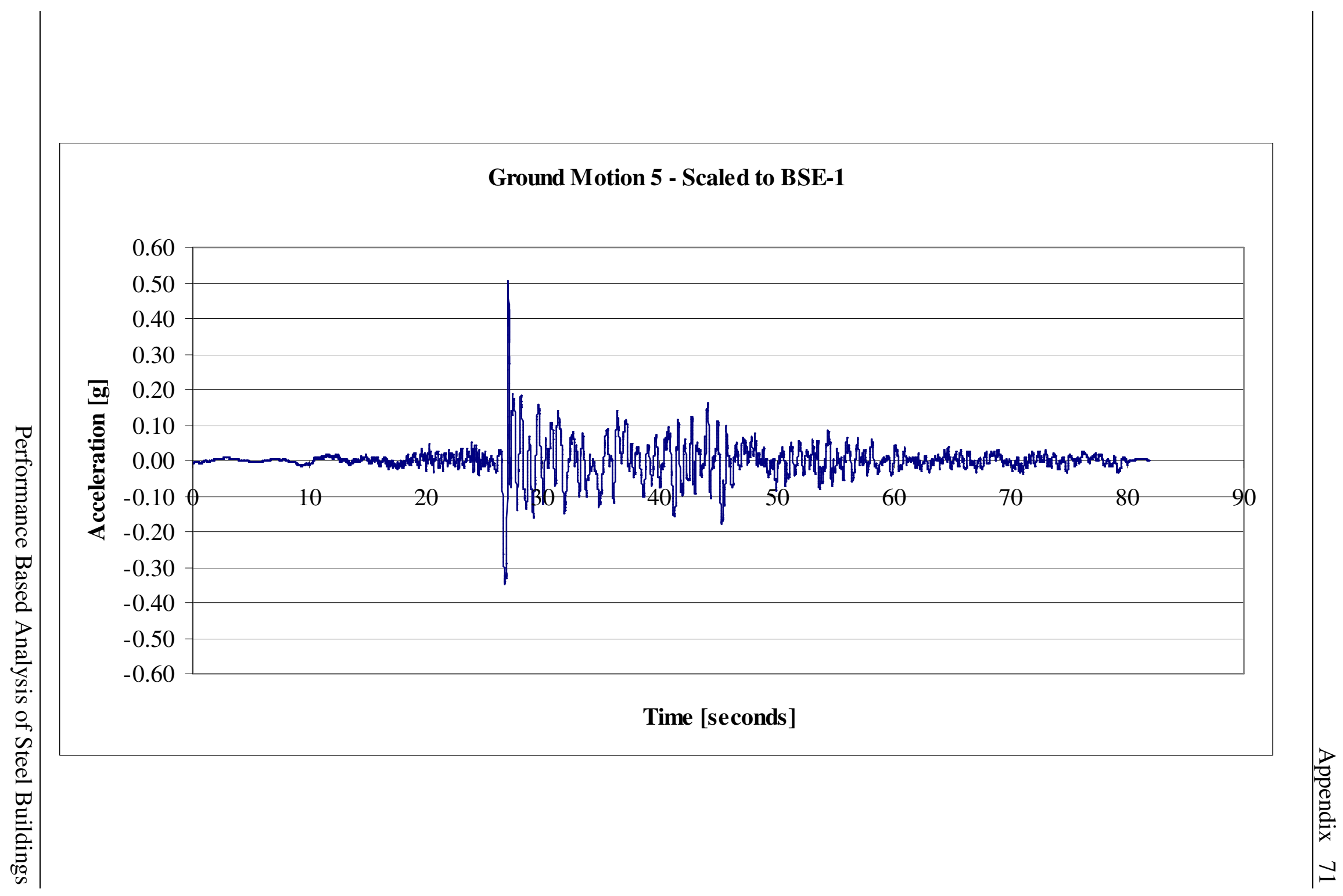




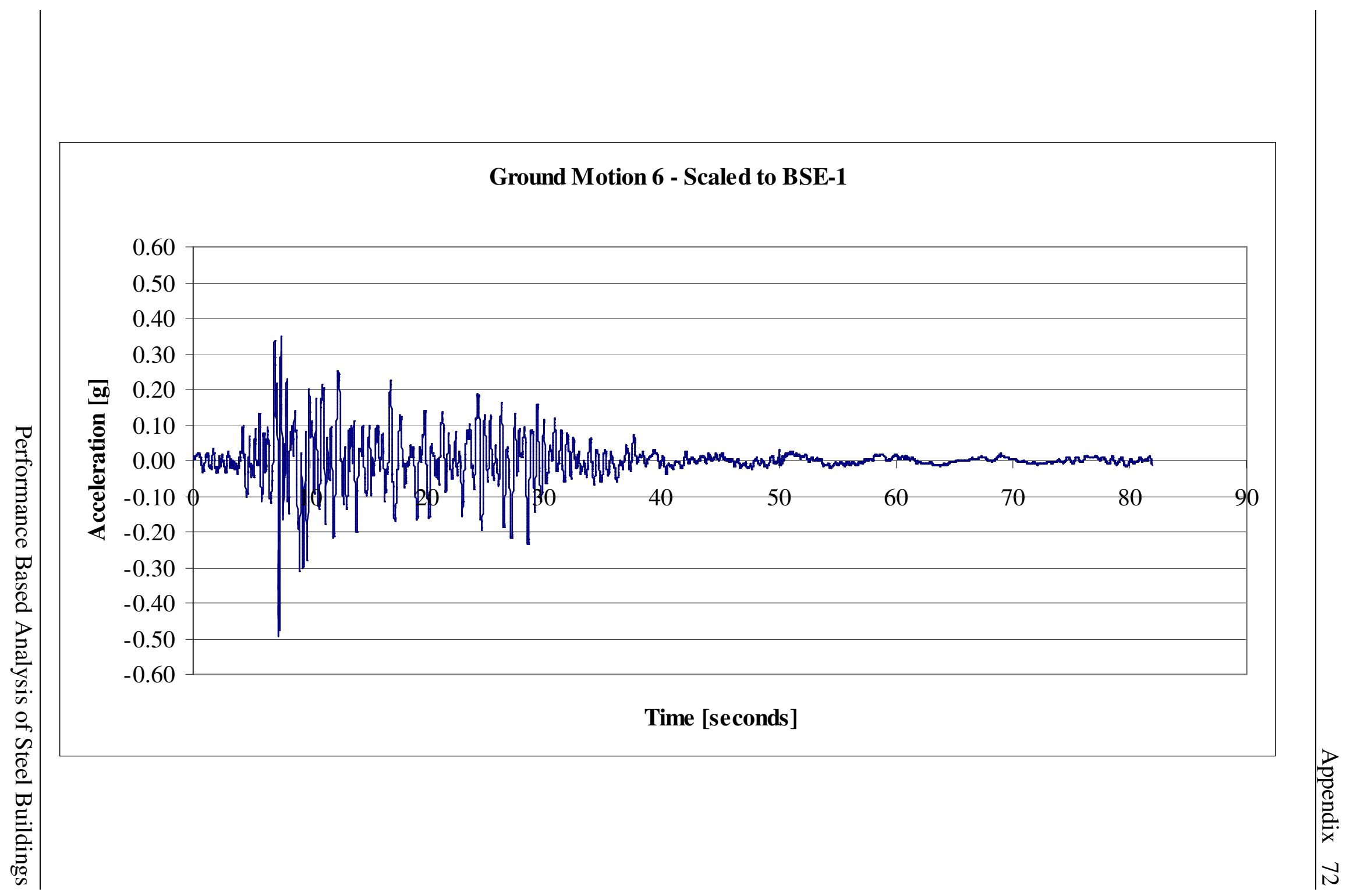




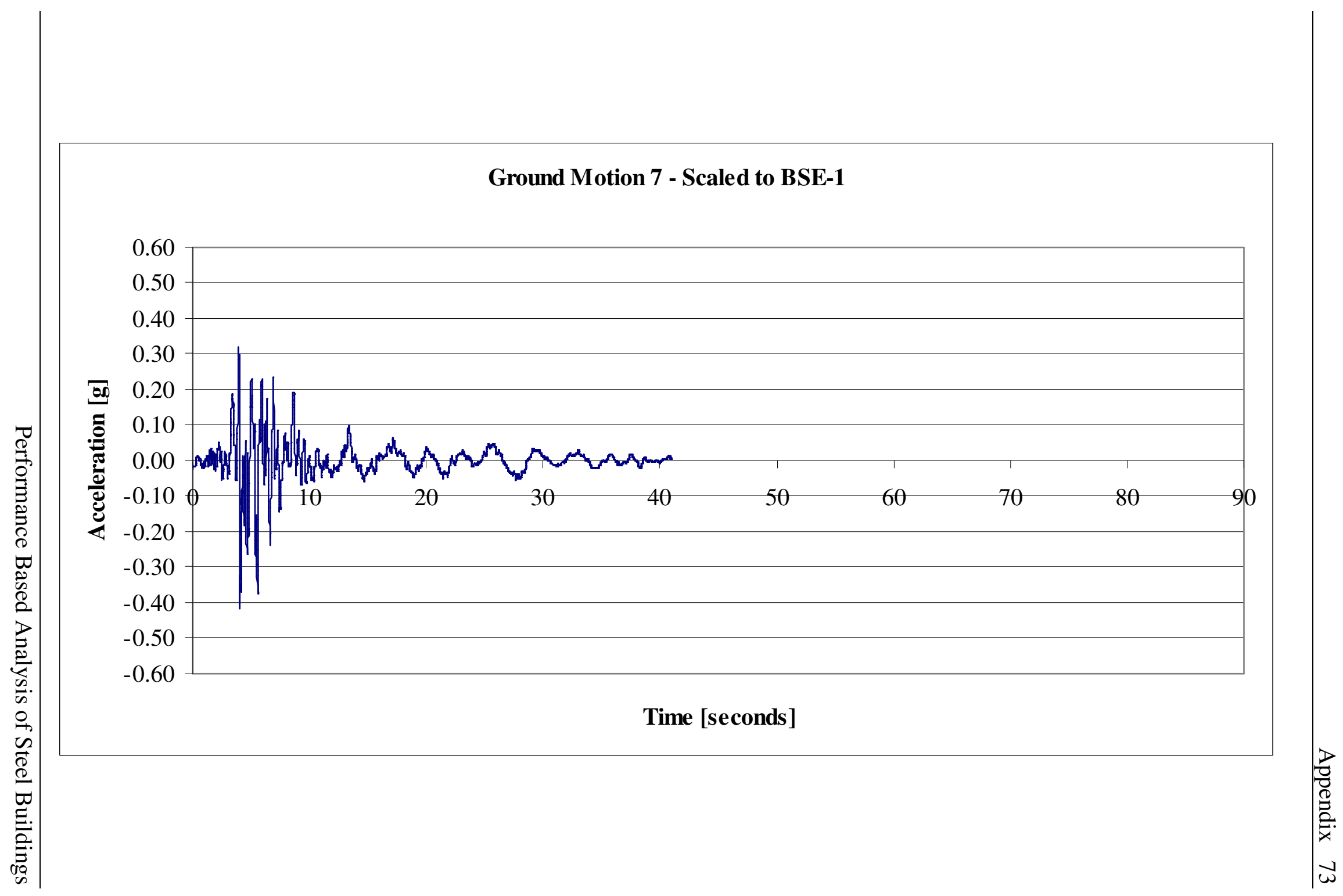


